


\title{
Is Walking and Cycling Irresistible? Community Perceptions and Awareness of Active Travel in \\ Hastings, New Zealand
}

\author{
Dylan Muggeridge
}

Thesis

ENVIRONMENTAL STUDIES 593

2012
A 90 point thesis submitted to Victoria University of Wellington, as partial fulfilment of requirements for the degree of
Master of Environmental Studies
School of Geography, Environment, and Earth Sciences
Victoria University of Wellington
March 2012




\title{
Is Walking and Cycling Irresistible? Community Perceptions and Awareness of Active Travel in Hastings, New Zealand
}

\begin{abstract}
Walking and cycling — commonly termed 'active travel' or 'active transport' - are fun, cheap, clean and healthy modes of transport. In June 2010, Hastings received central government funding from the New Zealand Transport Agency through its Model Communities Programme (MCP), to encourage active travel. The MCP was renamed $i$ Way by the Hastings District Council, with a vision of 'making walking and cycling irresistible'. This study examines varying community perceptions and awareness levels of walking and cycling in Hastings at an early stage of the implementation of the $i$ Way programme. Findings from focus groups, interviews, and a household questionnaire suggest that Hastings people generally have positive attitudes and opinions about walking and cycling, but these attitudes are not necessarily translated into high levels of active transport, or high intentions to walk and cycle more often in the near future. This is mainly due to other determining factors perceived by the Hastings community as barriers to walking and particularly to cycling. Cycling is generally not perceived as a safe activity, and the perceptions of risk and safety are a hindrance to both walking and cycling. The improvement of current infrastructure, the creation of new, dedicated, off-road facilities for cycling, and more education on driver and cyclist behaviour and cohabitation on the road are some of the key factors to work on to further improve perceptions of active transport in Hastings.
\end{abstract}

Key words: walking; cycling; active travel; active transport; perceptions; awareness; safety; Hastings. 


\section{Acknowledgements}

This study would not have been as enjoyable without the support of a number of people, and I would like to take this opportunity to sincerely thank them.

Thanks first and foremost to my supervisor Associate Professor Ralph Chapman, for your availability, wisdom, dedication, and guidance all along the way. Thank you also for helping me develop an expert taste for a good coffee!

Thanks to Philippa Howden-Chapman and the New Zealand Centre for Sustainable Cities for your financial support, and for giving me the opportunity to join the Centre and the ACTIVE research team. I feel truly privileged.

Thanks to you, Em, for always being there. You have really made this whole operation easier. Oh, and cheers for keeping me well fed and watered throughout this tiresome process!

Thanks to my parents for their constant encouragements and support from a land far, far away. I am too well aware that it hasn't always been easy to deal with distance, but I never failed to feel your unconditional support.

Thanks to my family and friends in Hawke's Bay for always making me feel welcome when I was on research trips in Hastings, or simply when I wanted to escape the big city for a relaxing weekend or break fuelled by good times and adventures in the great outdoors.

Thanks to Dad, Meghan and Em for taking the time to proofread and provide valuable feedback on this piece of work.

Thanks to my office and other post-grad mates for all the feedback, entertainment and coffee breaks. If procrastination is not always recommended, you have certainly made it enjoyable!

Thanks to the focus group and interview participants, and to Whitney for helping with the note taking during the focus groups. Thanks also to all the ACTIVE study interviewers in Hastings for all their hard work, particularly to John Maxted and his team at the Eastern Institute of Technology.

Acknowledgements must finally also go to the Stewart Charitable Trust for awarding me the J.L. Stewart Postgraduate Scholarship. Your financial help was much appreciated. 


\section{Table of Contents}

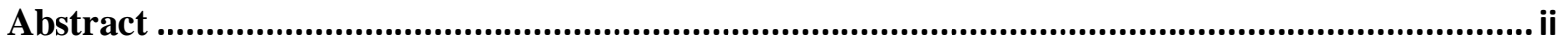

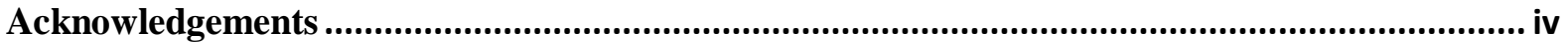

Figures, Boxes \& Tables ..................................................................................................................... vii

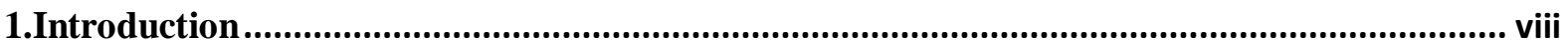

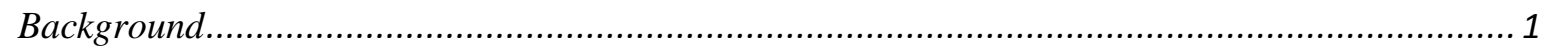

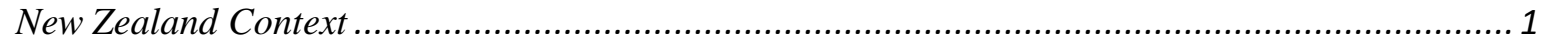

Model Communities Programme ……................................................................................ 3

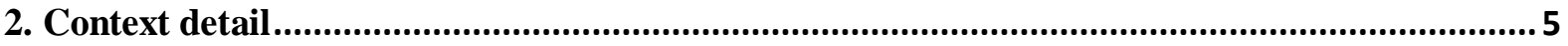

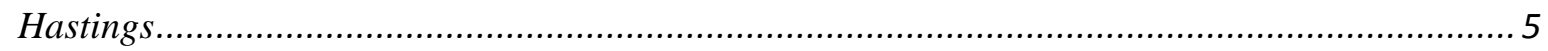

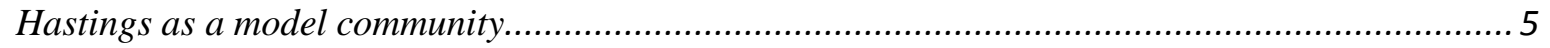

3. Literature review

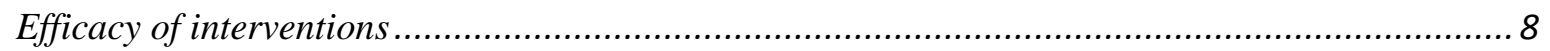

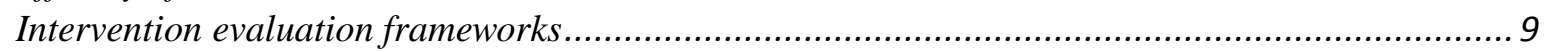

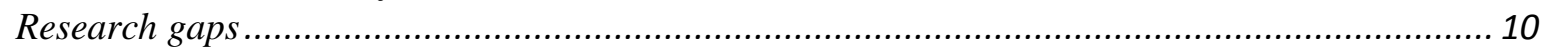

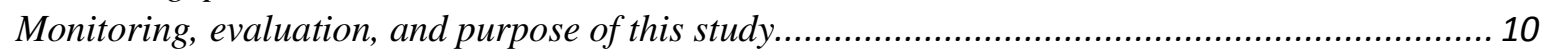

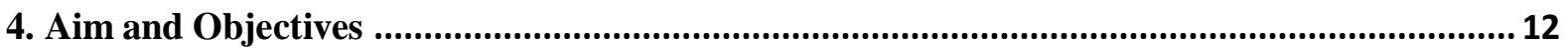

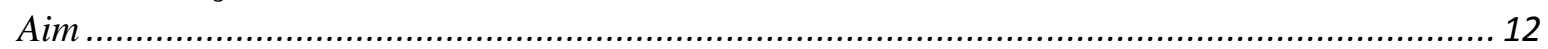

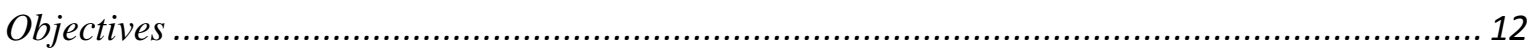

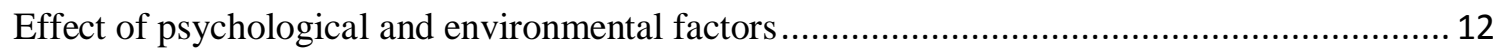

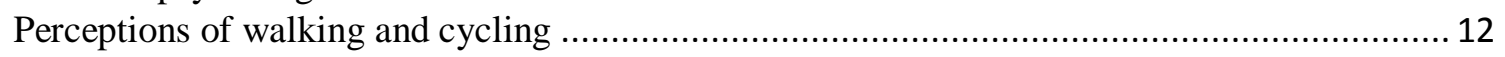

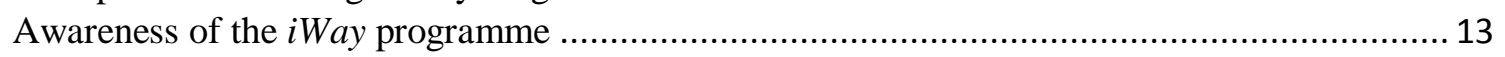

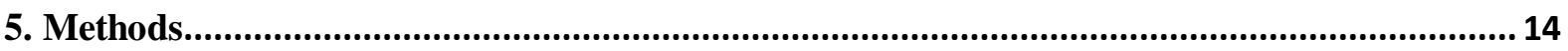

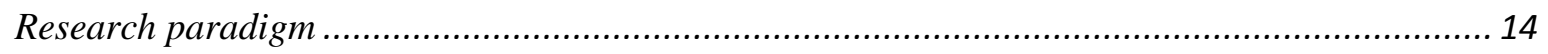

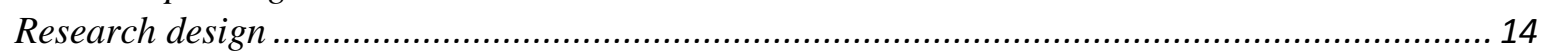

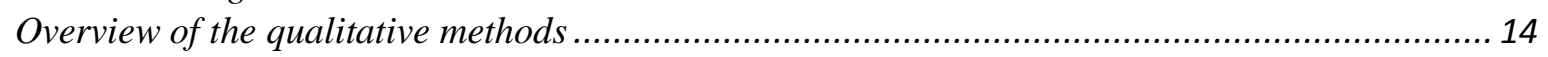

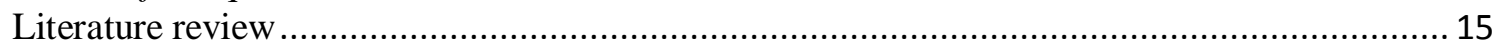

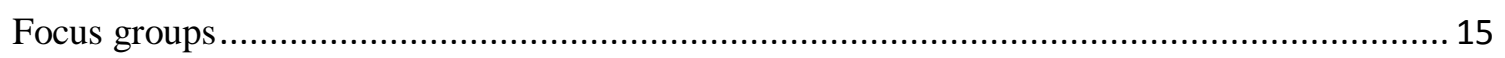

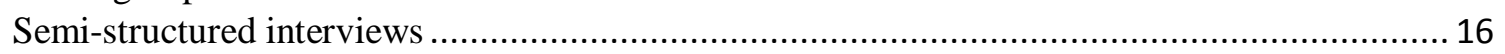

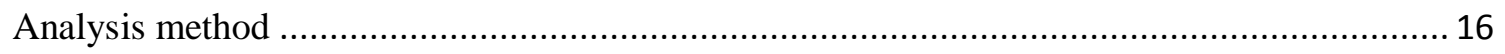

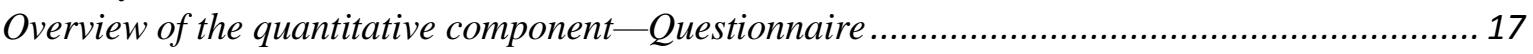

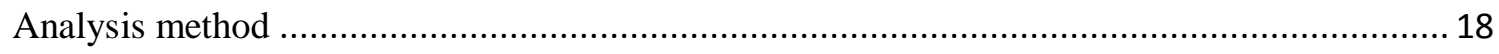

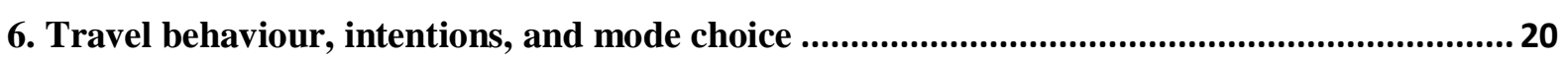

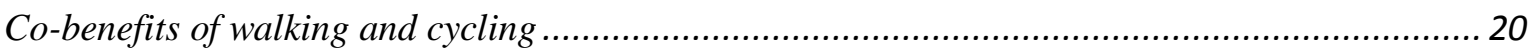

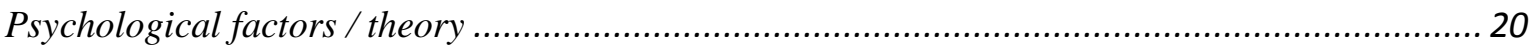

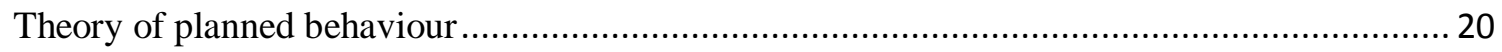

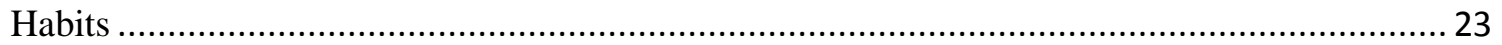

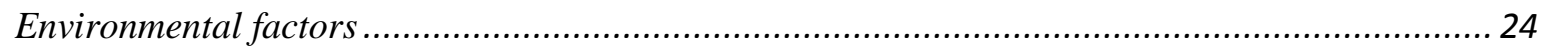

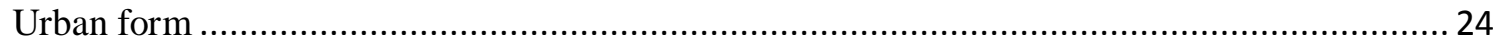

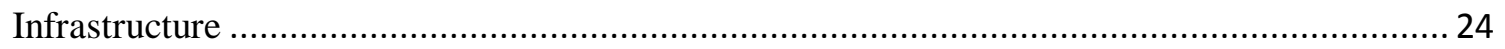

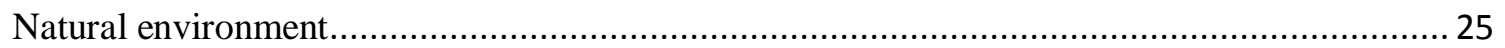

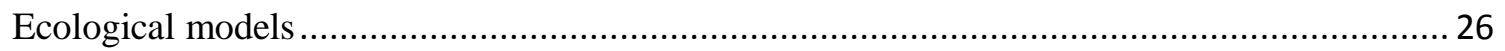

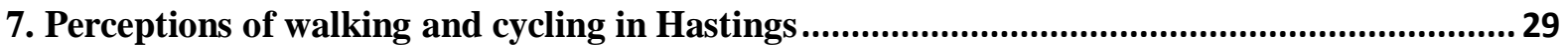

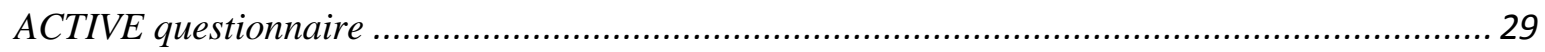

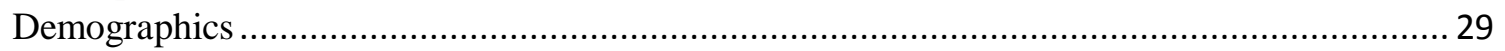

Factors influencing choice of route, mode, and safety perceptions ......................................... 31

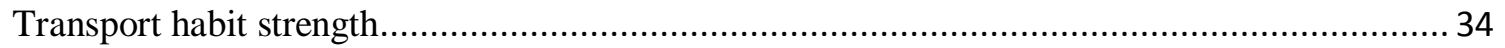




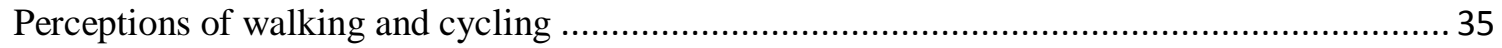

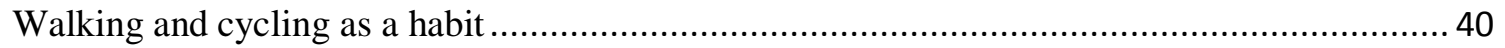

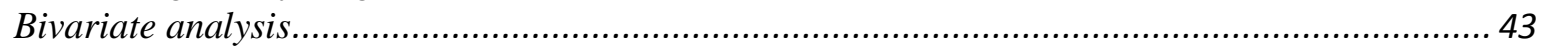

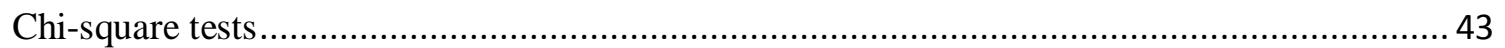

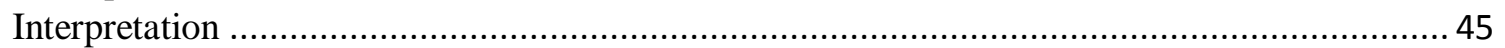

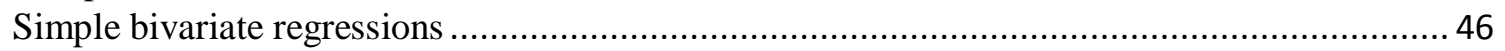

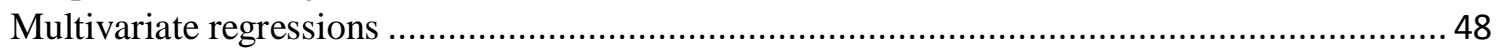

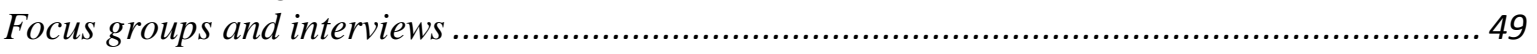

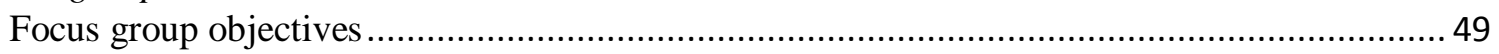

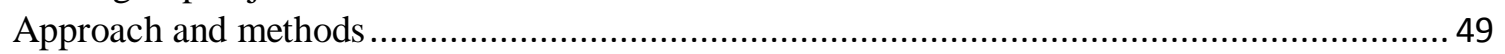

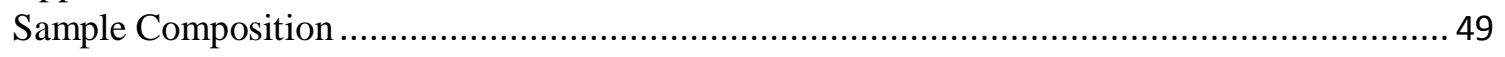

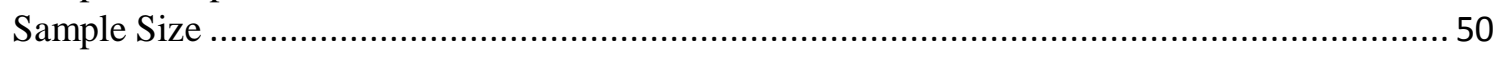

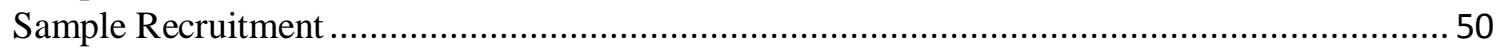

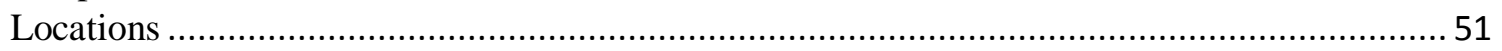

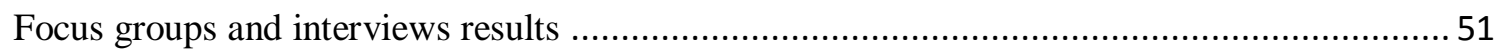

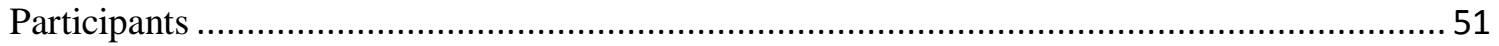

Themes

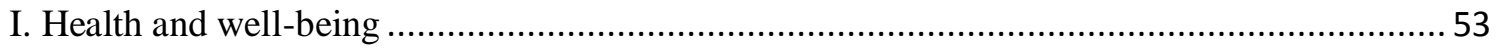

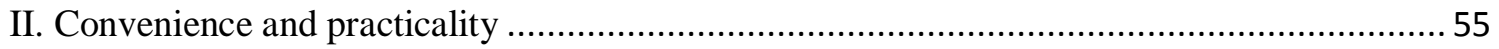

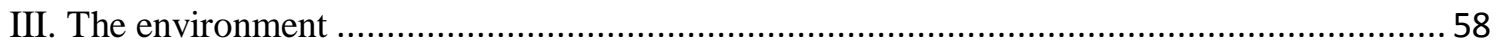

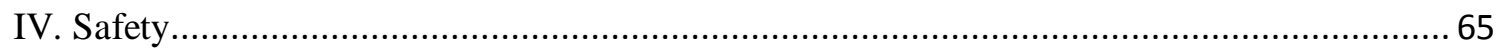

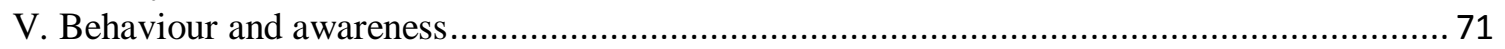

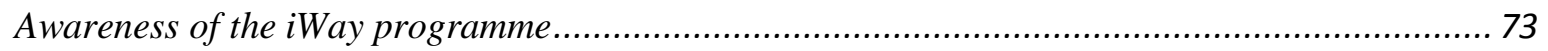

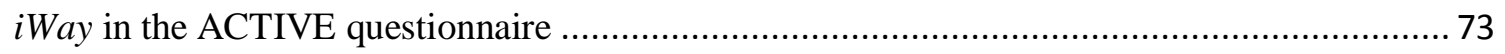

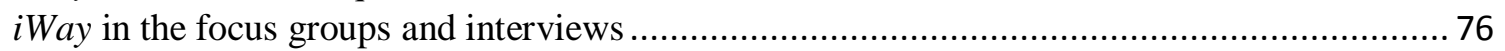

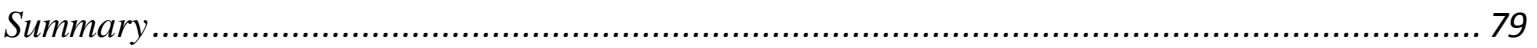

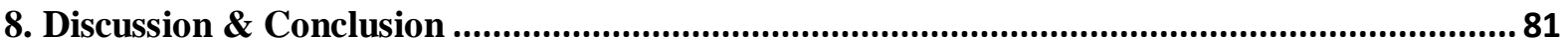

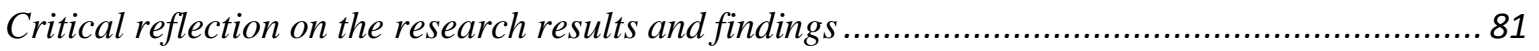

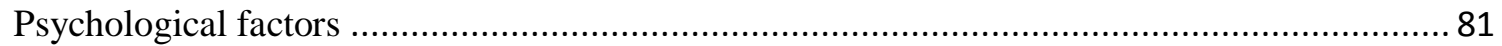

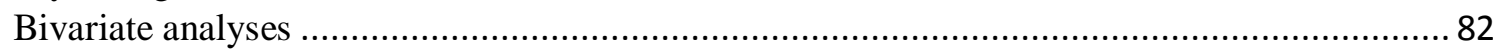

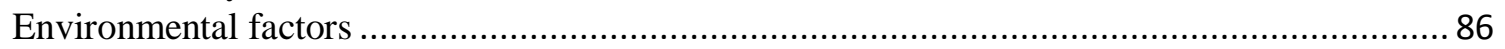

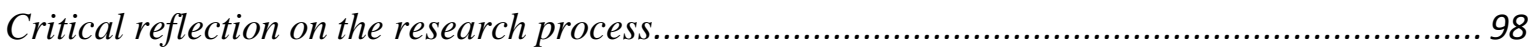

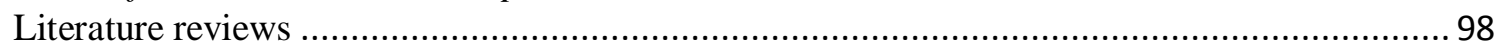

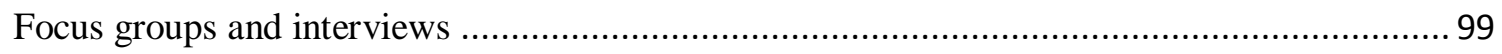

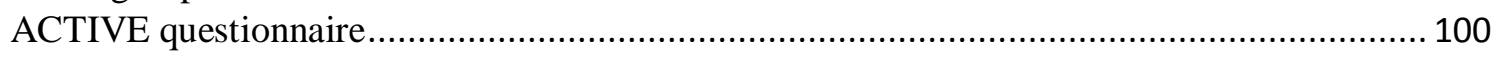

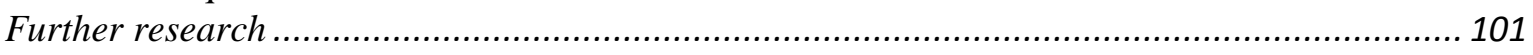

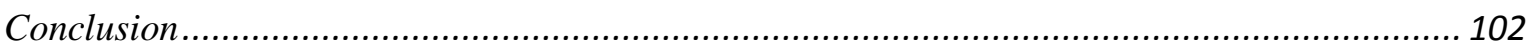

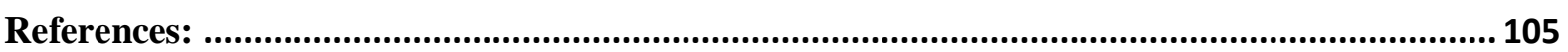

Appendix One: Extracts from the ACTIVE questionnaire (Transport and Lifestyle Survey)...........113

Appendix Two: Habitual modes of transport for different destinations..........................................123

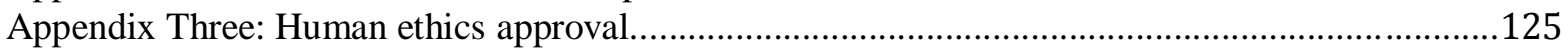

Appendix Four: Information sheet for focus group and interview participants..............................127

Appendix Five: Statement of informed consent for focus group and interview participants............ 129 


\section{Figures, Boxes \& Tables}

Figure 2.1: The four key arterials in Hastings (Hastings District Council, 2010b) ................. 6

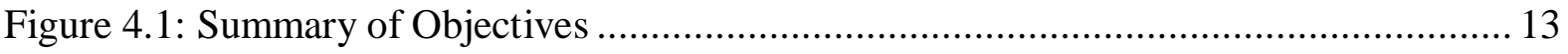

Figure 6.1: The model of Saelens et al., describing environmental and psychosocial correlates of walking and cycling (Saelens et al., 2003) .............................................................. 27

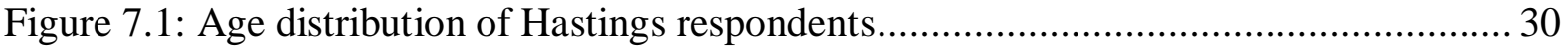

Figure 7.2: Ethnicity distribution of Hastings respondents ............................................ 30

Figure 7.3: Income (personal, before tax or superannuation) distribution of Hastings

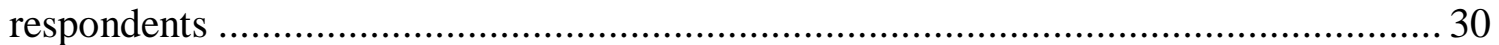

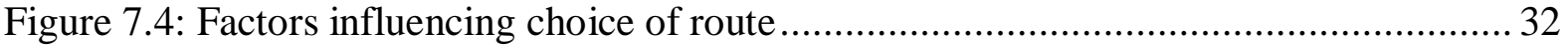

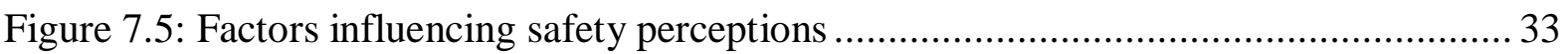

Figure 7.6: Factors influencing choice of mode of transport …....................................... 34

Figure 7.7: Composite variable: opinions of walking as 'desirable' .................................. 36

Figure 7.8: Composite variable: opinions of cycling as 'desirable' ................................... 37

Figure 7.9: Composite variable: ability and confidence in walking ................................ 38

Figure 7.10: Composite variable: ability and confidence in cycling ................................ 38

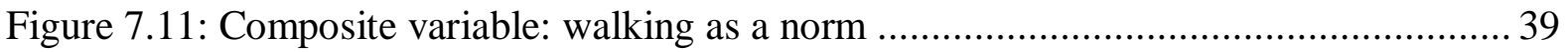

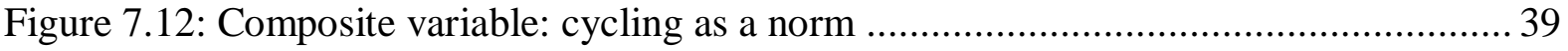

Figure 7.13: Composite variable: walking as a habit .................................................... 40

Figure 7.14: Composite variable: cycling as a habit ................................................... 41

Figure 7.15: Intentions to walk more often in the near future ...................................... 41

Figure 7.16: Intentions to cycle more often in the near future ......................................... 42

Figure 7.17: Days cycled in the last four weeks ....................................................... 43

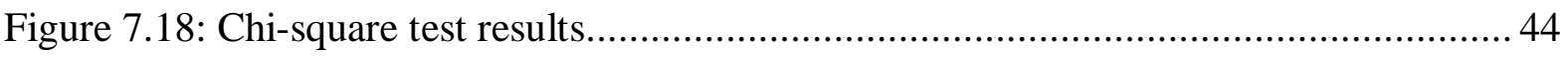

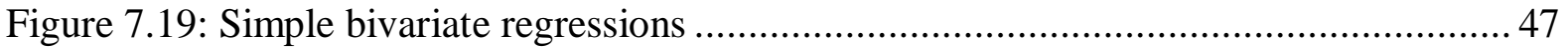

Figure 7.20: Programme awareness in Hastings and New Plymouth ................................ 74

Figure 7.21: Attendance at organised programme activities ........................................ 75

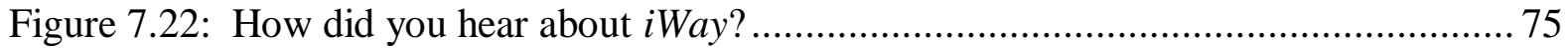


Box 1: Walking and cycling to exercise, for fitness and recreation 53

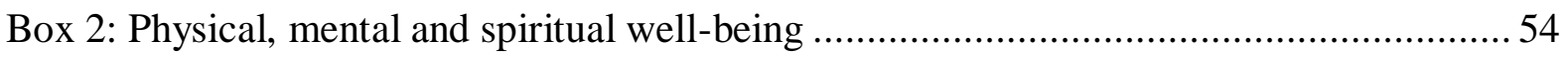

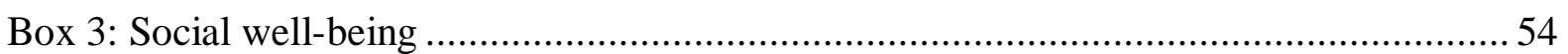

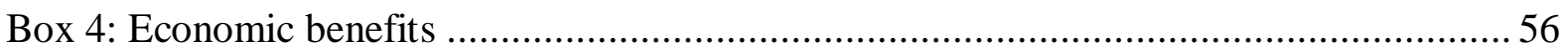

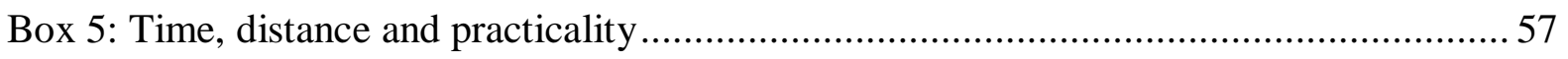

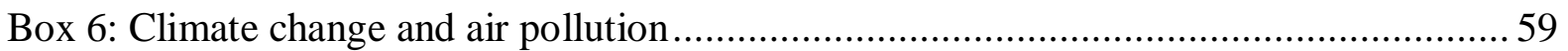

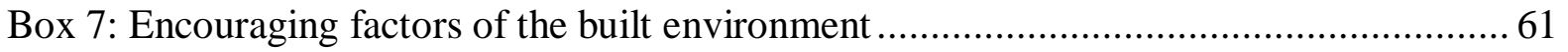

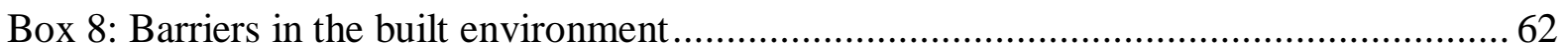

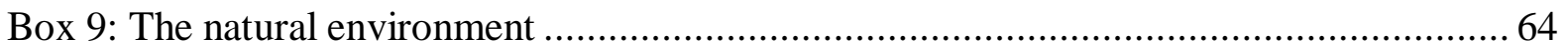

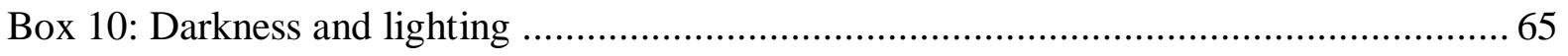

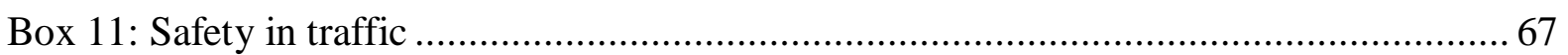

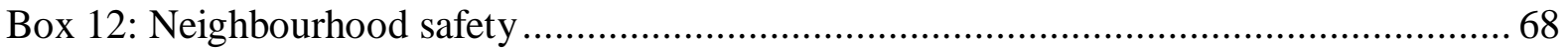

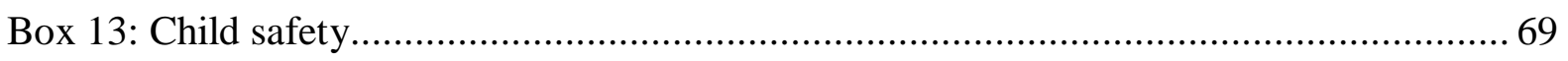

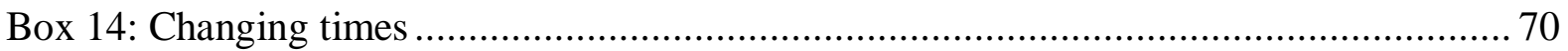

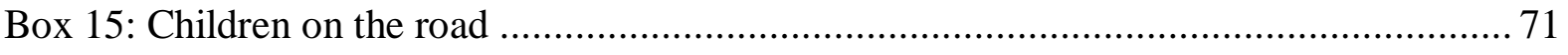

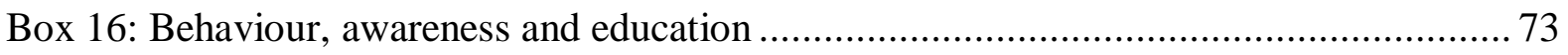

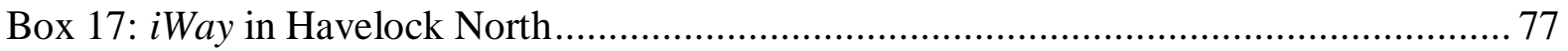

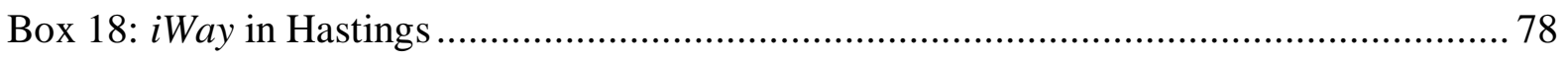

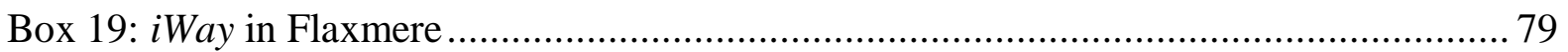

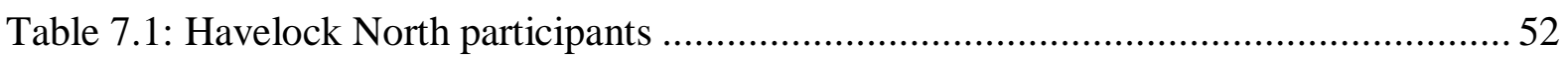

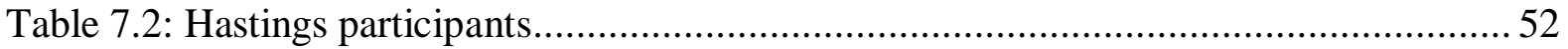

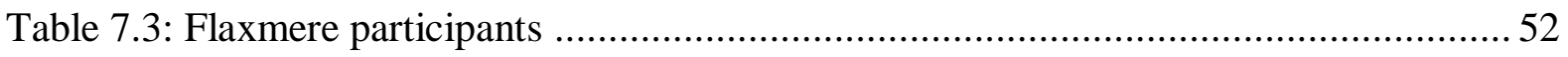




\section{Introduction}

\section{Background}

Walking and cycling-commonly termed 'active travel' or 'active transport'-are crucial modes of transport in many senses. Several government agencies and public health organisations around the world have in recent years explicitly advocated more active travel as a means to improve individual health as well as to reduce harmful impacts associated with motor-vehicle use (Giles-Corti, Foster, Shilton, \& Falconer, 2010; Ogilvie, Egan, Hamilton, \& Petticrew, 2004; Pucher, Dill, \& Handy, 2010; WHO, 2000; Woodcock, et al., 2009). Walking and cycling offer multiple benefits, both individual and environmental, as they are healthy, cheap and clean ways to travel. Active travel integrates regular physical activity into daily life, which in turn improves physical and mental health, and decreases obesity and the risk of cardiovascular and other diseases (Genter, Donovan, Petrenas, \& Badland, 2008). Walking and cycling are also cost-effective modes of transport, which help reduce noise, air pollution and carbon emissions in urban areas (Hillman, 1997; Kingham, et al., 2011; New Zealand Transport Agency, 2011a; Pucher \& Dijkstra, 2003; Woodcock, Banister, Edwards, Prentice, \& Roberts, 2007; Woodcock, et al., 2009). Additionally, Giles-Corti et al. (2010) argue that investment in active transport has the potential to produce substantial co-benefits across multiple sectors.

\section{New Zealand Context}

The need to develop sustainable modes of transport has also been underlined in New Zealand in recent years. At national government level, the Ministry of Transport published in 2005 the Getting there - on foot, by cycle national strategy, which sets out to advance walking and cycling in New Zealand transport. This strategy aims to ensure supportive walking and 
cycling environments are offered in New Zealand communities, that safety is improved for pedestrians and cyclists, and that people walk and cycle more as part of their day-to-day transport mix (Ministry of Transport, 2005). Additionally, the New Zealand Transport Strategy fixed in 2008 a target to increase walking, cycling and other active modes of transport to $30 \%$ of total trips in urban areas by 2040 (Ministry of Transport, 2008). Even though this is an ambitious target, it is important to note that the Transport Strategy acknowledges the need to ensure environmental sustainability, improve access and mobility and protect and promote public health. At local government level, there were, as of 2008, sixty-one walking and cycling strategies prepared by fifty-five different councils to help local authorities identify the most important ways of improving provision for walking and cycling, and encouraging further uptake of these sustainable, affordable and active modes of travel (New Zealand Transport Agency, 2008).

Active transport research is also gaining increasing interest among New Zealand researchers (New Zealand Transport Agency, 2011a; Sullivan \& O'Fallon, 2011). Authors and academics around the country have been advocating the necessity for a change in transport modes and urban forms in New Zealand. Woodward and Lindsay (2010, p. 62) for example argue that "substantial changes need to be made in patterns of travel in New Zealand cities", and that a shift towards more active transport would reduce fuelconsumption, greenhouse gas emissions, ill-health due to local air pollution and diseases as a result of being more active. An increase in the uptake of active travel could therefore be most beneficial to New Zealand and New Zealanders.

However, Ministry of Transport (2009b) data from three New Zealand Household Travel Surveys since 1989 show that walked and cycled time and distance have on average decreased across New Zealand, while the time and distance spent driving have largely increased. These figures also prove 
how car-dependent this country is, with the latest survey (conducted from 2003 to 2007) showing that $81 \%$ of total travel time was spent in a motor vehicle, $12 \%$ was spent on foot, and only about $1 \%$ was spent on a bicycle. The New Zealand situation is in sharp contrast with many European countries, where active travel holds a two to three times greater share of all travel (Woodward \& Lindsay, 2010).

\section{Model Communities Programme}

It is in this context that the New Zealand Transport Agency (NZTA) announced in 2010 the implementation of the 'Model Communities Programme' (MCP), and called for programme implementation tenders from city councils throughout New Zealand ${ }^{1}$. The NZTA embarked on this programme following the Government Policy Statement on Land Transport Funding (2009a), through which the government requires that walking and cycling improve their contribution to the reduction of congestion in urban areas (New Zealand Transport Agency, 2010).

The NZTA presents Model Communities as urban environments where walking and cycling are offered to the community as the easiest transport choices. Model Communities are also meant to deliver safe environments to suit novice users commuting to school or to work. Through this programme, the NZTA aims to encourage a planning and investment approach that fully integrates walking and cycling in urban planning as well as in urban transport networks (New Zealand Transport Agency, 2011b). However, the amount of funding for this programme is limited.

On $25^{\text {th }}$ June 2010, Hastings and New Plymouth were announced as New Zealand's two first Model Communities. The intervention package allocated by the NZTA consists of funding for both district councils (\$3.71 million for the New Plymouth District Council and \$3.57 million for the Hastings

\footnotetext{
${ }^{1} 22$ proposals from local councils were received, and four councils were shortlisted (Nelson, Taupo, New Plymouth and Hastings).
} 
District Council) over the 2010/11 and 2011/12 financial years, i.e. a total of $\$ 7.28$ million. This grant has in turn been allocated by the councils for infrastructural changes (e.g. new or improved cycle lanes or cycle paths, footpaths...) and informational-educational campaigns to promote and encourage walking and cycling for people of all ages. Additionally, a small proportion of the grant is devoted to the evaluation of the programme. Both New Plymouth and Hastings successfully presented their candidature based on ambitious and attractive agendas (Hastings District Council, 2010a; New Plymouth District Council, 2010).

This study aims to examine the intervention in Hastings, and to focus particularly on community perceptions and awareness of walking and cycling among different communities in the Hastings District. 


\section{Context detail}

\section{Hastings}

Hastings is located on the Heretaunga Plain in Hawke's Bay, on the eastern coast of the North Island of New Zealand. The Hastings District has a population of 70,842 (Stats NZ, 2006), and is composed of five main centres, Hastings, Havelock North, Flaxmere, Clive and Whakatu. The median income in Hastings, according to the 2006 New Zealand Census, is $\$ 22,600$, the unemployment rate is $4.6 \%$, and $23.8 \%$ of the population belongs to the Maori ethnic group. This compares with a median income of $\$ 24,400$, an unemployment rate of $5.1 \%$, and a share of $14.6 \%$ Maori population for all of New Zealand (Statistics New Zealand, 2006).

\section{Hastings as a model community}

The Hastings District Council put forward a proposal to address NZTA guidance and criteria, and claim the title of one of New Zealand's two first Model Communities. The general approach of the Hastings strategy is a targeted approach, directed at four key user groups:

- Walking and cycling to work

- Walking and cycling to school

- Walking and cycling to shop

- Walking and cycling for fun.

Much focus is also put on connectivity to link major hubs of population, employment and education. The strategy thus focuses on four main on and off-road arterial routes linking Hastings city to its satellite communities (see figure 2.1):

- The Havelock arterial (between Hastings and Havelock North)

- The Flaxmere arterial (between Hastings and Flaxmere, via Raureka and Akina) 
- $\quad$ The Omahu arterial (between Hastings and Flaxmere, via Omahu Road)

- The Whakatu/Clive arterial (between Hastings, Whakatu and Clive).

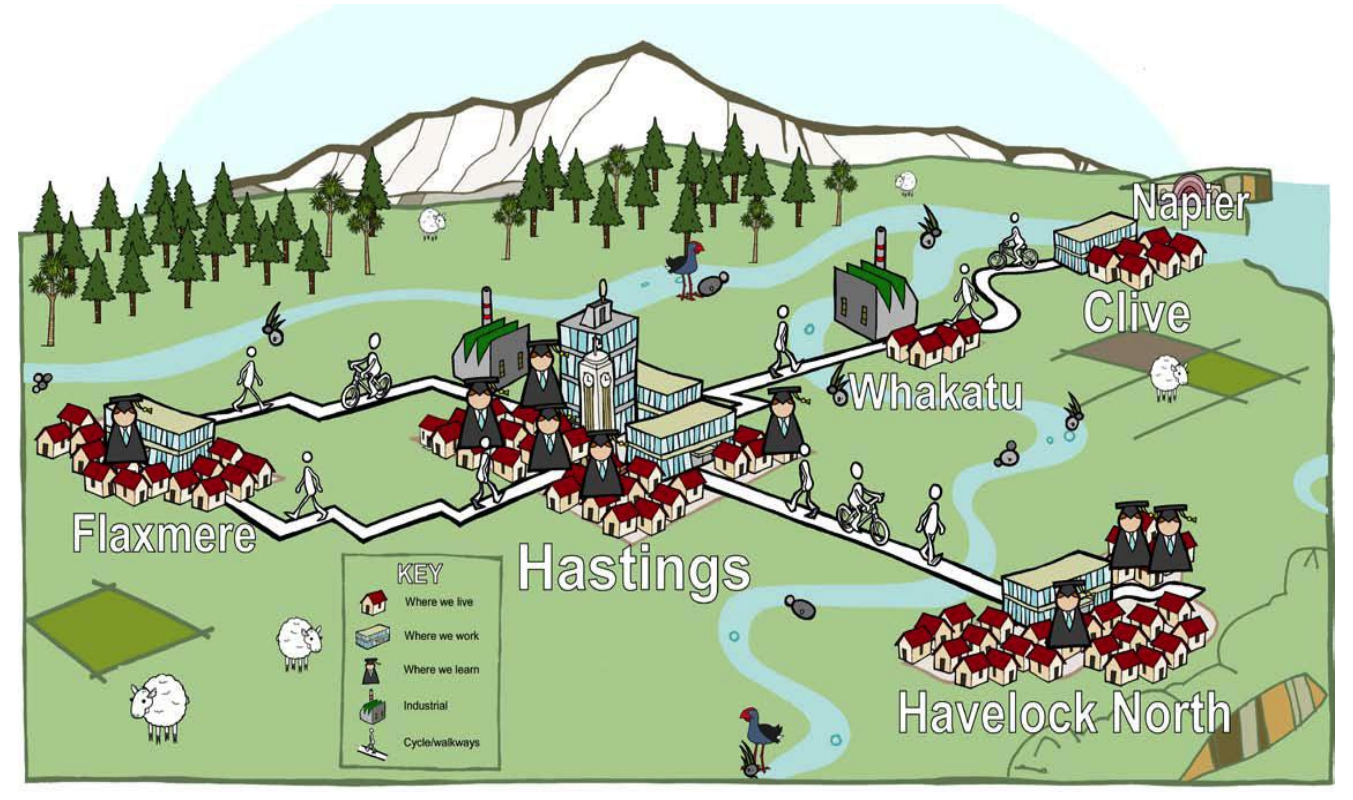

Figure 2.1: The four key arterials in Hastings (Hastings District Council, 2010b)

Collector routes, to connect schools, residential areas, community facilities and major attractions are also being put in place or improved, by reallocating road space on low-volume local roads and linking them to the main arterials, thus creating a network of active transport-friendly routes.

Other components of the Hastings package include shared pathway projects, footpath renewals, improved street lighting, a network of information signs, bike stands and seats etc...(New Zealand Transport Agency, 2011b). The vision the council has is of 'making walking and cycling irresistible' (Hastings District Council, 2010b), and the 'Model Communities Programme' was renamed $i$ Way by the project management team at the district council a few months after the intervention started. 
According to the programme's website (Hastings District Council, 2011a), $i$ Way exists to:

- "Prioritise upgrades to roads and footpaths

- Identify new commuter routes

- $\quad$ Enhance current cycle and walk tracks

- $\quad$ Educate kids in schools about walking and cycling benefits

- $\quad$ Provide opportunities to revive old bikes

- $\quad$ Help people make that first step

- Make it fun and learn to love it

- Build community spirit by making friends

- $\quad$ Save emissions to the environment

- Build an active and healthy community."

The Hastings District Council has a set of eight key project indicators (KPIs) for the $i$ Way programme. These KPIs can be considered as the goals for the $i$ Way project:

Primary level indicators:

- Walking and cycling mode share is increasing at $8 \%$ per annum

- Number of injury crashes involving pedestrians and cyclists is trending downwards, especially in the 0-14 age group

- Community perception of cycling safety has trended upwards by at least $50 \%$ over 3 years.

Sub-level indicators:

- Average traffic speeds on routes with cycling facilities is trending downwards

- $100 \%$ uptake of travel planning within target organisations and quotas being met

- Patronage of the Commuter Express is trending upwards

- iWay marketing awareness exceeds $50 \%$

- Percentage of residents achieving recommended weekly physical activity target of 2.5 hours is trending upwards. 


\section{Literature review}

Walking and cycling are fun, cheap, clean and healthy modes of transport. A wide array of literature covers the many benefits and co-benefits of increasing levels of active travel in urban areas, including health benefits, environmental benefits or economic benefits (Genter, et al., 2008; GilesCorti, et al., 2010; Pucher \& Dijkstra, 2003; WHO, 2000; Woodcock, et al., 2009). However, the empirical peer-reviewed literature reveals that while much is known about the benefits of active travel in urban areas, there is limited knowledge about ways to positively invest in walking and cycling to increase levels of these modes of transport, and to create a mode shift from motor-vehicle use.

\section{Efficacy of interventions}

A systematic review to assess what interventions are effective in promoting a mode shift from car use to walking or cycling in urban areas by Ogilvie et al. found that targeted behaviour change programmes can be effective in changing the transport choices of motivated subgroups, but also highlighted the fact that there is a lack of good evidence on which interventions are likely to be effective in promoting a shift from cars towards walking and cycling (Ogilvie, et al., 2004). The same study also underlined the fact that traditional interventions such as publicity campaigns and engineering measures showed no significant evidence of a positive shift from car use to active travel (Ogilvie, et al., 2004). However, a recent international review of programmes to encourage cycling, which draws on a more recent and wider range of research than included in Ogilvie's paper, emphasizes that the lack of evidence of a positive effect of some specific interventions does not signify a lack of positive effect (Pucher, et al., 2010). The key message of this review is that some individual interventions (e.g. building or improving bike lanes, education and marketing programmes, changes to local bylaws) can increase levels of active travel to varying degrees, but the 
increases are not usually large. This, however, does not mean that individual interventions are not important, but that they may be more effective as part of a comprehensive and integrated package of many different complementary interventions, including infrastructure provision, educational campaigns and policy changes (Pucher, et al., 2010). In other words, while targeted interventions can achieve measurable mode shifts, a combination of different interventions (infrastructural, educational, financial etc...), integrated into a package of interventions, is likely to achieve the best results. To the best of the author's knowledge, only two studies have attempted to comprehensively measure the effect of a package of interventions aimed at increasing active travel in urban areas; the study of the Cycling Demonstration Towns programme in the United Kingdom (Cycling England, 2009; Sloman, Cavill, Cope, Muller, \& Kennedy, 2009), and the study of the Non-motorised Transportation Pilot Programme in the United States of America (Krizek, Barnes, Wilson, Johns, \& McGinnis, 2007).

\section{Intervention evaluation frameworks}

In the past decade, ecological models have summarised the factors known to influence a person's choice to undertake active travel in urban areas. A model by Saelens et al. for example argues that it is a combination of environmental and psychosocial factors that can explain one's choice to walk or cycle (Saelens, Sallis, \& Lawrence, 2003). This study also underlines that a good understanding of both psychological and environmental correlates of walking and cycling at a population level could lead to policy changes that will provide more people with environments that will facilitate active lifestyles (Saelens, et al., 2003). While an applied ecological framework for evaluating the public health effects of interventions in the built environment has been set up in the context of the Connect 2 initiative in the United Kingdom (Ogilvie, et al., 2011), there are however, to the best of the author's knowledge, to date no published studies 
that comprehensively evaluate both psychological and environmental factors in the context of an intervention to increase walking and cycling.

\section{Research gaps}

Gaps remain, therefore, in our understanding of the efficacy and relative importance of different components of interventions to increase walking and cycling. More information also needs to be collected and made available on how to best evaluate the efficacy and potential successes of integrated packages of interventions designed to encourage active travel in urban areas. Finally, there also appears to be a lack of applied evidence on the relative influence of psychological and environmental factors with regard to mode choice and travel behaviour.

\section{Monitoring, evaluation, and purpose of this study}

The NZTA is working closely with both New Plymouth and Hastings district councils to learn as much as possible about investing in model communities, so this knowledge can be shared with other communities and cities around New Zealand who have shown enthusiasm about making progress towards encouraging more active travel (New Zealand Transport Agency, 2011b). To gain this knowledge however, the NZTA requires monitoring and evaluation of the MCP. The opportunity thus arose for the academic community to lead an investigation of the impacts, costs and benefits of such an intervention. In collaboration with NZTA and the two relevant district councils, the New Zealand Centre for Sustainable Cities is currently leading a project to measure these impacts, costs and benefits in Hastings and New Plymouth.

This particular study is a component of the New Zealand Centre for Sustainable Cities project, and its purpose is to focus on one aspect of the evaluation in Hastings. This research will examine varying community perceptions of walking and cycling in different neighbourhoods in Hastings. The study will look at what people think of walking and cycling in their 
community, and whether a local authority programme can influence the behaviour and perceptions of active travel within the community. 


\title{
4. Aim and Objectives
}

\begin{abstract}
Aim
In June 2010 the Hastings District Council was awarded approximately $\$ 3.5$ million to improve walking and cycling levels in its jurisdiction, and to encourage more people to partake in active travel. The aim of this study is to respond to the following research question: What are the perceptions and awareness levels of Hastings people in relation to walking and cycling at an early stage of a local authority programme to encourage active travel?
\end{abstract}

\section{Objectives}

\section{Effect of psychological and environmental factors}

Much research on active travel has focused on the effect of various psychological factors on travel behaviour, intentions and mode choice, including the effects of attitudes, social norms, perceived behavioural control and habits (Ajzen, 1991; Heinen, Maat, \& van Wee, 2011; Heinen, Van Wee, \& Maat, 2010; Verplanken, Aarts, \& Van Knippenberg, 1997). There is also strong evidence that suggests that an integrated range of factors from the built environment such as infrastructure and facility improvements may play an important part in people's choice to walk or cycle to get to places (Forsyth \& Krizek, 2010; Giles-Corti \& Donovan, 2002; Saelens, et al., 2003). The first objective of this study is to explore the effect of these various factors on travel behaviour, intentions, and mode choice in the Hastings district.

\section{Perceptions of walking and cycling}

A second objective of this research is to examine how citizens from different neighbourhoods in Hastings perceive walking and cycling in their community, and whether differences in perceptions and behaviour arise in different socio-demographic groups. 


\section{Awareness of the $i$ Way programme}

The third objective of this project is to examine the community's awareness of the iWay programme one year after it was launched in the Hastings district. This is of inherent interest, but is also necessary to establish a baseline that will enable future research to determine whether a local authority programme to encourage active travel can have an influence on the behaviour and perceptions of the Hastings community in the long-term.

Objective 1: Explore the effect of psychological and environmental factors on travel behaviour, intentions, and mode choice.

Objective 2: Examine how citizens from different neighbourhoods in Hastings perceive walking and cycling in their community.

Objective 3: Examine the community's awareness of the $i$ Way programme one year after it was launched.

Figure 4.1: Summary of Objectives

The following chapter outlines the methodology used to address these different objectives in addition to the research aim. 


\section{Methods}

\section{Research paradigm}

This research takes a pragmatic approach to answer its set aims and objectives. Multiple methods of data collection and analysis, both qualitative and quantitative, are used to best answer the research questions. According to Creswell (2007, pp. 22-23), a pragmatic paradigm takes the view that "instead of a focus on methods, the important aspect of research is the problem being studied and the questions asked about this problem", and that the researcher "will focus on the practical implications of the research, and will emphasise the importance of conducting research that best addresses the research problem".

\section{Research design}

Because a pragmatic paradigm is adopted for this study, the research is based on a mixed methods design. As argued by Morse (2003, p. 189), "while specific research methods enable us to describe, understand, and explain the complexity of living by providing us with various perspectives, different methods are best designed for, and used to answer, particular types of questions. They provide us with different perspectives that enable us to best answer individual questions." Because of the nature of the objectives set out in this research, a combination of qualitative and quantitative methods seems the most appropriate way of addressing these objectives. It is for these reasons that a mixed methods approach was selected as the methodology for this study. This chapter focuses on dissecting and explaining the various methods used to address the objectives and research aim of this project.

\section{Overview of the qualitative methods}

This section will give a brief outline of the qualitative methods used in this research project. 


\section{Literature review}

Whilst a short literature review was used earlier to introduce the topic and help define the research aim and objectives, a literature review is also used to address the first objective of this study, and is presented in Chapter 6 below. This literature review was systematically developed with the aid of key-word searches in search engines, databases and websites. Some references were also obtained through a 'snowballing' effect from other references' bibliographies.

The literature review focuses particularly in the fields of environmental psychology and sustainable transport, and provides important background information to this project. It also identifies key theoretical concepts used in international and domestic research surrounding active travel. Literature reviews provide a framework for establishing the importance of a study as well as a benchmark for comparing the results with other findings (Creswell, 2009). Thus, some of the theoretical concepts will be examined with close attention, and be put in context with the findings of the other objectives and methods of this study. The review also reveals important gaps in the literature that this research can illuminate.

\section{Focus groups}

Focus groups were held in two communities within the Hastings district, in Havelock North and Hastings itself, and are used to address objectives two and three. According to Khan and Manderson (1992, p. 57), a focus group interview is a qualitative method "with the primary aim of describing and understanding perceptions, interpretations, and beliefs of a select population to gain understanding of a particular issue from the perspective of the group's participants." The information arising from these focus group interviews is also used to complement and validate the findings of the quantitative methods used in this study, as they provide a deeper understanding of the perspectives of participants in the study population (Liamputtong \& Ezzy, 1999). The focus groups thus allow the researcher a 
privileged position to obtain in-depth information to address the study objectives, as well as to get a more intimate sense of experiences within the selected population.

\section{Semi-structured interviews}

Three focus groups were originally scheduled to take place for this research. However, difficulties in participant recruitment for the third and final focus group in Flaxmere led the researcher to cancel the event, and to replace this focus group with semi-structured interviews, which carried the same aim as the focus group interviews. Further details are provided in the Focus groups and interviews section in Chapter 7.

\section{Analysis method}

The focus groups and semi-structured interviews were transcribed and coded for common elements and themes, following a thematic analysis framework. Thematic analysis is a method to identify, regroup and report patterns and themes within data (Braun \& Clarke, 2006). Braun and Clarke (2006, p. 86) explain that "thematic analysis involves the searching across a data set, be that a number of interviews or focus groups [...] to find repeated patterns of meaning." They also argue that it is more likely that the researcher develops themes as they think about their research topic and the data they have gathered. This signifies that the researcher's theoretical and analytic interests in the area may drive the analysis. This analysis framework can therefore be considered as a 'theoretical' thematic analysis, as it is more explicitly analyst-driven (Braun \& Clarke, 2006). Because the focus group and interview data sets are used to complement findings from the quantitative methods used in this study, and are linked directly to concepts emerging from the literature review, a theoretical thematic analysis approach seems an ideal analysis method.

Themes were summarised and the frequency with which they were reported was recorded. The most frequently reported themes were not necessarily 
considered as the most important themes, but were considered as the most representative of the prevailing views at the time. A set of 'key themes' was established after repeated reading of the transcripts, based on the frequency and emphasis placed on themes by participants, and on the researcher's own knowledge of the subject area gained from experience through the research period. A quantitative summary of focus group and interview responses (e.g. ' $20 \%$ of participants felt that...') was avoided as this could be misleading and/or inaccurate based on the varying sample sizes of both focus groups and interviews. However, the terms 'many' and 'most', or alternatively 'one' or 'a few', were used to emphasise when an idea or comment was widely held or only rarely held by the interview participants collectively.

\section{Overview of the quantitative component-Questionnaire} In partnership with the Hastings District Council, the New Plymouth District Council and the NZTA, the New Zealand Centre for Sustainable Cities is leading a study to evaluate the impacts, costs and benefits of the Model Communities Programme in the two intervention cities. This study is called the ACTIVE study, for 'Activating Communities to Improve Vitality and Equity'. The overall aims of the ACTIVE study are to (Chapman, et al., 2011):

- Assess whether the MCP intervention results in an increase in walking and cycling physical activity (including recreational walking and cycling); and an increase in transport-related active travel activity, including a mode shift (from car use) within the intervention communities;

- Assess whether changes in the number and proportion of active travel (walking and cycling) journeys within the intervention communities varies by neighbourhood and by ethnicity and socio-economic status; 
- Analyse the MCP's overall costs and benefits (including estimated health benefits, and energy and carbon savings from mode substitution).

To determine a baseline for each city, a face-to-face household survey was conducted between June and September (winter) 2011. Each person over the age of ten in the sampled households was asked to participate. These households were selected from 1), a stratified random sample of low socioeconomic deprivation mesh-blocks and high socio-economic deprivation mesh-blocks, and 2), areas close to, and distant from, MCP infrastructure. A follow-up survey will be conducted in a year's time (winter 2012), which will enable a measurement of changes in relative inequalities in active travel behaviour associated with the intervention, and the calculation of a costbenefit ratio.

The author took part in the process of designing the household questionnaire, and played a significant role in training interviewers and administering the survey's implementation. Some of the elements of the survey conducted in Hastings are used in this Master's thesis, in order to add a quantitative component to the analysis, and to allow the researcher to examine different perspectives to best answer the research objectives and research aim (Morse, 2003). These elements are detailed and explained in Chapter 7.

\section{Analysis method}

The quantitative data from the questionnaire was analysed in four different ways:

- A simple observational analysis was at first conducted after having presented the relevant data in graph form.

- Chi-square tests were then conducted to examine whether potential relationships occurred between different factors, 
namely between socio-demographic characteristics and intentions to walk and cycle more often in the near future, and between socio-demographic characteristics and cycling levels in the last twelve months.

- Simple bivariate regressions were also undertaken to determine whether potential relationships exist in the sample between declared intentions to walk and cycle more in the near future, and psychological factors.

- Two multivariate regressions were conducted to determine the relative influence of different psychological factors on intentions to walk and cycle more in the near future. 


\section{Travel behaviour, intentions, and mode choice}

\section{Co-benefits of walking and cycling}

The empirical literature on active transport insists on the fact that walking and cycling carry multiple benefits and co-benefits. There has been an abundance of international peer-reviewed research in the last decade suggesting that walking and cycling are cost-effective, healthy and environmentally friendly transport alternatives to motor-vehicle use in urban areas (Giles-Corti, et al., 2010; Ogilvie, et al., 2004; Pucher, et al., 2010; WHO, 2000; Woodcock, et al., 2009). While providing a full review of the literature surrounding the benefits of active transport is beyond the scope of the study, the benefits associated with active transport are nevertheless a critical part of the motivation of this study. It is thus important that one bears in mind the positive effects walking and cycling have on public health, economic and social well-being, and on the environment when evaluating a community intervention aimed at encouraging active transport.

\section{Psychological factors / theory}

Heinen et al. (2010) review a considerable body of recent research focused on the effect of attitudes and other psychological factors on travel behaviour, intentions, and mode choice. Because research into psychological constructs tends to be embedded in theory, this section begins by examining theoretical frameworks used to assess psychological factors influencing travel behaviour, intentions, and mode choice.

\section{Theory of planned behaviour}

According to Verplanken et al. (1997), research surrounding the area of attitude-behaviour relations was dominated for many years by two theories, the theory of reasoned action (Ajzen \& Fishbein, 1980; Fishbein \& Ajzen, 1975) and its successor the theory of planned behaviour (Ajzen, 1991). 
Ajzen (1991, p. 206) argues that "attitudes toward the behaviour, subjective norms with respect to the behaviour, and perceived control over the behaviour are usually found to predict behavioural intentions with a high degree of accuracy". Therefore, with respect to the theory of planned behaviour, travel behaviour and intentions can be determined by examining the attitudes, subjective norms and perceived behavioural control of a population. One must however first understand the meaning of each of these factors.

\section{Attitudes}

Ajzen (1991, p. 188) defines the attitude toward the behaviour as "the degree to which a person has a favourable or unfavourable evaluation or appraisal of the behaviour in question". For the purposes of this study, the 'behaviour in question' is the choice of a person to walk or cycle rather than use a car. Thus, a person who holds strong beliefs that positive outcomes will result from performing the behaviour will have a positive attitude toward the behaviour, and vice versa (Montano \& Kasprzyk, 2008). Attitudes can be assessed by asking respondents to evaluate the behaviour under study on, for example, a good-bad or pleasant-unpleasant scale (de Bruijn, Kremers, Schaalma, van Mechelen, \& Brug, 2005). Dill and Voros (2007) for instance argue that attitudes can have a significant influence on travel behaviour and physical activity, citing a study by Kitamura et al., (1997) that found that attitudes related to urban life, such as being proenvironment, were significant factors in explaining people's travel behaviour. It is however noteworthy that many authors have found that, in general, attitudes are only weakly associated with behaviour despite their role in predicting behavioural intention (Giles-Corti \& Donovan, 2002; Sallis \& Owen, 1999).

\section{Subjective norms}

According to Ajzen (1991, p. 188), the second predictor for behavioural intentions is a social factor termed subjective norms, which the author 
defines as "the perceived social pressure to perform or not perform the behaviour". Thus, a person who believes that certain referents thinks he or she should perform a behaviour and is motivated to meet expectations of those referents will hold a positive subjective norm, and vice versa (Montano \& Kasprzyk, 2008). Subjective norms can therefore be directly assessed by asking an individual if important people around him or her believe he or she should engage in the behaviour in question (de Bruijn, et al., 2005). In a study examining the value of personal norms in an addition to the theory of planned behaviour, Haarland, Staats and Wilke (1999) investigated by means of a mail survey a sample of 305 Dutch citizens who were enlisted to participate in a behavioural change intervention programme on environmentally relevant behaviour. While the impact of attitudes on behaviour is often found to be stronger than the impact of subjective norms, in this study the only significant effect of subjective norms was that on intention with respect to transportation decisions (Harland, et al., 1999).

\section{Perceived behavioural control}

The third and final factor influencing behavioural intentions, under the theory of planned behaviour, is perceived behavioural control (PBC). Ajzen (1991, p. 188) defines PBC as "the perceived ease or difficulty of performing the behaviour, and it is assumed to reflect past experience as anticipated impediments and obstacles". Ajzen added PBC to the theory of reasoned action based in part on the idea that behaviour is determined both by intention and ability. Thus, a person's perception of control over the behaviour, together with intention, is expected to have a direct effect on the behaviour (Montano \& Kasprzyk, 2008). PBC can be assessed by asking someone about his or her perception of the extent to which the behaviour in question is easy or difficult, and the individual's perception of his or her abilities to succeed in performing the behaviour (de Bruijn, et al., 2005). In a study aimed at explaining two behaviours, namely bicycle use for transportation and snacking behaviour in a Dutch adolescent sample, de 
Bruijn et al. (2005) found that students with a more positive intention to use a bicycle for transportation also had more perceived behavioural control towards using their bicycle.

The theory of planned behaviour therefore suggests that decisions regarding behaviour are made on the basis of rational evaluation (Heinen, et al., 2010). However, this model has been challenged in recent years, with questions posed about the role of habits and habitual factors in the decision making process.

\section{Habits}

Another psychological construct that may influence walking and cycling behaviour and mode choice is habits. Verplanken and colleagues suggest that the popularity of the theory of planned behaviour may have led social psychologists to underestimate the importance of repetitive habitual aspects of behaviours (Verplanken, et al., 1997). In a study in 1998 aimed at examining the determinants of repeated behaviours, and the decision processes underlying them, using travel mode choices as an example of such behaviours, Aarts, Verplanken and van Knippenberg point out that:

"If one day individuals perform a given behaviour to achieve a specific goal (e.g. using a car to travel to their work), they are likely to use the experiences of that behaviour in making a decision concerning a similar opportunity to act on the next day. Thus, in the context of travel behaviour, decisions to use a mode of transportation are influenced by experiences gained from previous journeys" (1998, p. 1357).

Additionally, in a study aimed at measuring habit strength in adult active transportation, de Bruijn et al. (2009) found that after controlling for theory of planned behaviour variables, habit strength was the strongest predictor of bicycle use. This study also found that habits are a moderator of the intention-behaviour relationship regarding bicycle use, with intentions becoming less relevant when bicycle use increases in habit strength (de Bruijn, et al., 2009). The empirical literature therefore shows that daily 
routines and habits have a direct influence on people's behaviours regarding travel mode choice.

\section{Environmental factors}

While the psychological factors involved in decision-making and behavioural processes are important, so too are the environmental factors. Many of the early theories and models examining the psychosocial constructs of behaviour do not encompass the influence of environmental factors in decision-making processes regarding travel mode choice (Ogilvie, et al., 2011). However, according to the same source (p. 475), "it is increasingly accepted that habitual patterns of behaviour may be environmentally cued, and that a supportive environment for active living may be a necessary, if not sufficient, prerequisite for sustained behaviour change". This is important in the sense that a large share of the $i$ Way project funding in Hastings has been allocated to improve the current environment to support walking and cycling by building new infrastructure.

\section{Urban form}

Evidence shows that the presence of attractive and large urban public open spaces are associated with higher levels of walking and cycling (Giles-Corti, et al., 2005). Additionally, non-motorised modes of transport are most favourable for short-distance trips, where other modes of transport are comparatively slow. This may explain the tendency for the share of walking and cycling to be higher in higher density areas (Rietveld, 2000). Street connectivity and destination proximity are therefore important factors to achieve higher rates of walking and cycling in the urban environment (Forsyth \& Krizek, 2010). This suggests that thoughtful urban design and planning is required to encourage active travel for multiple uses, including for commuting and recreation (Giles-Corti, et al., 2005).

\section{Infrastructure}

There is thus strong evidence to suggest that an integrated range of built environmental factors such as infrastructure and facility improvements may 
play an important part in people's choice to walk or cycle to reach destinations (Forsyth \& Krizek, 2010). Greater numbers of cycling lanes and pedestrian paths for example can induce more walking and cycling, and a higher level of street connectivity can lead to more active travel (Pucher, et al., 2010; Randall \& Baetz, 2001).

Pucher (2001) notes that countries with more cycling facilities, for example Germany or the Netherlands, have a higher share of cycling than countries with less dedicated infrastructure. It has also been argued that the provision of separate cycling facilities along roads and at intersections is the most important approach to making cycling safe, practical and convenient, particularly when connecting utilitarian origins and destinations to promote cycling to work, school and for shopping trips (Pucher \& Buehler, 2008). Other infrastructural provisions which may have a positive effect on levels of active travel, particularly on cycling, include the provision of parking facilities (e.g. racks), clearly marked and signed routes, car-free zones, etc. (Pucher, et al., 2010).

However, according to Ogilvie et al. (2011, p. 473), "Evidence is limited from studies of actual interventions to show that altering transportation infrastructure or other aspects of the built environment has led to an increase in walking or cycling or a modal shift away from car use, let alone changes in overall physical activities or carbon emissions". This sentiment is also shared by Heinen et al., who argue that it is unclear whether the presence and continuity of bicycle infrastructure increases bicycle mode share or cycling frequency (Heinen, et al., 2010). This implies that more work needs to be done to assess the efficacy of particular, targeted infrastructural changes on the overall levels of active travel of a selected population.

\section{Natural environment}

While a certain amount of control can be applied to the built environment in urban areas, less can be done in regard to the natural environment. A study 
in the San Francisco Bay Area for example showed that urban landscapes, shaped by well-connected streets, mixed land uses and close proximity to retail activities can induce non-motorised transport, but other exogenous factors such as topography, darkness and rainfall had far stronger influences (Cervero \& Duncan, 2003). Heinen et al., in their review of the literature surrounding cycling for commuting, make the point that in contrast to motorised transport, a person's choice to cycle is strongly determined by the natural environment, namely by the landscape, hilliness, weather and climate (Heinen, et al., 2010). It has been suggested in a number of studies that slopes and hilliness have a negative effect on bicycle use (Parkin, Wardman, \& Page, 2008; Rietveld \& Daniel, 2004), and patterns in active travel can be linked to seasonality, with higher rates of walking in summer than in winter (Nankervis, 1999). The weather also plays an important part in people's choice to walk or cycle, with rain or the chance of precipitation being cited as the most negative weather aspect (Nankervis, 1999). Other exogenous factors to be taken into account are temperature, as some studies show that higher temperatures lead to higher cycling rates (Parkin, et al., 2008), while darkness has been associated with people choosing to cycle less (Cervero \& Duncan, 2003).

\section{Ecological models}

Psychological and environmental factors therefore prove to play an important role in people's choices to walk and cycle, but the strength of these factors in influencing outcomes is often unclear. All of these elements need to be taken into account when examining the travel behaviour, intentions, and mode choice of a selected population. In 2003, Saelens and colleagues put forward an ecological model which encompasses the effect of neighbourhood environments as well as individual factors on walking and cycling (Saelens, et al., 2003). According to the authors, ecological models emphasise that behaviours have multiple levels of influence that need to be examined. In this model the physical environment as well as individual 
factors, such as demographic and psychosocial, are proposed to directly contribute to a person's choice to walk or cycle, both for transport and recreation purposes.

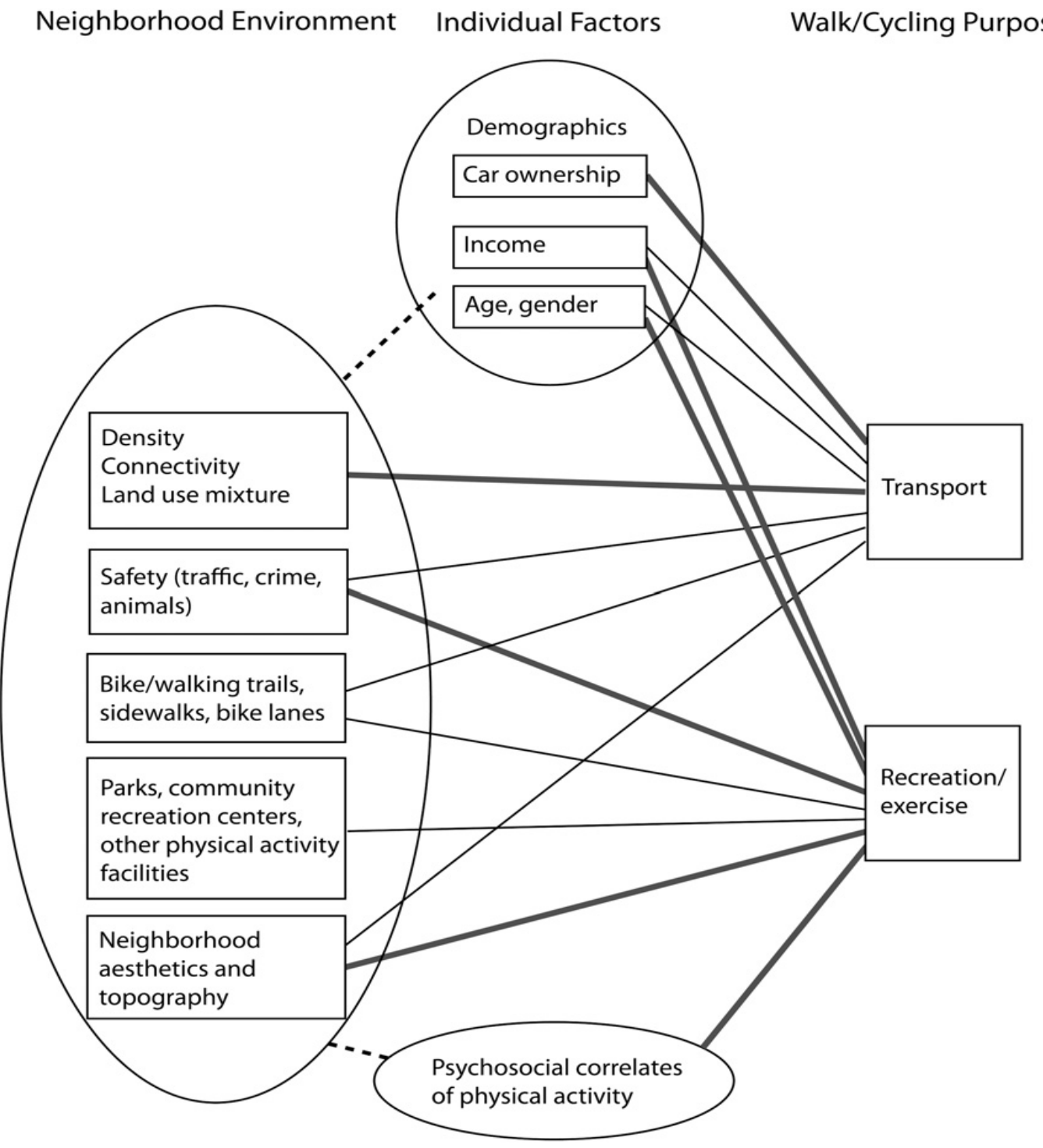

Figure 6.1: The model of Saelens et al., describing environmental and psychosocial correlates of walking and cycling (Saelens et al., 2003)

It is with Saelens' model in mind that the second objective of this study will be examined, by looking at results from both the household questionnaire and the focus groups and interviews, to determine the role and relative 
significance of a range of factors in travel behaviour, intentions, and mode choice in Hastings. 


\section{Perceptions of walking and cycling in Hastings}

\section{ACTIVE questionnaire}

To determine a baseline for future study as part of the ACTIVE project, a face-to-face household survey was conducted in Hastings in winter (June to September) 2011. This questionnaire aimed to examine travel behaviour in general, and active transport in particular, across the Hastings district (Appendix One). Information was collected on:

1. Frequency and mode of transport for utilitarian journeys (namely trips to work, to school, to shop, to leisure, and to accompany family and friends)

2. Factors influencing choice of route, choice of mode and safety perceptions

3. Walking and cycling physical activity (not necessarily transport related)

4. Transport habit strength

5. Opinions about walking and cycling

6. Awareness of the $i$ Way programme

7. Cycling frequency and use of public transport

8. Psychological well-being

9. Demographics (age, ethnicity and income).

This section presents the results from parts 2, 4, 5, 6, 7 and 9 (see Chapman et al., 2012, for further information).

\section{Demographics}

Questions were asked of respondents about their age, income (for participants 15 years and over) and ethnicity. Sample sizes for these three questions were respectively $n=125, n=121$, and $n=129$ (figures 7.1-7.3). 
Figure 7.1: Age distribution of Hastings respondents

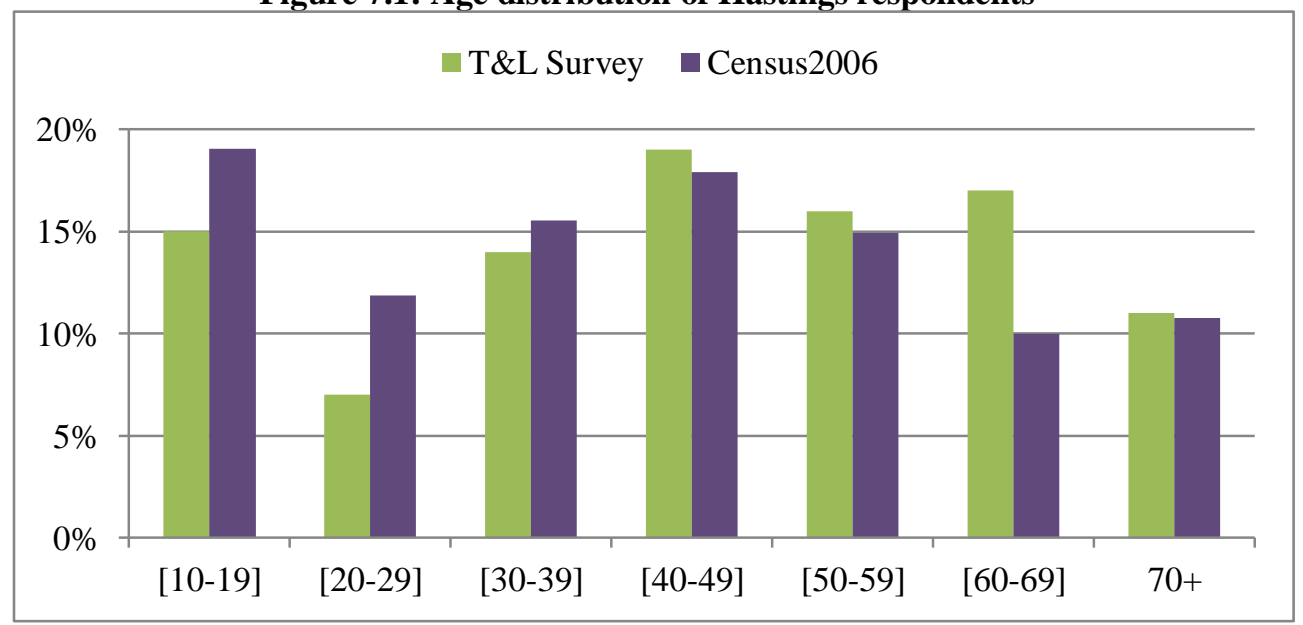

Figure 7.2: Ethnicity distribution of Hastings respondents

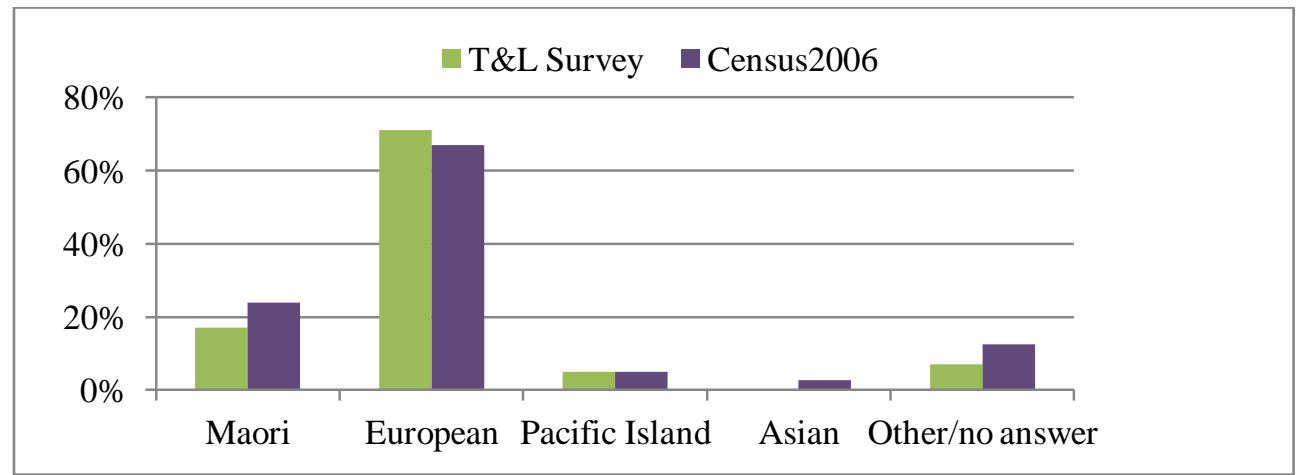

Figure 7.3: Income (personal, before tax or superannuation) distribution of Hastings respondents

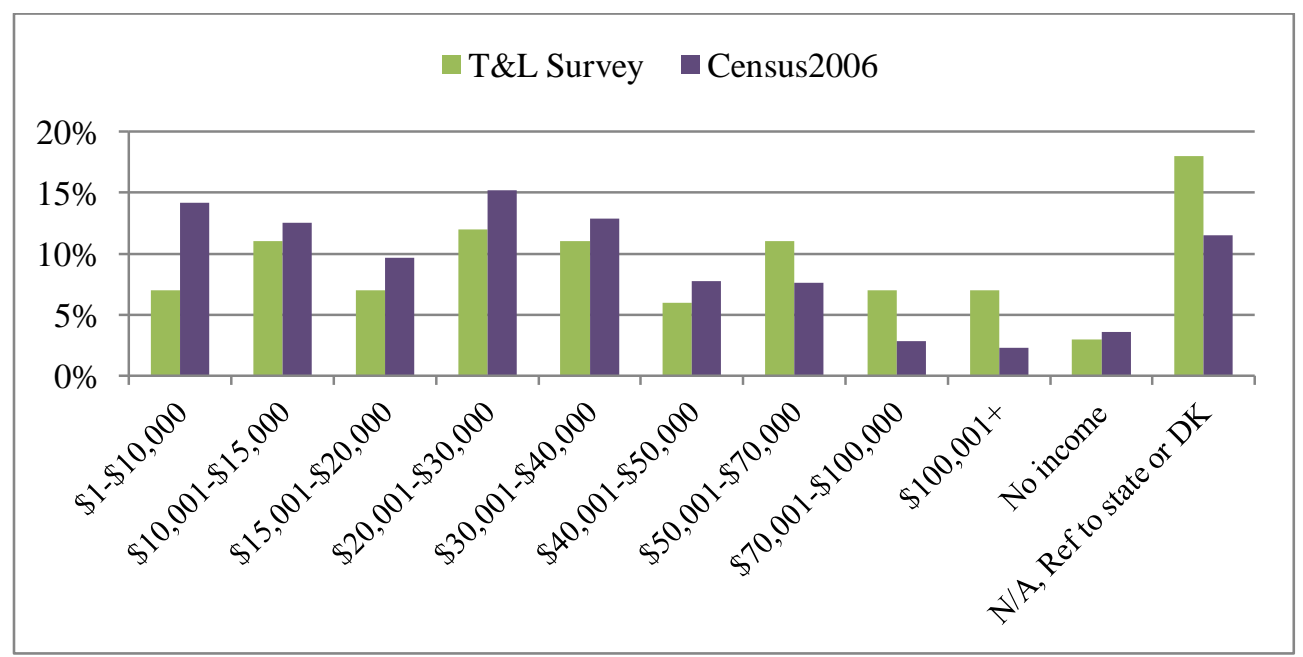


Figures 7.1-7.3 show the distribution of the Hastings respondents in the ACTIVE baseline survey, here labelled 'T\&L Survey' (Transport and Lifestyle Survey), against the distribution of the 2006 Census for Hastings. Some bias towards older people was found compared with the Census pattern for the Hastings district. This may be due to younger people (below 30 years) being significantly less often at home when interviewers visited, although up to three call-backs were made by interviewers. Similarly, lowincome groups were under-represented in the sample compared with the Census results. However, no significant divergence from the Census was found in terms of ethnicity.

Factors influencing choice of route, mode, and safety perceptions

Questions focusing on the choice of route ${ }^{2}$ were asked of respondents who had walked or cycled to work or school in the seven days preceding the interview, a total of 41 respondents. Respondents rated different factors on a five-point Likert scale $(1=$ not at all important, to $5=$ very important $)$. The findings from this compound question show that directness and personal safety are the dominant considerations. Factors such as convenience (e.g. shops en route), enjoyment and quality of surface were not insignificant, but were rated as less important (figure 7.4).

\footnotetext{
${ }^{2}$ 'I would now like to ask you about your route to your workplace or place of education. I will list a few factors that may influence your choice of route. Could you please rate these factors according to their importance to you?'
} 
Figure 7.4: Factors influencing choice of route

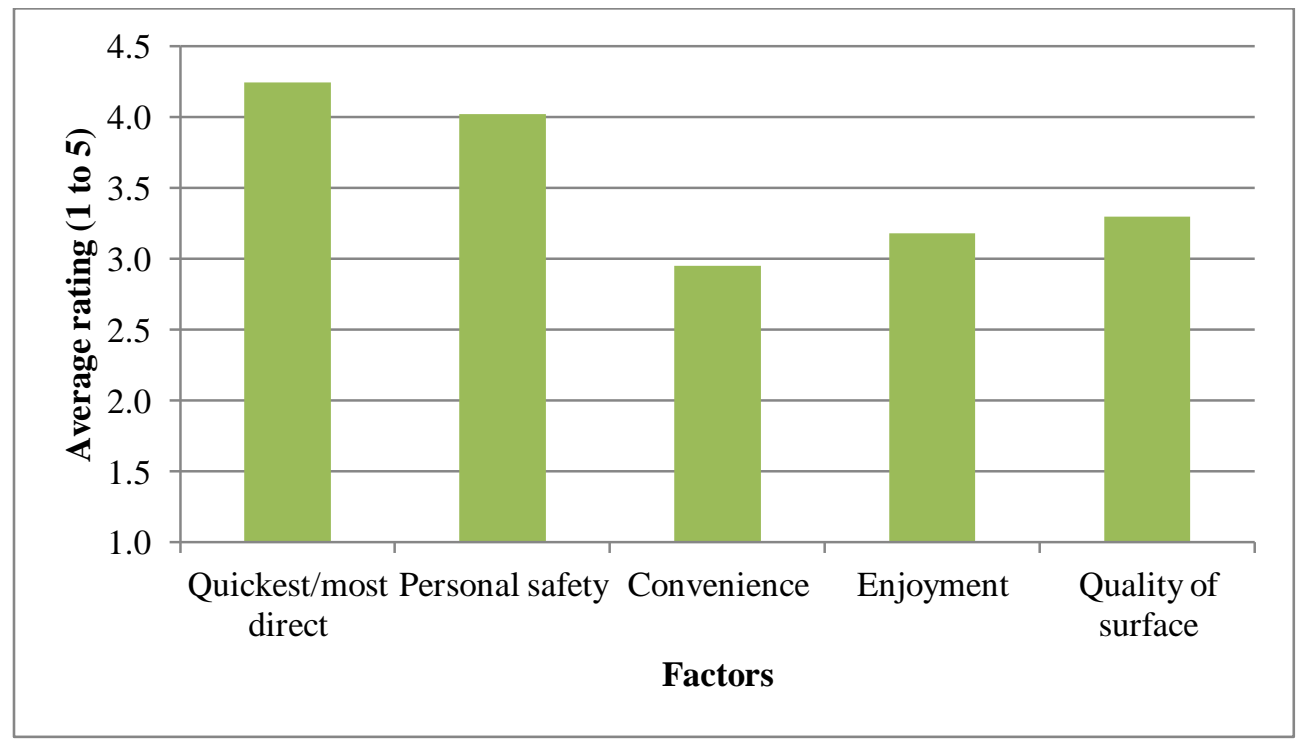

While the 'choice of route' questions were put to cyclists and walkers only, questions about the factors influencing safety perceptions ${ }^{3}$ were put to all respondents who were working or studying $(n=75)$, as safety has been identified as an important determinant in people's choice of route. Participants were thus again asked to rate several factors on a five-point scale in terms of their importance in influencing their choice of route. The results below show that the factors of driver behaviour, traffic volume and traffic speed were dominant. Parking provision, a separated route for cycling and the number of intersections were of moderate importance, while street lighting and the presence of people on the footpath were considered to be of lesser importance (figure 7.5).

\footnotetext{
${ }^{3}$ 'I would now like to focus on safety in getting to your workplace or school. I will list a few safety factors. Could you please rate each of them according to how important they are to your choice of route?'
} 
Figure 7.5: Factors influencing safety perceptions

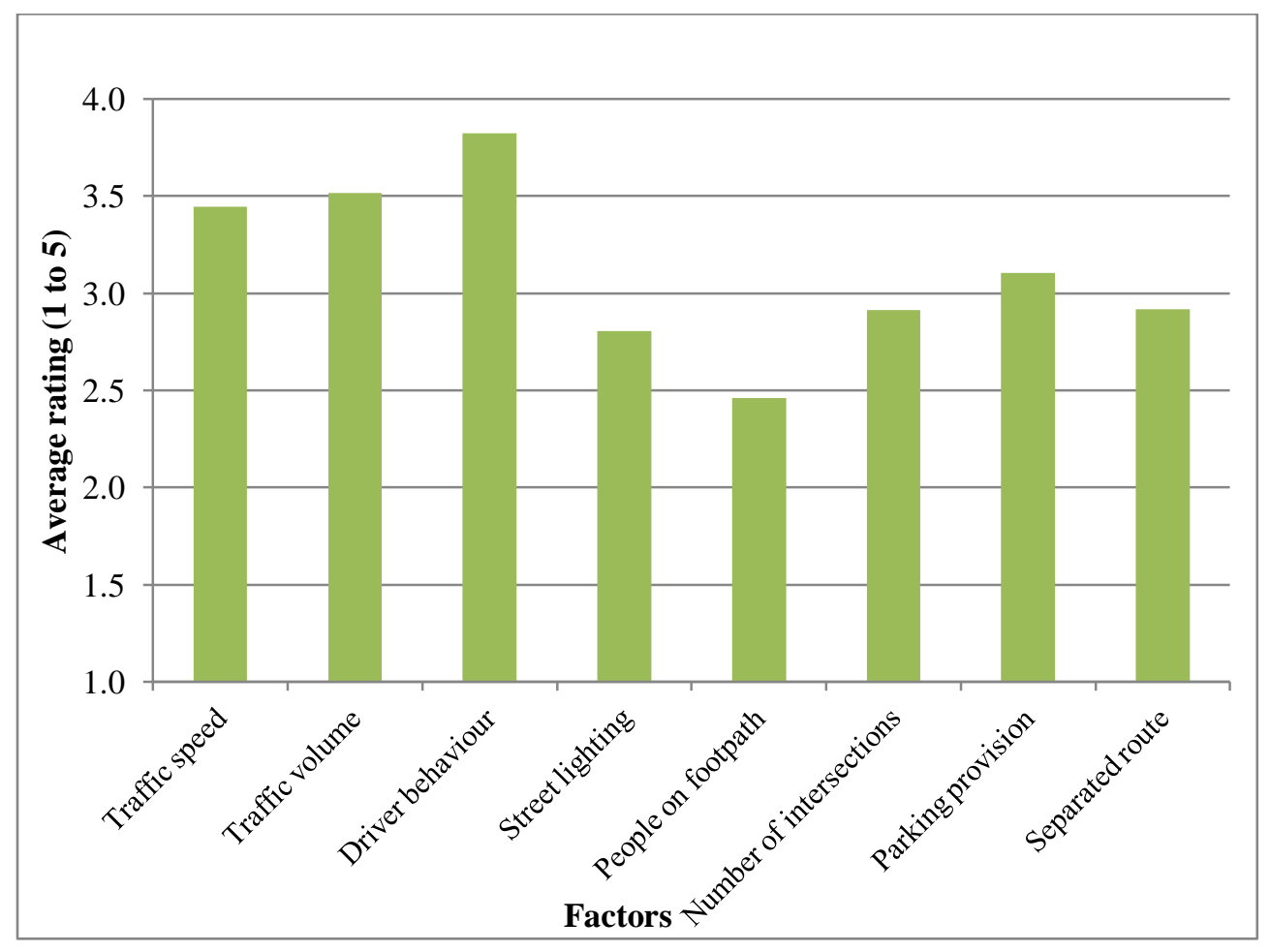

The same respondents were also asked to rate factors that may influence their choice of mode of transport ${ }^{4}$. While quickness, personal safety and convenience were the dominant factors, only the environmental factor (e.g. taking into account carbon emissions etc...) was considered as notably less important, with an average rating of below 3 (figure 7.6).

\footnotetext{
${ }^{4}$ 'I would now like to ask you about the reasons why you choose to walk, or drive a car, etc. to your workplace or school. I will list a few factors that may or may not influence your choice of mode. Could you please rate these factors according to their importance to you?'
} 
Figure 7.6: Factors influencing choice of mode of transport

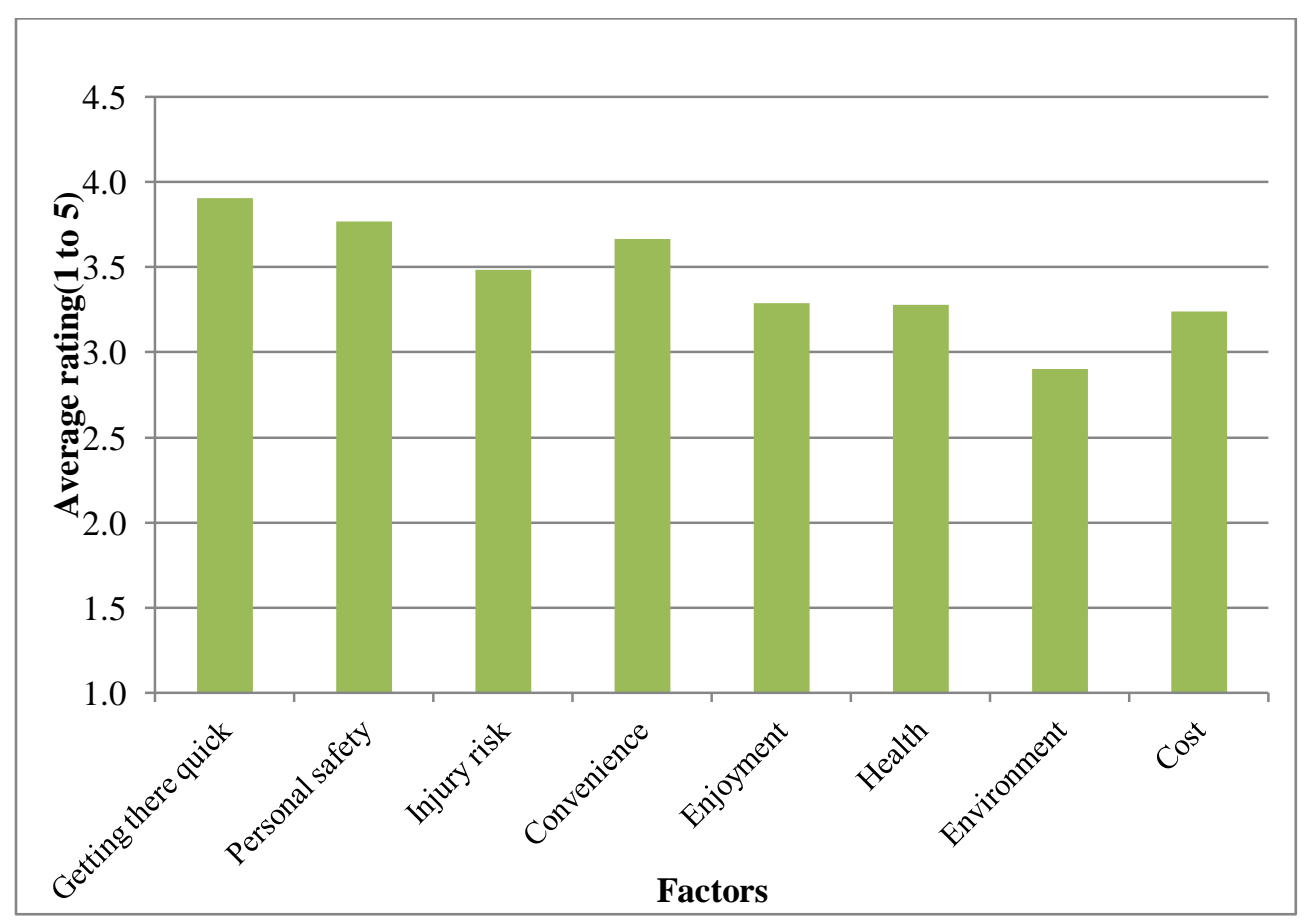

\section{Transport habit strength}

Part of the questionnaire focused on the choice of mode of transport for everyday trips. This fourth part of the questionnaire examined transport mode habit strength in relation to nine common trips, namely trips to:

- Shop in town

- Work

- School or education facilities

- Sport or other recreational activities

- The nearest park or green space for a walk

- The nearest supermarket

- Visit someone who lives elsewhere in town

- The beach

- The local dairy. 
With the help of a showcard indicating several transport mode options (walking, cycling, taking the bus, driving a car, being driven, or something else), respondents $(n=129)$ were asked to indicate as quickly as possible the transport mode that would first come to mind when prompted about each of the nine trips listed above.

Figures showing results for each of the nine trips can be found in Appendix Two. The large dominance of driving among transport mode choices was evident in all but the trip to the nearest park or green space for a walk, where walking was the preferred mode choice for over two thirds of the respondents. It is also notable that the proportion of respondents who would cycle for these common trips was consistently less than $10 \%$.

In order to assess whether these habitual mode choices might have been influenced by access to bicycles and cars, or by a physical disability impeding participants' use of active transport, respondents were asked if they had access to functioning bikes and cars, and if they had a physical condition preventing them from walking and cycling in the seven days prior to the interview. The results showed that $59 \%$ of the sample reported having access to a functioning bike, $94 \%$ had access to a car, while $14 \%$ reported a physical condition.

\section{Perceptions of walking and cycling}

A large part of the questionnaire was devoted to investigating perceptions about walking and cycling as a means of transport (i.e. for getting from place to place). With the theory of planned behaviour in mind, questions were put to participants to examine their attitudes and perceived behavioural control towards walking and cycling, as well as their intentions to walk and cycle more in the near future. To augment results relating to the theory of planned behaviour, questions were also asked about habitual behaviour towards walking and cycling. 


\section{Attitudes towards walking and cycling}

In order to investigate attitudes towards active transport, a set of six questions focused on the 'desirability' of, or positive attitudes towards, walking and cycling. Respondents were thus asked to rate on a seven-point Likert scale ( $1=$ strongly agree to $7=$ strongly disagree $)$ whether, in their opinion, walking as a means of transport is:

- $\operatorname{Bad} \ldots \operatorname{good}$

- Pleasant ... unpleasant

- Sensible ... not sensible

- Realistic ... unrealistic

- Foolish ... not foolish

- Safe ... unsafe

The same questions were also asked about attitudes to cycling. The six subquestion ratings were then converted to a seven-point composite variable rating (figures 7.7 and 7.8).

Figure 7.7: Composite variable: opinions of walking as 'desirable'

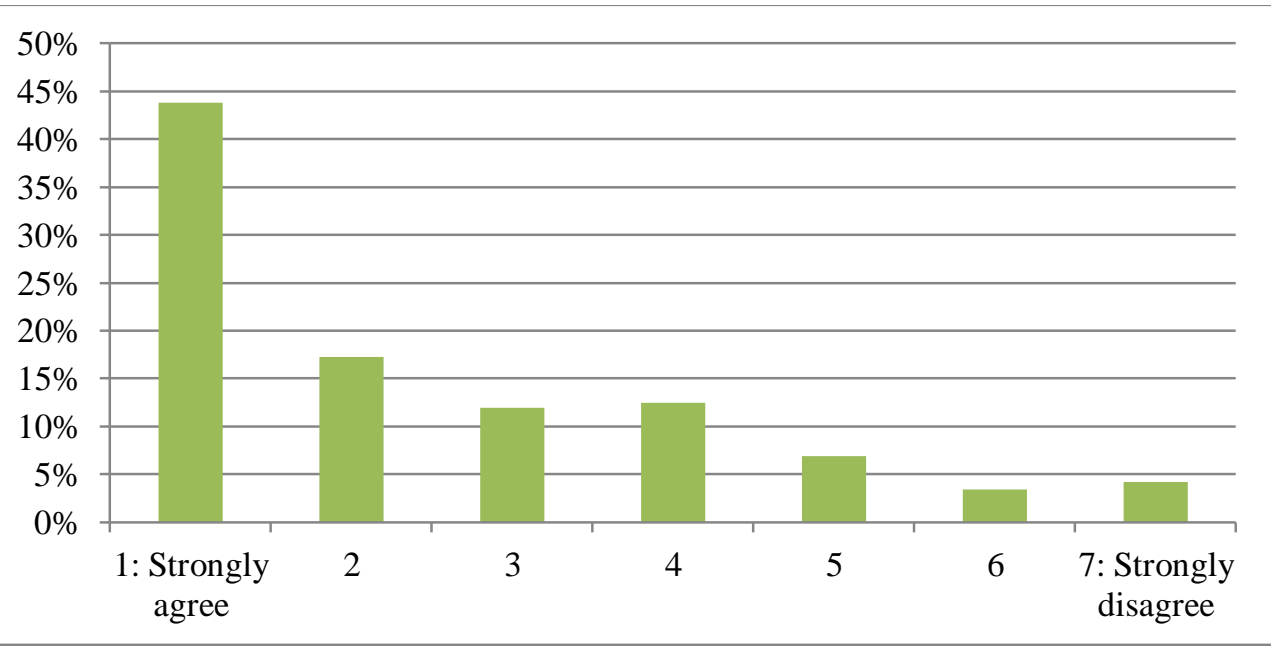


Figure 7.8: Composite variable: opinions of cycling as 'desirable'

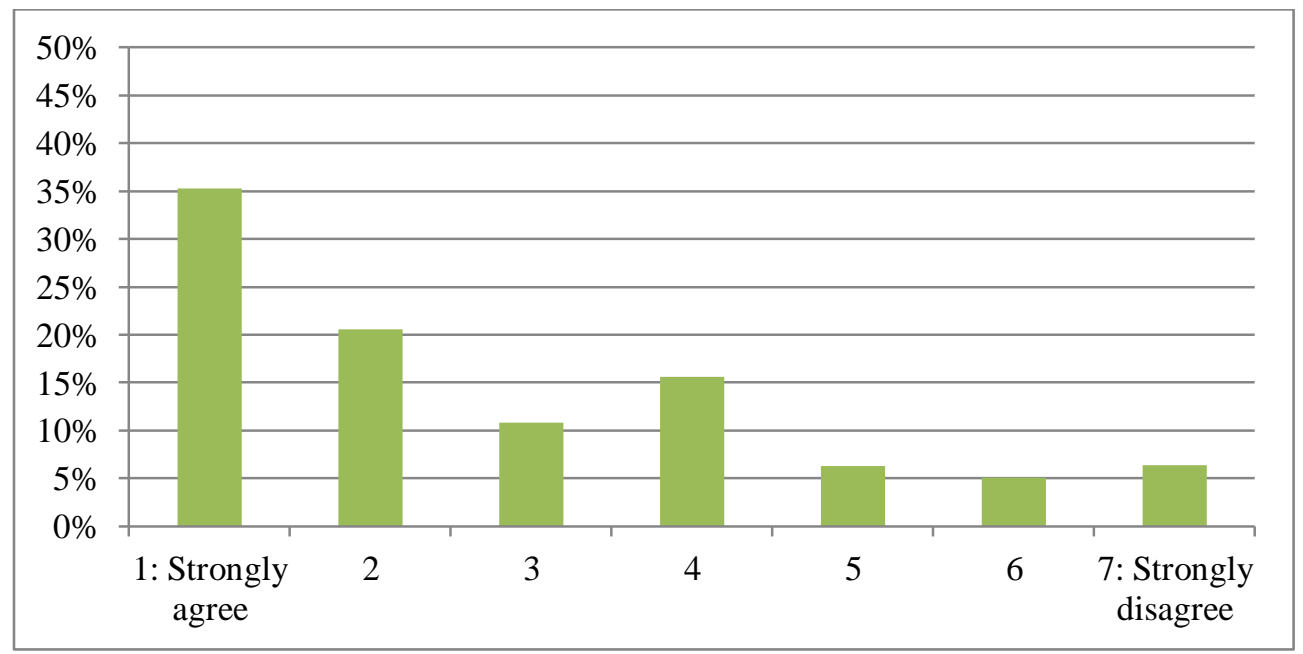

The results show that a large proportion of participants $(n=128$ for the walking composite variable and $n=122$ for the cycling variable) agree that walking and cycling are desirable as modes of transport. Cycling may be seen slightly less favourably than walking, but the differences are not marked.

\section{Perceived behavioural control}

The difference between walking and cycling in terms of perceived behavioural control is however clearly more significant. Participants were asked to rate on a 1 to 7 scale a set of three statements focusing on their perceived ability to walk and cycle as a mode of transport. The three statements respectively examined whether or not it was possible for the respondent to walk or cycle, whether he or she felt confident, and whether the respondent felt capable of walking and cycling as a means of transport. The results were compounded into a composite variable, and are presented in figures 7.9 and 7.10 below $(n=128,122)$. 
Figure 7.9: Composite variable: ability and confidence in walking

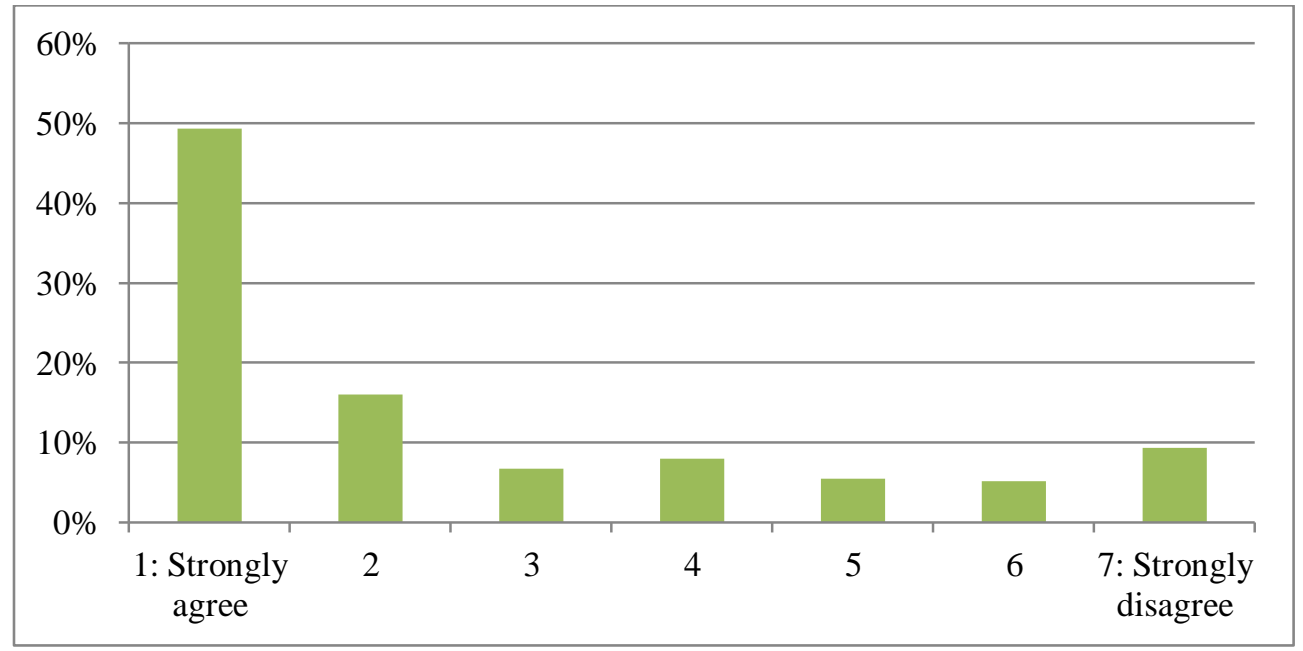

Figure 7.10: Composite variable: ability and confidence in cycling

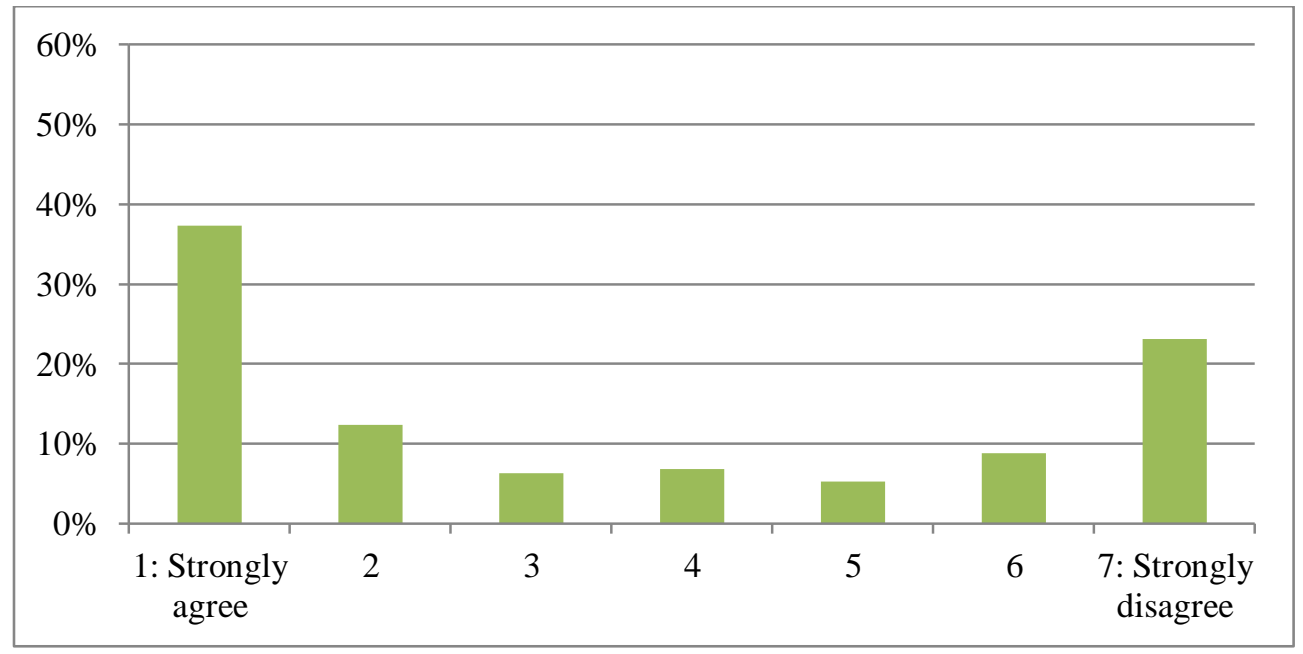

It is clear that perceived behavioural control is significantly higher for walking than for cycling, as nearly $50 \%$ of respondents strongly agree that they feel able and confident to walk as a means of transport, compared to less than $40 \%$ for cycling. Additionally, more than $20 \%$ of participants feel completely unable to cycle as a means of transport, as opposed to less than $10 \%$ for walking. 


\section{Walking and cycling as a social norm}

Walking and cycling were also investigated as subjective norms (figures 7.11 and 7.12). A composite variable was constructed from answers to a set of four statements that respondents were asked to rate:

- Most of my friends would approve of me walking as a means of transport

- Most people who are important to me approve of my walking as a means of transport

- Most people who are important to me walk as a means of transport

- Most people like me walk as a means of transport.

Figure 7.11: Composite variable: walking as a norm

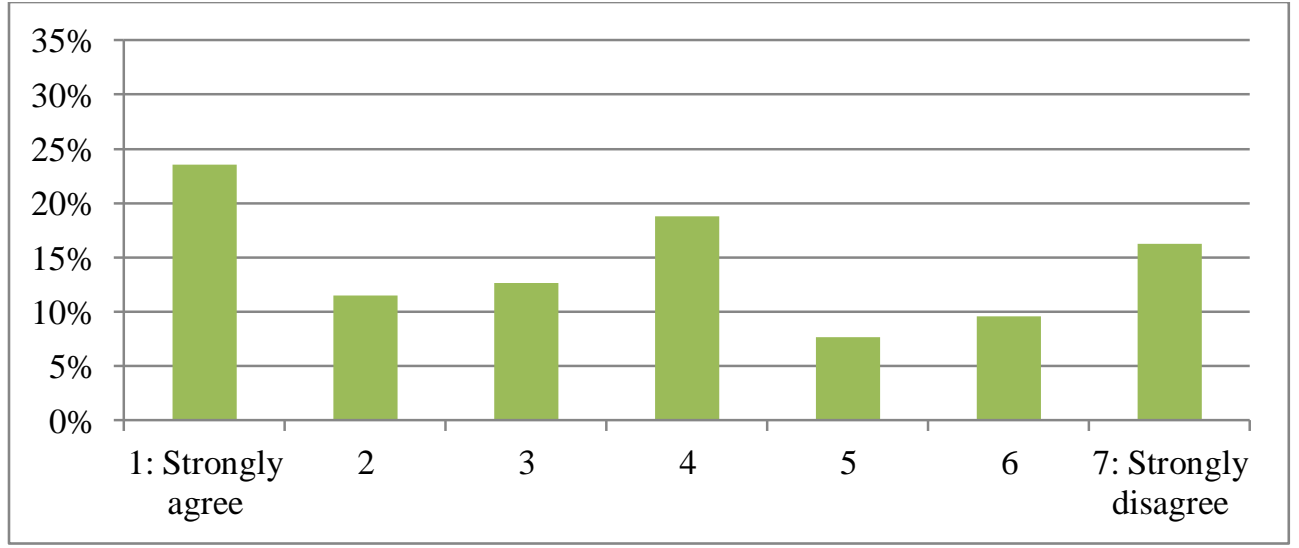

The same questions were asked about cycling:

Figure 7.12: Composite variable: cycling as a norm

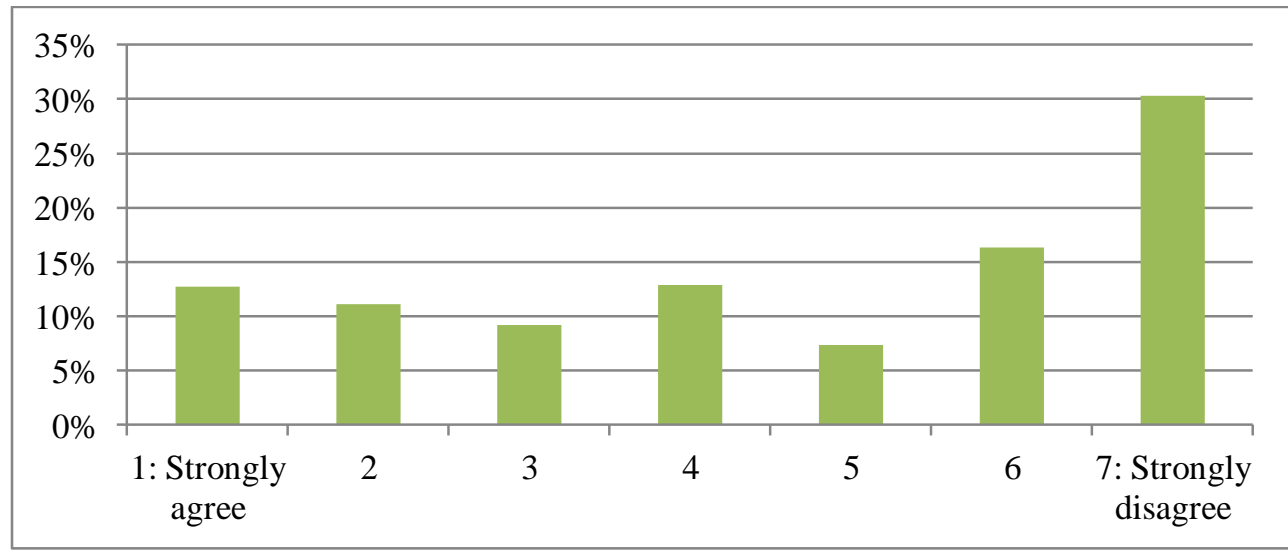


Figure 7.11 and 7.12 show that while walking is not a norm for everyone, it is nonetheless more strongly considered a social norm than cycling. Even though some respondents agreed or were neutral, a large majority did not see cycling as a norm.

\section{Walking and cycling as a habit}

To supplement questions relating to the theory of planned behaviour, seven statements were put to the respondents about active transport as a habitual mode of transport:

- Walking as a means of transport belongs to my daily or weekly routine

- It would make me feel strange if I did not walk as a means of transport

- Walking as a means of transport is something that I have done for a long time

- I never walk as a means of transport

- Walking as a means of transport is something that is typically me

- It is easy and natural for me to walk as a means of transport

- I automatically walk as a means of transport.

The same questions were also asked about cycling. The results were then compounded in a composite variable in figures 7.13 and 7.14 below.

Figure 7.13: Composite variable: walking as a habit

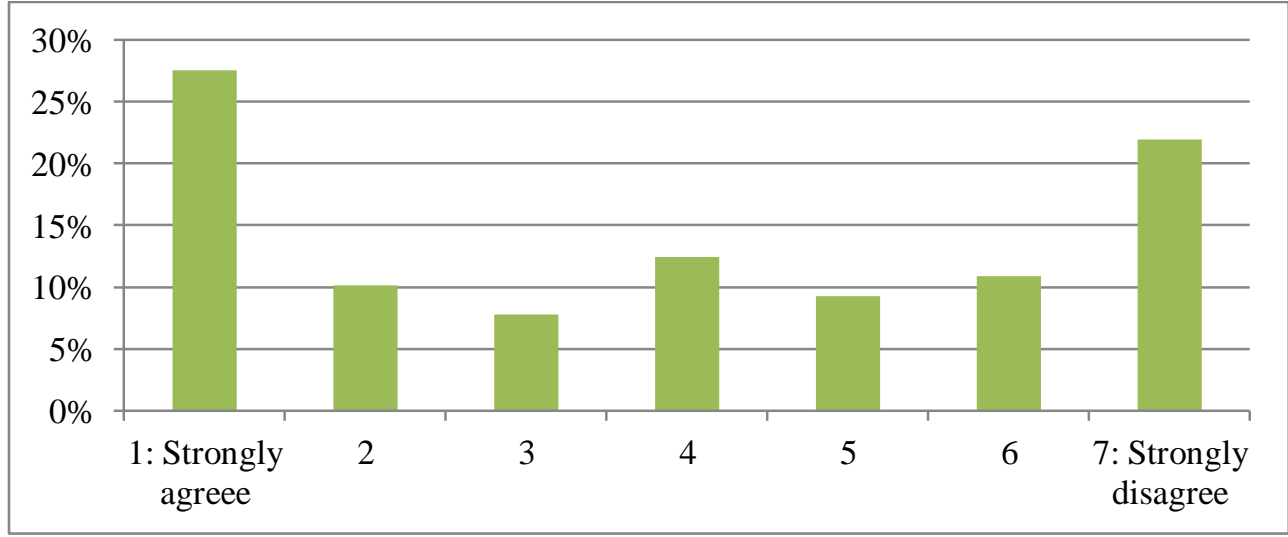


Figure 7.14: Composite variable: cycling as a habit

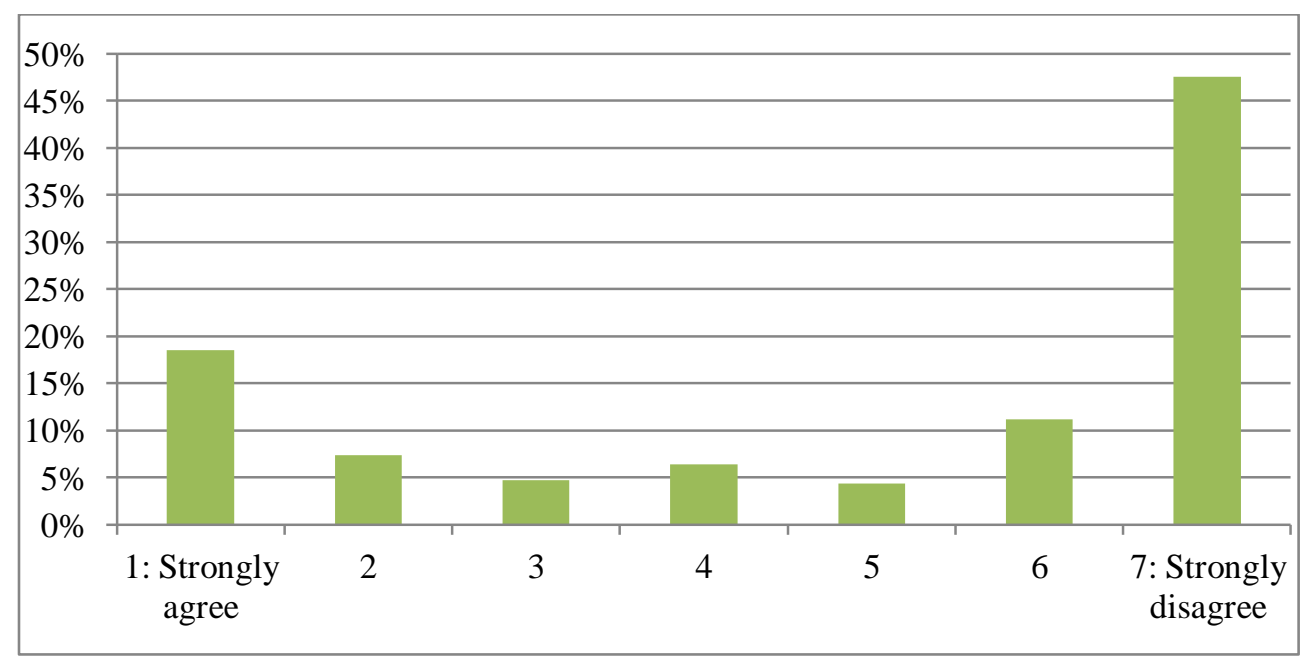

While walking as a mode of transport is a habit for just over a quarter of all respondents, a comparison of figures 7.13 and 7.14 suggests that walking is nevertheless significantly more engrained as a habit than cycling.

\section{Intentions to walk and cycle more}

As the theory of planned behaviour argues that attitudes, subjective norms and perceived control over the behaviour are usually found to predict behavioural intentions (Ajzen, 1991), a question was put to the respondents to determine their intentions to engage in active transport. The question was put in terms of rating on a seven-point Likert scale the statement 'I intend to walk more often as a means of transport in the near future' (figure 7.15).

Figure 7.15: Intentions to walk more often in the near future

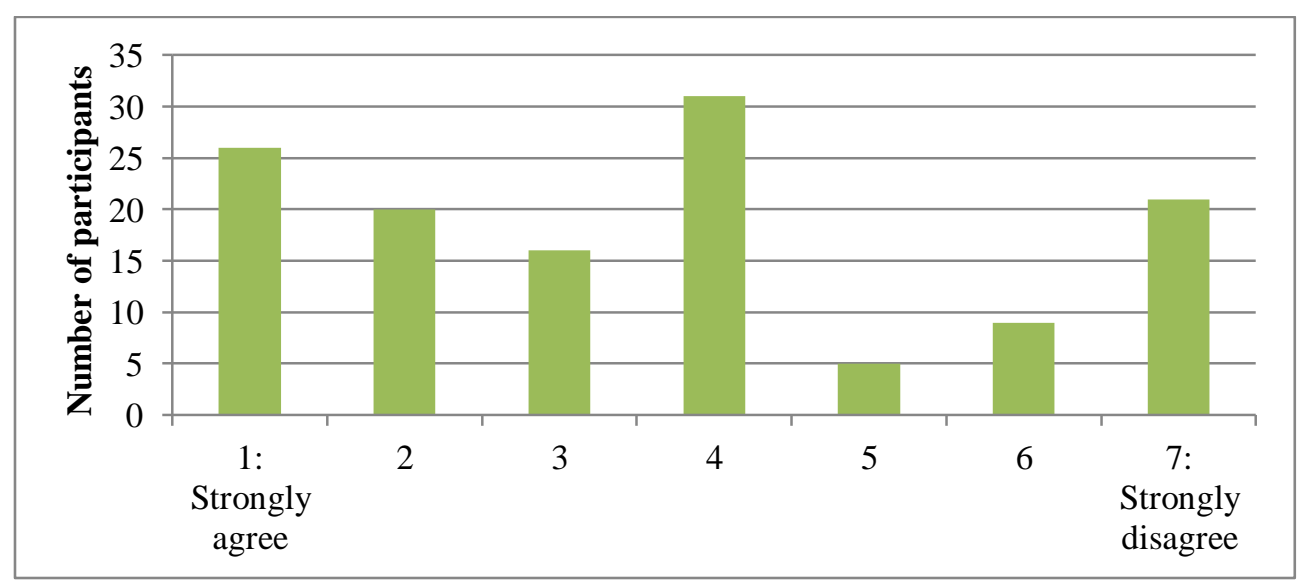


The same statement was also put to participants with regard to cycling:

Figure 7.16: Intentions to cycle more often in the near future

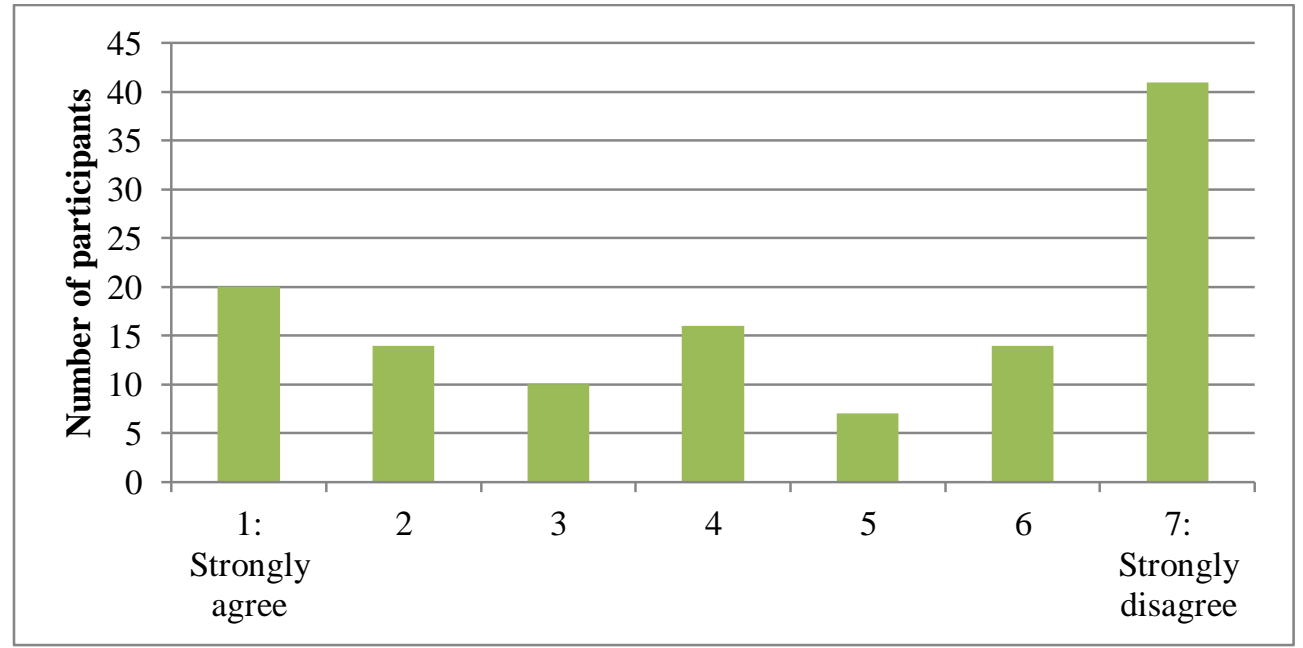

Figures 7.15 and 7.16 show that about $60 \%$ of 128 respondents intended to walk more often in the near future. Additionally over $50 \%$ of 122 respondents had no intention of cycling in the near future, whereas only about half that number did not intend to walk more.

\section{Cycling levels}

To complement the data on attitudes, perceptions, habits and intentions, respondents were asked two questions to determine their actual cycling levels. Participants were first asked if they had cycled in the last year. Half of the 129 respondents declared having cycled at least once in the past twelve months. A second question was then put to the 65 participants who had cycled in the past twelve months to examine cycling frequency in the last four weeks (figure 7.17): 
Figure 7.17: Days cycled in the last four weeks

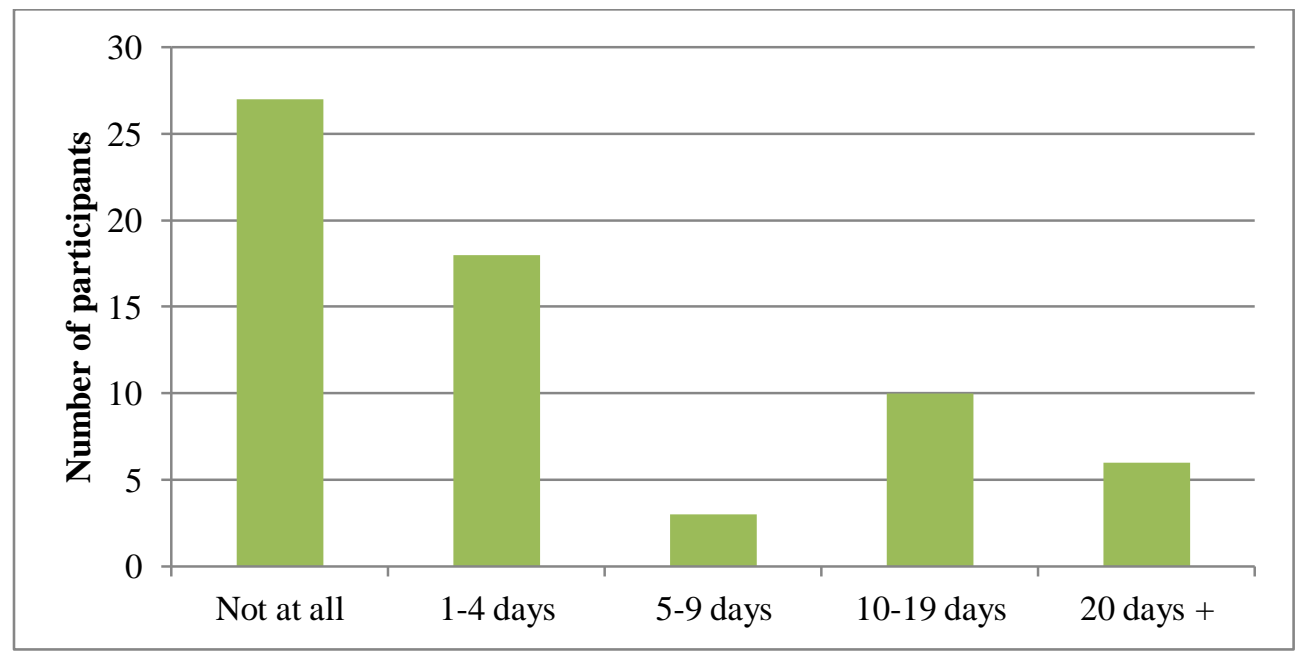

A large majority (approximately 70\%) of the 65 respondents cycled less than four days in the past four weeks, with over a third of the respondents not cycling at all. These results however also show that some of the respondents do cycle regularly, with six people cycling more than twenty days per month.

\section{Bivariate analysis}

\section{Chi-square tests}

Chi-square tests were used to examine whether potential relationships occurred between intentions to walk and cycle more often in the near future and socio-demographic variables, namely income, age, ethnicity and gender. The same method was also applied to determine potential relationships between actual cycling frequency in the last twelve months and the last four weeks, and the aforementioned socio-demographic characteristics. The following table presents the results. The cells highlighted in yellow represent the tests which were statistically significant. 
Figure 7.18: Chi-square test results

\begin{tabular}{|c|c|c|}
\hline Null Hypotheses & $\begin{array}{c}\text { Chi-Square Test } \\
\text { Result }\end{array}$ & Interpretation \\
\hline Income does not have an influence on intentions to walk more often in the near future & $\begin{array}{c}\chi^{2}(2, N=99)=0.277, p= \\
0.871\end{array}$ & We fail to reject the null hypothesis \\
\hline Income does not have an influence on intentions to cycle more often in the near future & $\begin{array}{c}\chi^{2}(2, N=99)=0.519, p= \\
0.771\end{array}$ & We fail to reject the null hypothesis \\
\hline Income does not have an influence on cycling levels in the last 12 months & $\begin{array}{c}\chi^{2}(1, N=99)=0.813, p= \\
0.367\end{array}$ & We fail to reject the null hypothesis \\
\hline Income does not have an influence on cycling levels in the last 4 weeks & $\begin{array}{l}\chi^{2}(1, N=55)=1.155, p= \\
0.694\end{array}$ & We fail to reject the null hypothesis \\
\hline Age does not have an influence on intentions to walk more often in the near future & $\begin{array}{l}\chi^{2}(4, N=125)=7.174, p= \\
0.127\end{array}$ & We fail to reject the null hypothesis \\
\hline Age does not have an influence on intentions to cycle more often in the near future & $\begin{array}{c}\chi^{2}(2, N=125)=11.691, p= \\
0.003\end{array}$ & $\begin{array}{l}\text { Age is associated with intentions to cycle more often in the near } \\
\text { future }\end{array}$ \\
\hline Age $([\leq 30][31-60][\geq 61]) *$ does not have an influence on cycling levels in the last 12 months & $\begin{array}{c}\chi^{2}(2, N=125)=5.308, p= \\
0.070\end{array}$ & We fail to reject the null hypothesis \\
\hline Age $([\leq 30][31-65][\geq 66]) *$ does not have an influence on cycling levels in the last 12 months & $\begin{array}{c}\chi^{2}(2, N=125)=8.511, p= \\
0.014\end{array}$ & Age is associated with cycling levels in the last 12 months \\
\hline Age does not have an influence on cycling levels in the last 4 weeks & $\begin{aligned} \chi^{2}(2, N= & 64)=0.863, p= \\
& 0.293\end{aligned}$ & We fail to reject the null hypothesis \\
\hline $\begin{array}{l}\text { Ethnicity does not have an influence on intentions to walk more often in the near future (Maori and } \\
\text { Others vs. European) }\end{array}$ & $\begin{array}{c}\chi^{2}(2, N=125)=1.909, p= \\
0.385\end{array}$ & We fail to reject the null hypothesis \\
\hline $\begin{array}{l}\text { Ethnicity does not have an influence on intentions to cycle more often in the near future (Maori and } \\
\text { Others vs. European) }\end{array}$ & $\begin{array}{c}\chi^{2}(2, N=125)=7.014, p= \\
0.03\end{array}$ & $\begin{array}{l}\text { Ethnicity is associated with intentions to cycle more often in the } \\
\text { near future }\end{array}$ \\
\hline $\begin{array}{l}\text { Ethnicity does not have an influence on cycling levels in the last } 12 \text { months (Maori and Others vs. } \\
\text { European) }\end{array}$ & $\begin{array}{c}\chi^{2}(1, N=125)=1.086, p= \\
0.297\end{array}$ & We fail to reject the null hypothesis \\
\hline $\begin{array}{l}\text { Ethnicity does not have an influence on cycling levels in the last } 12 \text { months (Maori vs. European and } \\
\text { Others) }\end{array}$ & $\begin{array}{l}\chi^{2}(1, N=125)=7.264, p= \\
0.007\end{array}$ & Ethnicity is associated with cycling levels in the last 12 months \\
\hline $\begin{array}{l}\text { Ethnicity does not have an influence on cycling levels in the last } 4 \text { weeks (Maori and Others vs. } \\
\text { European) }\end{array}$ & $\begin{aligned} \chi^{2}(1, N= & 64)=1.958, p= \\
& 0.162\end{aligned}$ & We fail to reject the null hypothesis \\
\hline Gender does not have an influence on intentions to walk more often in the near future & $\begin{array}{c}\chi^{2}(2, N=129)=1.254, p= \\
0.534\end{array}$ & We fail to reject the null hypothesis \\
\hline Gender does not have an influence on intentions to cycle more often in the near future & $\begin{array}{l}\chi^{2}(2, N=129)=6.566, p= \\
0.037\end{array}$ & $\begin{array}{l}\text { Gender is associated with intentions to cycle more often in the } \\
\text { near future }\end{array}$ \\
\hline Gender does not have an influence on cycling levels in the last 12 months & $\begin{array}{l}\chi^{2}(1, N=129)=4.581, p= \\
0.032\end{array}$ & Gender is associated with cycling levels over the last 12 months \\
\hline
\end{tabular}




\section{Interpretation}

Each of the statistically significant relationships is briefly interpreted in this section.

\section{Hypothesis 1}

\begin{tabular}{ccc} 
Age does not have an influence on & $\chi^{2}(2, N=125)=$ & Age is associated with intentions \\
intentions to cycle more often in the & $11.691, p=$ & to cycle more often in the near \\
near future & 0.003 & future \\
\hline
\end{tabular}

Interpretation: Participants over the age of 61 are less likely to cycle more often in the near future than younger participants. Participants aged between 31 and 60 are also more likely to cycle more often in the near future than all other participants.

\section{Hypothesis 2}

\begin{tabular}{ccc|}
\hline $\begin{array}{c}\text { Age }([\leq 30][31-65][\geq 66]) \text { does not have an } \\
\text { influence on cycling levels in the 12 last } \\
\text { months }\end{array}$ & $\begin{array}{c}\chi^{2}(2, N=125)= \\
8.511, p=0.014\end{array}$ & $\begin{array}{c}\text { Age is associated cycling } \\
\text { levels in the last } 12 \\
\text { months }\end{array}$ \\
\hline
\end{tabular}

Interpretation: Participants under the age of 66 are more likely to have cycled at least once in the last twelve months than participants aged 66 and over.

\section{Hypothesis 3}

Ethnicity does not have an influence on intentions to cycle more often in the near future (Maori and Others vs. European)

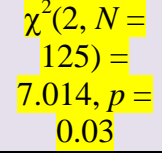
intentions to cycle more often in the near future

Interpretation: Maori and other ethnicities are more likely to be neutral on their intentions to cycle more often in the near future, while Europeans have more polarised intentions: some are more likely to have high intentions to cycle more, while some have firm intentions not to cycle more often in the near future. 


\section{Hypothesis 4}

Ethnicity does not have an influence on cycling $\quad \chi^{2}(1, N=125) \quad$ Ethnicity is associated with levels in the last 12 months (Maori vs. $\quad=7.264, p=\quad$ cycling levels in the last 12 European and Others) 0.007 months

Interpretation: Maori are more likely to have cycled at least once in the last twelve months than Europeans and other ethnicities.

\section{Hypothesis 5}

$\begin{array}{ccc}\text { Gender does not have an influence on } & \chi^{2}(1, N=129)= & \text { Gender is associated with cycling } \\ \text { cycling levels in the last } 12 \text { months } & 4.581, p=0.032 & \text { levels over the last } 12 \text { months }\end{array}$

Interpretation: Males are more likely to have cycled at least once in the last twelve months than women.

\section{Hypothesis 6}

Interpretation: Males are more likely to have stronger intentions to cycle more in the near future than females.

These results are further analysed in the discussion section in relation to empirical literature and to the other findings of this study.

\section{Simple bivariate regressions}

Simple bivariate regressions were also undertaken to determine whether potential relationships exist in the sample between declared intentions to walk and cycle more often in the near future, and attitudes, social norms, perceived behavioural control and habits. The following table presents the results. 
Figure 7.19: Simple bivariate regressions

\begin{tabular}{|c|c|c|}
\hline & $\begin{array}{c}\text { Simple Bivariate } \\
\text { Regression }\end{array}$ & Estimated Relationship \\
\hline \multirow{4}{*}{ 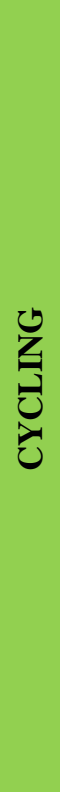 } & Intentions $=\mathrm{f}($ Attitudes $)$ & $\begin{array}{c}\text { Intentions }=\underset{(0.45)}{2.630 * *}+0.672 * * \text { Attitudes } \\
(0.14) \\
\left(\mathrm{R}^{2}=0.151, \mathrm{df}=120, \mathrm{~F}=21.43\right)\end{array}$ \\
\hline & Intentions $=\mathrm{f}($ Norms $)$ & $\begin{array}{c}\text { Intentions }=0.864+0.786 * * \text { Norms } \\
(0.54) \quad(0.11) \\
\left(\mathrm{R}^{2}=0.294, \mathrm{df}=120, \mathrm{~F}=50.06\right)\end{array}$ \\
\hline & Intentions $=\mathrm{f}(\mathrm{PBC})$ & $\begin{array}{c}\text { Intentions }=2.209 * *+0.654 * * \mathrm{PBC} \\
(0.31) \quad(0.07) \\
\left(\mathrm{R}^{2}=0.383, \mathrm{df}=120, \mathrm{~F}=74.54\right)\end{array}$ \\
\hline & Intentions $=\mathrm{f}$ (Habits) & $\begin{array}{c}\text { Intentions }=\underset{(0.47)}{0.952 *}+0.715 * * \text { Habits } \\
\left(\mathrm{R}^{2}=0.344, \mathrm{df}=121, \mathrm{~F}=63.44\right)\end{array}$ \\
\hline \multirow{4}{*}{$\begin{array}{l}\vdots \\
z \\
z \\
3 \\
3\end{array}$} & Intentions $=\mathrm{f}($ Attitudes $)$ & $\begin{array}{c}\text { Intentions }=\underset{(0.40)}{2.197 * *}+0.581 * * \text { Attitudes } \\
(\mathrm{R} 2=0.15) \\
\\
0.110, \mathrm{df}=126, \mathrm{~F}=15.57)\end{array}$ \\
\hline & Intentions $=\mathrm{f}($ Norms $)$ & $\begin{array}{c}\text { Intentions }=\underset{(0.40)}{1.332 * *}+0.622 * * \text { Norms } \\
(0.10) \\
(\mathrm{R} 2=0.230, \mathrm{df}=127, \mathrm{~F}=37.91)\end{array}$ \\
\hline & Intentions $=\mathrm{f}(\mathrm{PBC})$ & $\begin{array}{c}\text { Intentions }=\underset{(0.29)}{2.602 * *}+0.399 * * \mathrm{PBC} \\
(\mathrm{R} 2=0.09) \\
(\mathrm{R} 2=0.128, \mathrm{df}=127, \mathrm{~F}=18.66)\end{array}$ \\
\hline & Intentions $=\mathrm{f}($ Habits $)$ & $\begin{array}{c}\text { Intentions }=\underset{(0.39)}{1.965 * *}+0.431 * * \text { Habits } \\
(\mathrm{R} 2=0.148, \mathrm{df}=127, \mathrm{~F}=22.04)\end{array}$ \\
\hline Not & (...) represents, in this case, & tion \\
\hline
\end{tabular}

These results show that each of the variables (attitudes, norms, perceived behavioural control and habits) is statistically significant (99\% confidence) 
in influencing intentions to walk and cycle more often in the near future when no other variables are controlled for.

\section{Multivariate regressions}

Two multivariate regressions were conducted to determine the relative influence of these different psychological factors on intentions to walk and cycle more often in the near future.

\section{Walking intentions}

$$
\begin{aligned}
& \text { Intentions }=0.076 \text { Habits }+0.079 \text { Attitudes }+0.442 * * \text { Norms }+0.154 \mathrm{PBC}+1.120 \\
& (\mathrm{~T}=0.62) \quad(\mathrm{T}=0.45) \quad(\mathrm{T}=3.12) \quad(\mathrm{T}=1.48) \\
& \mathrm{R}^{2}=0.254 \quad * * \mathrm{P}<0.01
\end{aligned}
$$

This regression shows that walking being considered a social norm is the only statistically significant explanatory variable (99\% confidence) in influencing intentions to walk more often in the near future. The other variables are however not statistically significant in influencing future intentions to walk more often in the near future.

\section{Cycling intentions}

$$
\begin{aligned}
& \text { Intentions }=0.262 * \text { Habits }+0.170 \text { Attitudes }+0.293 * \text { Norms }+0.343 * * \mathrm{PBC}+0.180 \\
& (\mathrm{~T}=2.20 \\
& (\mathrm{T}=1.29) \\
& (\mathrm{T}=2.31) \\
& (\mathrm{T}=3.41) \\
& \mathrm{R}^{2}=0.476 \quad * \mathrm{P}<0.05 \quad * * \mathrm{P}<0.01
\end{aligned}
$$

This regression shows that having positive attitudes towards cycling is not a statistically significant variable in influencing cycling intentions. It also shows that cycling being considered a habit and a social norm are statistically significant explanatory variables $(95 \%$ confidence $)$ in influencing intentions to cycle more often in the near future. The perceived behavioural control to cycle (PBC) is however a statistically significant 
explanatory variable at $99 \%$ confidence, signifying that $\mathrm{PBC}$ has a stronger effect on intentions to cycle more often in the near future than other explanatory variables.

\section{Focus groups and interviews}

\section{Focus group objectives}

The main objectives of the focus groups were to (1) evaluate varying community perceptions about walking and cycling among different socioeconomic groups in the Hastings District, as well as to (2) explore the community's awareness of the $i$ Way programme in its first year. The focus groups thus focused on three main themes:

- The factors that encourage people to walk and cycle in their community

- The barriers to walking and cycling in the district

- People's awareness of the $i$ Way programme.

\section{Approach and methods}

To attain objective (1), the sampling strategy needed to include people from different socio-economic groups. It was decided to conduct the focus groups in three different communities within the Hastings District-a low deprivation community in Havelock North, a community of medium to low deprivation in Hastings, and a high deprivation community in Flaxmere. The New Zealand Deprivation Index (NZDep2006) was used to select appropriate neighbourhoods.

\section{Sample Composition}

To be eligible, participants had to reside in one of those three communities, and had to take part in the focus group organised in their own neighbourhood. There was no ethnic or gender selection in the recruitment process, the only demographic constraint stipulated being that participants had to be 16 years old or over. 


\section{Sample size}

The recommended sample size for focus group research varies somewhat in the literature, generally between 6 and 12 participants (Morais, 2010; Morgan, 1988; Stewart \& Shamdasani, 1990). The targeted sample size for the three focus groups in this study was in accordance with these recommendations, between 6 and 8 participants.

\section{Sample recruitment}

Recruitment posters were put up in public spaces such as shops and libraries in all three locations approximately 5 weeks prior to the focus groups, in the first week of May 2011. Participation was incentivised by a $\$ 25$ grocery voucher. However, two weeks into the recruitment period only three people had expressed interest. The decision was made to put an advertisement in the local free newspaper, the Hastings Mail, in order to increase the response rate, with the expectation that the advertisement would be accessible to a wider audience, the Hastings Mail covering the three targeted areas. The result of this change in the recruitment strategy proved to be fruitful, with nineteen people expressing interest in the week following the publication of the advertisement. Thus, seven participants were confirmed for the Havelock North focus group, six for the Flaxmere group, and eight for the Hastings discussion.

However, due to low participation on the day in the focus group in Flaxmere (only one participant was interviewed), the decision was made to reorganise this focus group at a later date. The recruitment strategy was amended for the new event. The researcher obtained the help of a local community advocate and leader (highly recommended by Henare O'Keefe, a well-known Hastings councillor) to try to recruit participants in Flaxmere from his network of contacts. A new date and venue was arranged for this focus group. Yet, despite valuable efforts from the community leader, no participants were found. 
Rather than leave out the Flaxmere community, the researcher decided to lead semi-structured interviews later in the year, on the premise that people from this community may be more approachable in a more intimate setting than a focus group conversation. An arrangement was made to visit $\mathrm{Te}$ Aranga Marae in Flaxmere on Monday $12^{\text {th }}$ December 2011, where five people were willing to participate. Two sets of interviews were conducted on this day, the first one with two participants and the second one with the remaining three. These interviews were conducted following the same question schedule used for the focus groups, examining the same three themes.

\section{Locations}

A total of twenty-one people participated in this research in three different locations. Seven people took part in the Havelock North focus group held at the Havelock North Community Centre, eight participants joined the discussion in Hastings at the Camberley Community Centre, while six participated in Flaxmere, one at the Flaxmere Community Centre and five at Te Aranga Marae.

\section{Focus groups and interviews results}

This section presents the findings of both the focus groups and the interviews. Themes were identified after multiple readings of the transcripts. The quotes selected in this section reflect a range of views, but do not exhaustively present all themes discussed, as only the most important and frequently debated themes were selected. It is to be noted that these quotes are kept confidential as per the human ethics agreement (Appendix Three).

\section{Participants}

A letter-name was assigned to each participant during the focus groups and interviews, and information was collected on the age, gender and occupation of each participant. An imaginary name was subsequently given to each respondent for analysis and reporting purposes. Tables 2, 3 and 4 present the participant details. 
Table 7.1: Havelock North participants

\begin{tabular}{|c|c|c|c|}
\hline Participant & Gender & Age & Occupation \\
\hline Jane & Female & 35 & Teacher/Mother \\
\hline Lucy & Female & 66 & Retired nurse \\
\hline Chris & Male & 39 & $\begin{array}{c}\text { Computer } \\
\text { programmer }\end{array}$ \\
\hline Helen & Female & 43 & Massage therapist \\
\hline Esther & Female & 64 & Retired nurse \\
\hline Frank & Male & 67 & Retired \\
\hline Adam & Male & 68 & Retired \\
\hline
\end{tabular}

Table 7.2: Hastings participants

\begin{tabular}{|c|c|c|c|}
\hline Participant & Gender & Age & Occupation \\
\hline Andrea & Female & $50+$ & Personal assistant \\
\hline Ben & Male & 17 & Unemployed \\
\hline Celia & Female & 49 & Office assistant \\
\hline Laura & Female & 46 & Relieving teacher \\
\hline Eddy & Male & 17 & Unemployed \\
\hline Fiona & Female & 53 & Accountant \\
\hline Rachel & Female & 41 & Homemaker \\
\hline Heather & Female & $60+$ & Retired nurse \\
\hline
\end{tabular}

Table 7.3: Flaxmere participants

\begin{tabular}{|c|c|c|c|}
\hline Participant & Gender & Age & Occupation \\
\hline Beverly & Female & 39 & Cook \\
\hline Pania & Female & 29 & Home stay mother \\
\hline Kura & Female & 45 & Kaimahi \\
\hline Makareta & Female & 32 & Home stay mother \\
\hline Ngaire & Female & 53 & Freezing worker \\
\hline Phillip & Male & 35 & Student \\
\hline
\end{tabular}

\section{Themes}

Five main thematic groups were identified following the transcript analyses.

Most of these themes are in accordance with the literature as well as with the knowledge the researcher gained throughout the project.

The five thematic groups are:

- Health and well-being

- Convenience and practicality

- The environment 
- Safety

- Behaviour and awareness.

These themes are developed in the following sections, and participant quotes are used to illustrate the themes discussed.

\section{Health and well-being}

The themes of health and well-being were put forward by participants in all three locations when questioned about the factors that encourage them to walk and cycle in the Hastings district. Thus, participants identified exercise, fitness and recreation as some of the main attributes of walking and cycling (box 1). This underlines that the people of Hastings perceive walking and cycling as ways to regularly exercise and stay fit while enjoying a walk or cycle. These attributes were mainly highlighted for walking, as few participants from the focus groups and interviews cycled much, but were also underlined by the few regular cyclists.

Box 1: Walking and cycling to exercise, for fitness and recreation

'I probably do three times a week, either walking or cycling for recreation, and then five times a week is for exercise, a minimum half hour each time, purely for exercise.' Rachel

'Yeah, I walk every day. More for fitness, and I cycle too every day, except for the weekends. It is strictly fitness, fast walking.' Laura

'I don't bike anywhere or walk for a specific purpose, just for exercise for us if it's nice to go for a walk. I occasionally walk to the shop and walk back but that's about all. It's really just, just purely recreational.' Adam

Participants revealed that walking and cycling for exercise and recreation had a direct contribution to their personal well-being. The interviews also highlighted how walking and cycling were considered as important for personal health, both physically and mentally. This showed that participants acknowledged that active transport is a source of physical, mental and spiritual well-being, and in some cases a way to relax and calm down from the stresses of everyday life (box 2). 


\section{Box 2: Physical, mental and spiritual well-being}

'I find with walking, it's the ... I get spiritual, mental and physical well-being. There's beautiful days at the start of the year, it's just glorious to be out for an hour in the morning, it's lovely.' Lucy

'And I guess also just a fact of a good walk, long walk, does you a world of good, physically and mentally I guess.’ Adam

'Getting some exercise encourages me to walk, it gives you that extra fitness in you, because as a stay home mother you seem to get stressed at home. Then if you go out for some fresh air it just calms you down.' Pania

While the elements highlighted by boxes 1 and 2 are in accordance with the literature, another aspect, perhaps less predictable, was mentioned in the majority of sessions. This aspect fits within this theme of well-being, and is the social wellness which arises from walking and cycling. It thus seems that walking in particular offers opportunities to meet people and socialise, especially when taking part in walking groups (box 3).

\section{Box 3: Social well-being}

'I try and walk most days, depends on what I'm doing, but what I do is walking groups, one round Frimley on a Friday, one round Cornwall park on a Wednesday morning. I join these groups because there is more incentive if you're walking in a group of people rather than walk by yourself, they are good. (...) Yes there is [a social aspect] in the walking cause you know, you walk along and chat with folks, you almost forget you're walking!' Heather

'And it's surprising the great number of people you meet, nice people you meet on foot' Adam

'The other thing is that my cousin and I we've decided to start our walking again today, and it's also the company and being able to just talk about things.' Ngaire

It is clear that participants from all three communities are aware of the benefits of walking and cycling, as respondents in all discussions acknowledged the positive aspects of active transport on physical, mental and social well-being. Importantly, the impacts of walking and cycling on 
health and well-being were only mentioned when asked about the factors encouraging people to walk and cycle, which confirms the health benefits of active transport highlighted in the empirical literature.

\section{Convenience and practicality}

The second thematic group that emerged can be termed convenience and practicality, and takes into consideration what the participants judged to be factors that may encourage or discourage people to walk or cycle for convenience reasons. These factors include cost, time, comfort and distance particularly for utilitarian and commuting trips. These factors seem to play an important role in participants' choice to walk or cycle rather than use a motor-vehicle, or vice versa.

It was often argued that walking and cycling offer cheaper modes of transport than using a personal vehicle. In many cases, the cost factor was linked to the current economic world, with fuel prices and ongoing costs associated with a car (maintenance, insurance, registration...) rendering the ownership and use of a car uneconomic (box 4). This shows that economic savings can be considered as an encouraging factor for people to walk and cycle rather than use the car, and highlights another co-benefit of active transport.

But while the economic benefits of using active transport rather than driving are understood, some participants also acknowledged that using the car is culturally embedded, and that mentalities are hard to change. 
'For me I probably would walk or cycle $50 \%$ more than I was before the petrol prices went right up.' Rachel

'In the last few months, since I retired, we couldn't justify having two cars. The cost of running and insuring, registering two cars... So we just sold one, we have gone down to one car. And I find that I bike into the village, maybe into the supermarket. Small items that you want to pick up, I've now got a bag on my bike and I bike into the village.' Frank

'Well when we shifted up here from Invercargill, we were a one car family and we were looking for places to rent and we had no idea about Hastings at all, whether there was a good or bad place... But my husband looked at a few places in Havelock North, but if we rented there and he worked on Omahu Road, we'd have to buy another car. So in the end I guess the factor of having to have two cars, we preferred to have one and choose where we would live, because he bikes to work, so you know we found a place which was close enough so he could bike to work' Laura

'Yeah, I think that places like Hawke's Bay, it's very hard to get new ideas across to people. People are very set in their ways here. You know, people have always travelled by car, and that's what they do you know. I mean, it's just insanity economically.' Phillip

Time and distance were not mentioned and discussed significantly as barriers to walking and cycling. Time and distance were not often considered as discouraging factors to walking or cycling in Hastings, bearing in mind that participants were not prompted to answer specific questions focusing on their travel time and distance for utilitarian or commuting trips.

Interestingly though, when these two factors did arise in the course of the interviews, most participants generally praised the practicality of active transport for saving time and money on commuting and utilitarian trips. While distance seemed to have more of an impact on some participants, it did not seem to be a concern for one regular cyclist who cycles forty minutes to work and back daily during the summer. The main issue with active transport for utilitarian trips, particularly to go shopping, seemed to be the relative inconvenience of walking and cycling compared to the 
practicality of the car, even though many participants would often walk or cycle to the shop for small loads of groceries or to accompany children or family to places. Interestingly, the concept of trip-chaining (the necessity of making multiple stops) was not once raised. Finally, in some cases distance barriers had to be overcome by active transport because participants either did not own a car or have a driver's license (box 5).

\section{Box 5: Time, distance and practicality}

'I choose to cycle to work unless the weather is really, really bad. The reason I do it is 1) financial you know, saves petrol. 2) I've worked out that by the time I've got the vehicle out of the garage, get out the car, close the door again, drive to town and find somewhere to park, I've probably saved about 3 minutes, I might as well get on the bus and go! The car I have to leave outside in the sun, the bicycle we've got a garden shed at work so I can just leave the bicycle there and it's so much easier.' Fiona

'I think it's a distance thing too maybe. If I'm going a long distance I'll take the car, but if it's walking into town, I walk into town, so I'd much rather walk, I don't like my bike, so I walk.' Celia

'You're a bit limited if you're buying a lot of groceries and stuff cause we live on the fringe. It's about a 25 minute walk each way, but... I don't like sort of going up the hill home carrying too much.' Esther

'I walk every morning, I get up at half past four and take the dog for a walk, but that's sort of more of a gentle stroll. Then cycle to work, which is probably three kilometres. I try not to use the car except for grocery shopping or weekends when I'm going further away.' Fiona

'Well, having no licence, biking is just a lot easier and I probably do three to six hours a day just biking from Hastings to Havelock or Hastings to Flaxmere and all that sort of stuff... I just pretty much bike everywhere.' Eddy

This section highlights that participants are well aware of the potential economic benefits arising from active transport, whether they are in terms of strict financial savings or in terms of time savings. However, the fact that people are aware of these advantages does not necessarily mean that they fully benefit from them - there may be something of a discrepancy between awareness and action. One of the arguments put forward by some of the 
participants to explain this discrepancy is that the reliance on the car and love of driving may be culturally embedded in New Zealand, and that mentalities may be tough or may take time to change.

The participants' responses show that the distance to one's destination plays a part in people's choice or ability to walk or cycle to places rather than use a motor-vehicle. It is important to note however that participants did not necessarily portray distance as a strict impediment to active transport. Rather, it seemed that distance can become a hindrance to walking and cycling in some situations, particularly for utilitarian trips such as shopping or accompanying children to school.

These results are interesting in that they show that the difference between people taking part in active transport and driving may not necessarily be explained by measurable factors such as costs, time and distance, but may lie in more abstract concepts such as culture and practicality.

\section{The environment}

The title of this section, the environment, is deliberately vague; the focus groups and interviews highlighted that most of the participants were either encouraged to or constrained from walking or cycling in their neighbourhoods by various features of the environment. This section is therefore divided into three main sub-themes: pollution and climate change, the built environment, and the physical environment.

\section{a. Pollution and climate change}

In a few cases, and without being prompted to comment on phenomena such as climate change and global warming, participants explained that being environmentally considerate was a factor that would encourage them to use active transport rather than drive their car (box 6). In most cases however, participants would only consider these themes after being prompted. It is notable that in most cases climate change and carbon emissions were framed as local air pollution. This may show a certain lack of knowledge 
and understanding of the phenomena on the part of the participants. The lack of care in discriminating the issues may also signify that climate change is not a factor considered as relevant by most participants.

Respondents seemed well aware of the effects of driving a car on local air pollution. Nevertheless, the discussions suggested that the negative effects on local air pollution were not a determining factor to use active transport as a mode of transport. Rather, it appeared that reducing local air pollution was mainly considered to be a co-benefit of walking and cycling rather than a direct encouraging factor. A few participants also acknowledged that the effects on the environment, whether in terms of climate change or in terms of local air pollution, did not have any effect on their attitudes and habits.

\section{Box 6: Climate change and air pollution}

\footnotetext{
'My three main factors that I've always looked at as being the main reasons to use a bike for commuting... One of them is certainly cost, I mean there is no parking cost at the other end. Well petrol costs, there is none there. Fitness a big factor there, and the other being a little bit more environmentally friendly I guess, I think that is quite an important thing these days.' Chris

'And not only that, if your car is not in a good economical condition to run, for example if your muffler, you start up and then it puffs out that black smoke, that's actually, that's not good. So you'd rather just leave it at home to save the air coming out, and just walk it, or bike it if you are interested in biking.' Pania

'Well I think it's [carbon emission reductions] a happy side effect of it [active transport]. Personally, it wouldn't be a major factor for me.' Phillip

'Well I'm still on my restricted, I can go for my full, but I'm just like a kid, I like driving my car, so it doesn't really bother me about the climate change and stuff, it's more I want to get my bit out of it, just enjoy it a bit before I start slowing down.' Ben
}

\section{b. Built environment}

The effects of various aspects of the built environment on both attitudes towards, and levels of, walking and cycling among participants were evident. Having access to appropriate infrastructure was considered to be an encouraging factor to walk and cycle more often, while infrastructure 
considered as insufficient, inappropriate or dangerous was clearly considered a barrier to walking and cycling. Even though these results were anticipated, community-voiced arguments to support this knowledge are valuable. These results also confirm that the built environment is heavily linked to the concept of safety (discussed in the next section), as comments on both the assets and disadvantages of the built environment were most often based on how safe or unsafe the participants felt when using various facilities. The focus groups and interviews also had the advantage of focussing attention on issues surrounding the built environment which are characteristic to the Hastings district, and may have a negative impact on both perceptions and actual levels of walking and cycling in Hastings.

\section{Encouraging factors}

The preference for off-road paths to walk and cycle, separated from motor vehicle traffic, was extremely evident in comments in all sessions. Participants from both the Hastings and Havelock North focus groups praised the off-road facilities on Crosses Road, a road linking Havelock North and Hastings (box 7). On many occasions however, participants agreed that clearly marked lanes on the road were a good start, but that separated paths would be much better, since perceived as safer. Participants also showed understanding of the greater costs associated with implementing off-road infrastructure.

Much praise was given in all three communities to the Rotary Pathway on the Napier foreshore. It was common consensus that this type of facility is excellent to encourage more people to walk and cycle. The case was made that if this type of infrastructure was put in place in Flaxmere, for example a good quality walking trail throughout or around the neighbourhood, a good number of people would use it and it would benefit the entire community. 
'They've got a very good new cycleway on the side of a road, on a footpath down Crosses Road which is between here and Hastings, and if we could have more of that around the place it would just be wonderful because it is separated totally away from the cars.' Lucy

'Now they have put a wide one down Crosses Rd, it's a pedestrian/cyclist track. Perfect! It's not on the road, it's actually off.' Celia

'I think a path would be much better, but I also understand that would be far more expensive to put in place than sort of spray-painting paint, so as a start, I think that having the lane, the cycle lane... because I think that it makes people more aware. Like I know when I'm driving across a road where there is a cycle lane, then I am very aware of the cyclists there, because I know that's there and I know, you know, you have to be aware of that.' Jane

'They've actually done that walkway out at Pakipaki, and then they've got the beach walkway over in Napier, so it would be awesome for us to have a safe walkway route around Flaxmere. You know, look at all the area we've got out here, and it's got some nice stuff where we can have some plants and all that sort of stuff.' Ngaire

\section{Barriers}

While the discussion surrounding the encouraging factors of the built environment was heavily focused on the benefits associated with separated, dedicated infrastructure for cyclists and pedestrians, the discussion about perceived barriers from the built environment was somewhat more varied.

The lack of off-road facilities was criticised, and considered a real barrier to cycling in particular. Furthermore, some argued that while off-road paths are ideal for cycling, these paths are not always easily or safely accessible, and that more infrastructure investment needs to be done to link these facilities together (box 8).

Additionally, the lack of appropriate bicycle parking facilities was judged by some as a crucial hindrance to cycling in town, for both convenience and security (fear of theft) reasons. The main issue with built environment features with regard to walking was the quality of the footpath in some places, where tree roots, cracked footpaths or high kerbs could constitute 
hazards for pedestrians. Some participants however argued that footpaths were well maintained in general. Additionally, a major issue highlighted in the Hastings and Havelock North focus groups with regard to the built environment was the presence of a large number of traffic roundabouts in the city, judged by most participants as dangerous for both pedestrians and cyclists. For pedestrians the lack of clearly marked crossing areas was the biggest issue, while car drivers not indicating properly and turning right were considered as the main hazards for cyclists at roundabouts. It is important to note that most of these issues had an impact on participant choice of routes.

\section{Box 8: Barriers in the built environment}

'That's what they've built along Crosses Rd, you know they've got the pathway away from the road, but it's in the middle of... nowhere! I mean you've got to go on terrible roads to get to it, and then it just stops! Even if they continue that into Hastings would be a help!' Lucy

'Yes and I agree with that too [that infrastructural change is necessary to encourage more cycling], because it is all very well having some places with really good cycle lanes, but you've actually got to get there first! (...) You know, you just go back and forth on the same stretch to keep safe.' Jane

'But I just want somewhere, preferably handy to New World supermarket, where you can put your bike without putting it on the footpath or without tying it around a lamppost or something like that. But yeah, there just seems to be a lack of proper bike stands.' Helen

'With the walking I do I notice a lot of footpaths that are uneven, so if you're not watching you can trip. So I tend to choose the ones that I know are good' Rachel

'Footpaths are well maintained here...We're better than Havelock!' Beverly

'Yeah, the problem with roundabouts is they keep the flow of traffic so people actually still go through them quite quickly, and they, they sort of I guess give a quick glance to look down to see whether there's someone coming. I actually found myself doing it one day, I almost hit a cyclist myself, and it made me realise, wow, here I am a cyclist and almost put myself in that position, so I'm extra careful now.' Chris

This section suggests that while features of the built environment are important to be considered on their own, they are often linked, judged, criticised or praised depending on their influence on safety. The same can be 
said about some of the characteristics of the natural environment with regard to walking and cycling in the Hastings district.

\section{c. Natural environment}

While the influence of features of the built environment is certain, factors from the natural environment also play a significant role in determining perceptions, mode choice and actual walking and cycling behaviour.

Most participants who usually walk or cycle acknowledged the fact that they would either stay at home or use their car if the weather was unfavourable, even though a few argued that the weather was not important (box 9). Rain and cold temperatures were considered the most deterring factors, while warm temperatures and long sunshine hours would usually encourage participants to enjoy a walk or a cycle. Additionally, with regard to topography, the general consensus was that the Hastings district was easy to walk and cycle around because it is mainly flat. A few people in Havelock North mentioned that the hills there sometimes made it slightly tricky to walk or cycle back home, but one participant in Flaxmere commented that she enjoys walking in Havelock North because of the hills.

Seasonality seems to be an important factor for two main reasons. Firstly in strict climate terms, with participants acknowledging they cycle more often in the summer months than in the winter because the weather is more favourable, and secondly because of the reduction of daylight hours in the winter months. 
'I walk or cycle my daughter to school each day, I take the car for grocery shopping, but any other walking or cycling I do is normally weather dependent. If it's a nice day I will go for a bike ride to town, if it's freezing cold I will take the car!' Rachel

'Yeah I think I'm just sort of like programmed that when I get into my walking I have fixed times and regardless of what the weather is I still go do it. But it does definitely, the weather in Hastings is a lot better than other places I suppose.' Ngaire

'Well I've actually walked in Havelock, and I do like Havelock because of the hills and all that, and it seems like a lot more people are a lot more active out that way.' Ngaire

'Yeah, during the season, during summer, I regularly commute to and from work. At wintertime it's too dark, too dangerous on the roads and so on...' Chris

Darkness was the single most discussed issue in relation to the natural environment in the focus groups and interviews in Hastings and Flaxmere, and to a lesser extent in Havelock North. While darkness is a feature of the natural environment, there is a connection to the built environment, as many participants noted the lack of appropriate lighting as a barrier to walking and cycling at night. The general consensus was that participants would usually not walk or cycle at night, mainly for safety reasons: the fear of not being seen properly when walking or cycling and the risk of being hit by a car, and the fear of being harassed, mugged or assaulted (box 10). While it was agreed that participants would not necessarily venture out more often if the lighting was better, a few argued that they would perceive walking in the dark to be safer if lighting was improved. A main point of discussion was around lighting in parks. Most participants would rather walk the long way around at night rather than cut through a park, which they would normally do during the day, if there is no appropriate lighting. Interestingly though, Havelock North was perceived by a few participants to be safer to walk at night than Hastings and Flaxmere. 
'For me the difference between cycling in summer and winter is the time I leave the office in the evening. In the winter I tend to leave at about quarter past five, because I find it just safer to cycle in the full dark than in the dusk. I find dusk a very dangerous time to cycle because so many people just don't have their headlights on... So I'd rather do dark, or bright sunshine.' Fiona

'Walking, especially at night time is a big issue because no matter what you wear or anything, there's always people that are just trying to either get attention from their mates or something, or just trying to pick up fights, and it doesn't really matter who you are.' Eddy

'I think in Flaxmere the lighting is not terribly good, in sort of big stretches of parks and stuff like that. Probably no more so than anywhere else, I don't think you are statistically more likely for anything bad to happen to you in Flaxmere than in Wellington or Auckland. But you know, there's that sort of paranoia, neurosis that's going on, and you know because there is not a lot of people walking at night that adds to the safety factor as well.' Phillip

'My walking is every morning. I prefer to get up at 6am and go for an hour. I like to go round Frimley Park, and I prefer to go in the morning rather than at night because I think that it is safer. I don't like walking at night in Hastings but I did do it in Havelock North when I lived there, I think that it is a safer environment over there.' Celia

\section{Safety}

The previous sections show that many of the issues and themes discussed in the focus groups and interviews can be related to the concept of safety. As explained earlier, the researcher distinguished two main types of safety concerns:

- Perceptions of safety directly associated with walking on the streets and cycling on the roads (i.e. the risk or fear of an accident as a direct result of the traffic).

- Perceptions of safety with regard to the risk of being harmed by factors exogenous to the traffic (i.e. the risk of being attacked or robbed). 
This section is therefore structured around the two aforementioned perceptions of safety. Additionally, the issue of child safety, which was also extremely prominent, is presented at the end of this section.

\section{a. Traffic safety}

Traffic safety issues were discussed at length for cycling and less for walking. This is more than likely due to the fact that the vast majority of cycling is done directly on the road (whether in lanes or not) amid the motor-vehicle traffic, and not on the footpath where the majority of walking takes place. The issue and risks associated with being amid the traffic were discussed by both active cyclists and by non-cyclists, yielding views in relation to both direct risks from experience, and perceived risks.

For cyclists, the main concerns related to the ability to be seen properly, the presence of sufficient space for cycling and the risks associated with driver behaviour and infrastructural obstacles (box 11). The main reason noncyclists identified as to why they do not cycle was that they do not feel confident enough to cycle amid the traffic, and therefore perceive that they are more at risk of being harmed.

Additionally, the main issues identified by pedestrians were mainly to do with obstacles and hazards on the footpaths. These hazards included for example the presence of skateboarders and scooters on the footpaths or the risks associated with walking behind a car backing out of a driveway. The issue of driveways is further developed in the section on child safety. 
'Yes, well I wear a bright green jacket, I got two white lights at the front and two red lights at the back, and I'm still not seen.' Fiona

'The big trucks hurtling along Te Aute Road give me the heebees...You know, some of them pass with not much of a margin even if you are right over out on the left...' Esther

'People overtaking you at a roundabout. There you are trying to cycle through a roundabout and somebody overtakes you, and you think 'just show a little bit of patience, half a second later and we'll both get there.' Fiona

'No, I don't like bikes. I know how to bike but I don't like biking. It's just I think because I don't have enough confidence to actually go on the road with the cars, you know going by me.' Pania

'I just, just like you [Pania], don't feel confident. But mine's [my reason's] not my confidence, I don't have confidence in the drivers that are out there.' Beverly

'Maybe my concern as a pedestrian is the damn skateboards! They're just a damn nuisance!' Adam

\section{b. Neighbourhood safety}

The second type of safety focused on the risks and dangers from factors other than traffic that participants perceived as potentially harmful. Contrarily to the previous section, this type of safety was mainly discussed in relation to walking rather than cycling. Interestingly, this theme was discussed more prominently in the Hastings and Flaxmere focus groups and interviews, but not as much in Havelock North.

Many participants felt that it was sometimes not safe enough to walk alone in the Hastings district, particularly in Hastings and Flaxmere. Havelock seemed to be perceived as safer, possibly because of the perceived reassuring presence of more people on the streets (box 12). The issue of walking alone was often compounded with the problem of walking alone in the darkness, as explained earlier. Thus many people seemed to be genuinely afraid of walking alone at night. A few participants also 
complained about the presence of unsupervised dogs on the streets and in parks. The fact that some of these dogs had aggressive attitudes would sometimes put people off walking in certain parts of the district.

\section{Box 12: Neighbourhood safety}

'I do like Havelock because it's got the hills and all that, and it seems like a lot more people are a lot more active out that way, so you feel a little bit safer eh.' Ngaire

'And also, I live down Sunderland Drive, and the Flaxmere pub is down the road and I feel a little bit unsafe walking by myself sometimes, that's why I'm glad I've got a mate now.' Ngaire

'No, I mean I've never had anything untoward happen to me, but then again I'm always very careful about where I walk. And you know to be honest I don't particularly like walking around at night, especially in the weekends or when it's school holidays and there's a lot of younger people around. But you know, there's nothing to confirm that, I've never heard of anything like that. But I think a lot of people are wary of it.' Phillip

'Like my cousin, he was biking through town with his friend, and they passed a whole lot of these dudes. They didn't know what was happening, the town was empty as, and then the dudes stopped them and beat my cousin up, out of nowhere, just people helped him out, which was really different because you don't really seem, it doesn't really seem like it would happen.' Eddy

'The dogs, absolutely the dogs in Flaxmere. You've got to really pick where you're going to walk, because some dogs, you know, I've actually got a dog not too far from me, and it's a mean dog. And it actually came at me once, lucky the owner was out front, because I feel that it would've really attacked me.' Ngaire

\section{c. Child safety}

Even though focus group and interview participation was limited to 16 year olds and over, another prominent safety concern discussed was child safety in all three communities. While some parents were confident enough to let their kids cycle on their own, the majority of participants expressed major concerns. Thus, while no children per se participated in the discussions, parents and grandparents expressed strong reservations about letting their children or grandchildren out on the streets, particularly for cycling. 
Interestingly, this was both for reasons around traffic and neighbourhood safety, when commuting to school, or for recreation purposes (box 13).

\section{Box 13: Child safety}

'My younger son, who is 12, he bikes to school and back every day. And my oldest boy bikes from Flaxmere to Splash Planet (in Hastings) to work 5 days a week.' Beverly

[Asked how she would feel about sending her 7 year old kid to school on his bike on his own] 'Never! I won't because I'm just too afraid. Because he hasn't got enough confidence in himself anyway, I won't even let him ride his bike without me on his side. But he knows that, I tell him that 'I have to be your supervisor, I have to supervise you when you go on your bike because you are not old enough to ride'. And you know, there's kids here that might just come around and you know, say 'get off that bike it's mine', you get bullied. And we do get bullies, it does happen. Maybe when he's a little bit older, but not at this very moment because it is too risky.' Pania

'My daughter, she gets picked up at the bottom of our driveway, school bus, every day, and on that note I would not, her health is a little unstable, but even so I don't think I would be that keen on her biking from here to school which is in Hastings, yeah.' Helen

In most cases when child safety was discussed, participants would argue that mentalities, attitudes and behaviours seem to have changed over the last few decades. Most parents or grandparents held that it was the norm for them to cycle as kids, but that norms had gradually changed over the years. Some respondents blamed this change on an increase of traffic on the road with more people owning cars, while others blamed a wider cultural change to explain how it was no longer safe for children to play alone on the streets or in parks, let alone to commute to places, for fear of traffic and crime (box 14). 


\section{Box 14: Changing times}

'I used to bike around Havelock when I was a kid, so 30 years ago, but it's amazing to drive around now and find that it's so busy, you know, Havelock has become so busy, it's probably busier than the roads were in Hastings at that time. So it's really dangerous for kids. I wouldn't be, well my boys are younger so I have them at home anyway, but I would be reluctant to have them riding around roads'. Chris

'I remember doing gym practice, when I was in intermediate so I would have been say 12/13, and it was from 6 till 7.30 at night. I did have a light on my bike, back in those days you didn't wear a helmet. But my mum was never like 'Oh, I got to come pick you up', you know, 'make sure you get home safe'... It was like 'See you when you're finished!' [Fiona: Do you let your daughter do it?] 'No!!! I'd be like 'I'll take you, and then I'll come back and pick you up', because you know just the crime and what you hear about, you think 'Oh I'd be irresponsible if I let her bike in the dark at that hour', you know...' Rachel

'Life was a lot safer a generation or so ago. Nowadays, I mean you can't let kids go out and play by themselves in a park, you know, that sort of thing. We'd go out and play in the park with other kids and we'd be there for hours, and our parents knew we'd be quite safe, we'd turn up home eventually...but it's not that sort of...which is a terrible shame! It's not that sort of freedom there was a generation or so ago, not the same safety factor, I don't know [...] Yeah, it's just society in general. It's terrible, but that's the way society is these days.' Heather

Interestingly, though, the two youngest participants expressed concern that children nowadays were not given enough freedom to learn to cycle early and have more responsibilities. It was also generally agreed (most eloquently in Hastings) that walking buses, where a group of children/students is led to school by a pair of parents, was an excellent educational concept to allow for kids to partake in active transport to commute to school. Yet there was a general consensus that this concept would be impractical and too dangerous to apply to cycling, particularly if no appropriate off-road cycle infrastructure is present (box 15). 
'And like cause I'm not that old but my dad he said that we should ride more because when he was like probably 6 or 7 he used to bike out to the beach and stuff, just him with his mates, and there used to be no troubles, cause just common sense really.' Eddy

'You can't really restrict your kids to do what they're doing, otherwise it's just going to stop them from doing anything. [...] To gain the experience, you have to actually do it.' Ben

'They've got these walking buses, like a couple parents walk a whole group of children, maybe 20 children and perhaps two adults one at the start, one at the finish. They are very good I think to take kids to school safely.' Heather

'[Cycling buses] would work if there were decent cycle tracks, not on the road.' Laura

The theme of safety was thus the dominant theme discussed in all three neighbourhoods, whether in terms of traffic safety, neighbourhood safety or child safety. Clearly, citizens in all three locations have genuine concerns about their own well-being and that of their children's, relatives and friends. The discussion section below considers these matters further and makes the point that actual safety and perceived safety need to be distinguished. Additionally, many of the safety issues reported were in direct relation to behavioural problems arising with both drivers and active transport users, as explained below.

\section{Behaviour and awareness}

The themes of road user behaviour and awareness were an important aspect in all focus groups and interviews. It seemed that the traffic safety issue described previously was often linked back to driver behaviour and awareness with regard to cyclists, and cyclist behaviour and awareness with regard to drivers, thus highlighting what can be described as a major cohabitation issue on the road (box 16). Many drivers blamed safety issues on a lack of understanding and bad behaviour from cyclists, while cyclists blamed their concerns on the way drivers behaved on the road. In many 
instances, it appeared clear that these negative perceptions could easily lead to tensions on the road, which can potentially create hazardous and dangerous situations.

Lack of confidence and a fear to cycle were in many cases a result of participants being uncomfortable with driver behaviour on the road, and a perceived lack of regard and awareness from drivers towards cyclists. This perception was reported numerous times in the course of the focus groups and interviews in all three locations, highlighting the issue of cohabitation on the road. Some respondents felt that sometimes drivers thought they "owned the road", and often showed complete disregard for cyclists.

On the other end of the spectrum however, some participants felt that some cyclists, particularly recreational cyclists belonging to cycle clubs, were often in blatant breach of road rules, which could lead to hazardous situations for both cyclists and drivers. The main issue highlighted in this case was cyclists riding abreast on the road, making it difficult and dangerous for cars to overtake them.

The common conclusion of these debates, however, was that participants perceived that the best way to possibly reduce risks on the road, and increase safety for all road users, is more education for all. For most participants, education on road rules and how to properly ride a bicycle and drive a car should come at a young age, and could be carried out in the form of workshops or clinics. Participants from the Flaxmere community also strongly argued for the necessity of more policing, particularly with regard to helmet laws, and for education to be conducted at Marae level for Maori communities. 


\section{Box 16: Behaviour, awareness and education}

'Like they've got the cycle lanes and I must admit they've done them wide and everything else, but there's still idiots that will park up the car and go 'pssshht' [opening the door] without looking. You've got that, and then you've got people that just pull in behind you or in front of you, out of the driveway... The mentality with people is 'the drivers think they own the road'. There's got to be a lot of learning by everyone.' Beverly

' You guys might hate me for saying this, but a lot of cyclists think they own the roads, and they think that everyone is looking at them, they think the driver is supposed to take all the safety in their hands. It's not just them, you've got to think in case they don't do what they have to do, or what they're supposed to be doing, you've got to do it yourself.' Ben

'On the other side of the coin some cyclists should take a bit more responsibility too, cause there are some very very very inconsiderate ones, there really are... I really get... Riding sort of three abreast, they will not get single file!' Adam

'I mean you take your life in your own hands every time you get on a bicycle, that's all there is to it. Driver education. I always make sure at roundabouts they look at me in the eye. I know they've seen me, but even though I've got the right of way...' Fiona

'How do we do it? I think that they could maybe run programmes at our Marae (others agree). When people are getting ticketed and all that, and they're doing those terrible speeds, I think that they need to be attending a course of some sort definitely, and set up programmes at the Marae for safety things because a lot of the people that live in Flaxmere are Maori, and I strongly believe that Maori can get through to Maori a lot better, and I don't mean to be disrespectful in any way, but especially if you bring them on to a Marae and you have someone like our kaumatua being involved with it as well, because you've got to touch them in some way.' Ngaire

\section{Awareness of the $i$ Way programme}

The third objective of this study is to examine the community's awareness of the $i$ Way programme in Hastings one year after it was launched, in order to establish a baseline for future research.

\section{iWay in the ACTIVE questionnaire}

The ACTIVE questionnaire included a question ${ }^{5}$ to check the level of respondent awareness of the $i$ Way programme. This programme was launched over the course of the 2010 winter, and the ACTIVE questionnaire was run during the winter of 2011, thus providing an idea of the level of

\footnotetext{
5 'Have you heard of the $i$ Way programme?'
} 
awareness in the community in the first year of the programme. The survey found that awareness of $i$ Way in winter 2011 was at fairly low levels, as only $32 \%$ of the 121 respondents had heard of $i$ Way, while $68 \%$ had not (figure 7.20). Additionally, only $5 \%$ of the 39 respondents who had heard about the programme had participated in one of the organised activities. Interestingly however, a comparison with New Plymouth, which was also granted government funding, shows that these numbers are very similar in both intervention cities, even though slightly more people participated in organised activities in New Plymouth than in Hastings (figure 7.21).

Figure 7.20: Programme awareness in Hastings and New Plymouth

\begin{tabular}{|c|c|c|}
\hline \multicolumn{3}{|l|}{$80 \%$} \\
\hline \multicolumn{3}{|l|}{$70 \%$} \\
\hline \multicolumn{3}{|l|}{$60 \%$} \\
\hline \multicolumn{3}{|l|}{$50 \%$} \\
\hline \multicolumn{3}{|l|}{$40 \%$} \\
\hline \multicolumn{3}{|l|}{$30 \%$} \\
\hline \multicolumn{3}{|l|}{$20 \%$} \\
\hline \multicolumn{3}{|l|}{$10 \%$} \\
\hline $0 \%$ & Yes & No \\
\hline Wastings (n=121) & $32 \%$ & $68 \%$ \\
\hline New Plymouth $(n=133)$ & $33 \%$ & $67 \%$ \\
\hline
\end{tabular}


Figure 7.21: Attendance at organised programme activities

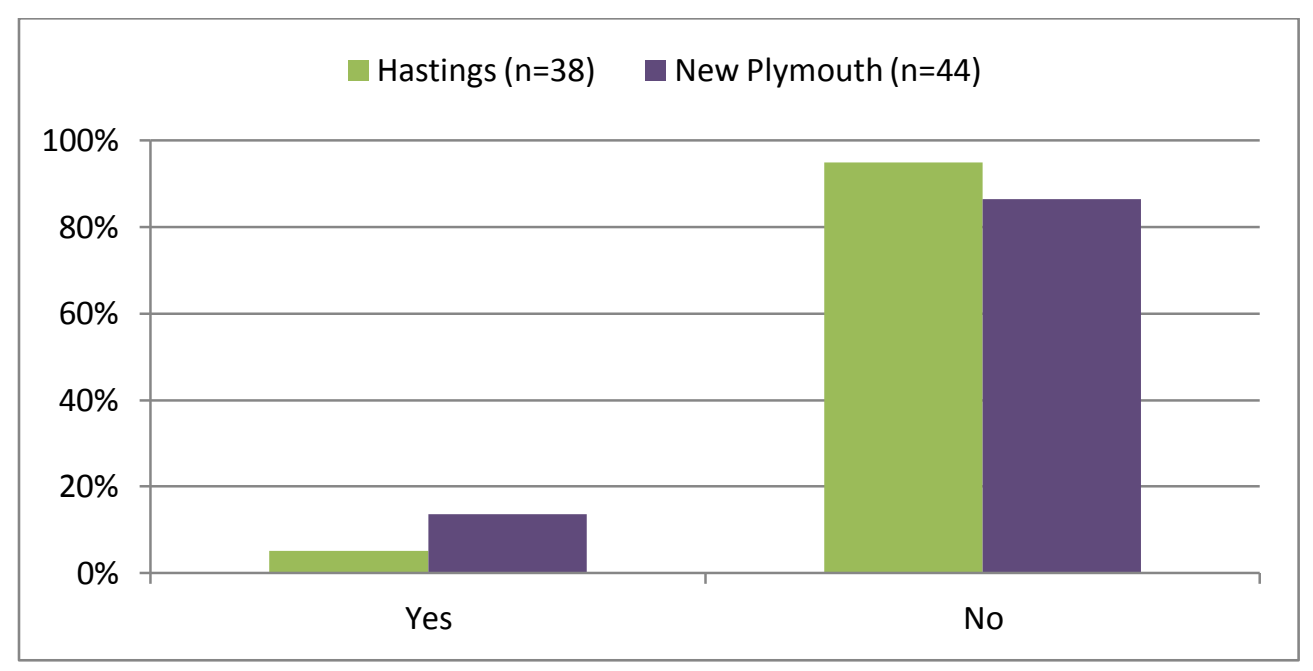

A question was also asked to determine how respondents had heard about $i$ Way (figure 7.22):

Figure 7.22: How did you hear about $i$ Way?

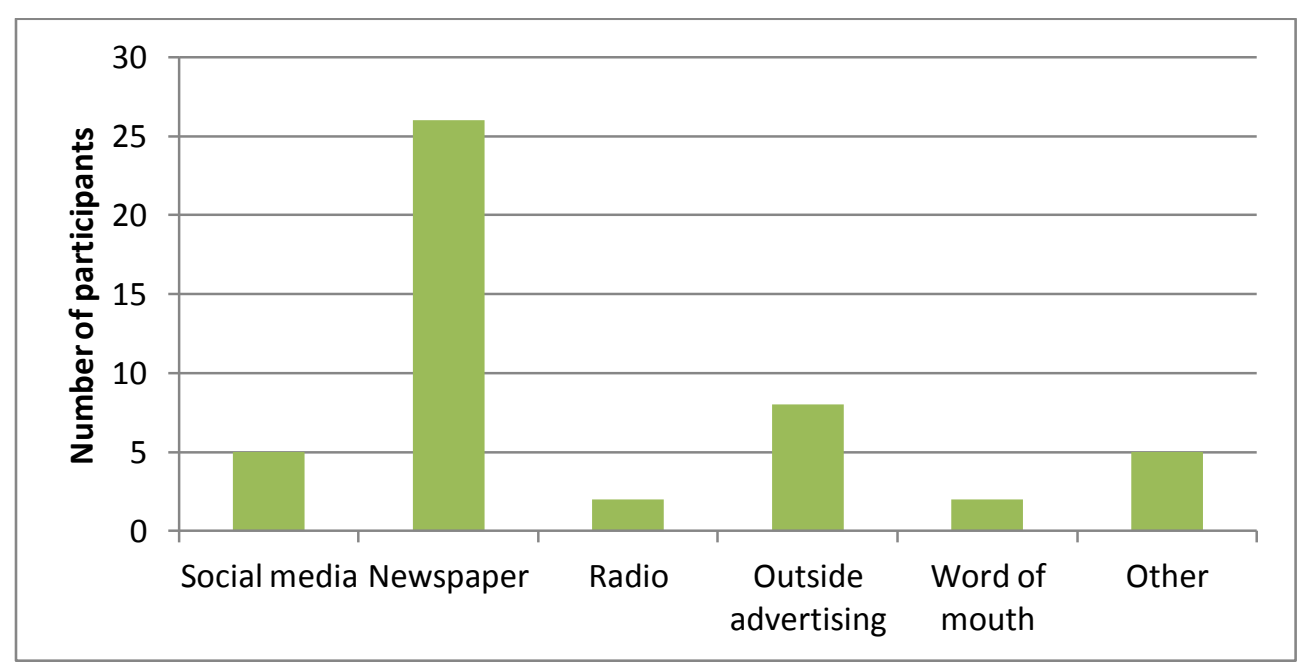

This figure clearly shows that most participants had heard about iWay through the newspaper, while a few had noticed it through outside advertising, social media and other means of communication. Radio and word of mouth were relatively insignificant in circulating information about the programme. 


\section{$i$ Way in the focus groups and interviews}

Awareness of the $i$ Way programme was also the third theme in the focus groups and interviews. Approximately the last ten minutes of each discussion session was devoted to trying to get a sense of whether participants had heard about $i$ Way and to try to understand how much and what they knew about it a year after the programme was launched in the district.

\section{Havelock North}

A small number of people in Havelock North had clearly heard about iWay (box 17). One participant for example knew about the basics of $i$ Way, while another had noticed advertising to promote the programme in Hastings. When asked about events, various participants mentioned a specific event, such as 'cycling to breakfast' or the 'Bike fix-up' event for example. However, it was apparent that the majority of the participants in this focus group did not know much about $i W a y$, as the conversation became very vague, with the researcher having to often prompt responses, and finally explain what the programme was precisely about. An interesting point, however, was that a number of people in Havelock North had heard of Hawke's Bay wanting to become the cycling capital of New Zealand. Nevertheless, much confusion reigned around various projects, with participants beginning to assume that well-documented headlines such as Hastings' bid to build a velodrome, or the Rotary Pathway on the Napier foreshore were all part of $i W a y$, which they are not. The confusion between the Rotary Pathway and $i$ Way was significant in all three localities. One important aspect was also that none of the participants had observed or noticed any change in the infrastructure in Havelock North, which is not surprising because infrastructural developments were only programmed to start there after the focus group was held. This highlights the fact that people in Havelock North seemed to know a little bit about the background 
of the project, but no-one had actually taken part in any organised activities or noticed any evident infrastructural change.

\section{Box 17: iWay in Havelock North}

'What I know about is just what I read in the paper. Was X amount of money, was it 6 or 7 mill gone towards...try to encourage cycling around the Bay, and education of children as well. So when I say cycling, I think it was all towards cycling. I thought it might have been walking as well, but yeah.' Chris

'They've got a big... poster thing you know across the whole street in Heretaunga Street I noticed the other day.' Lucy

'And I think there has been a few incentives that are part of that like getting people to bike to breakfast or something, that was all part of it, wasn't it over a week? There's been a few little projects like that. I presume that's part of it.' Jane

'The new Rotary Pathway, probably from Blackbridge I think it's called to Haumoana, Te Awanga, that's probably part of it.' Lucy

'Not a thing for cyclists, for cycling [infrastructure]. I keep an eye out for anything like that.' Chris

\section{Hastings}

The conversation around $i$ Way in Hastings was even vaguer than in Havelock North, with presumably fewer participants knowing much about the programme (box 18). A few of the events were mentioned such as 'Heels on Wheels' at the Opera House and the 'Big bike fix-up', but it was a sense of confusion that dominated the conversation. One participant knew it was about infrastructural change, while other participants thought that $i$ Way was an acronym and others again confused iWay with the Rotary Pathways. Some participants claimed to have read about $i$ Way in the newspaper, and others had noticed infrastructural changes, but did not know anything about the programme background. This suggests that progress on the programme has been noticed in Hastings, but that more information is required for the people of Hastings to understand the gist of $i$ Way. 


\section{Box 18: $i$ Way in Hastings}

'That Heels on Wheels promotion at the Opera House.' Fiona

'When they're designing walking and cycling tracks between Hastings and Flaxmere, Hastings and Havelock, and one to Napier or something...' Rachel

'You mean the Rotary Pathways? They're called the Rotary Pathways all those...' Heather

'So what does iWay stand for? What is it, something like 'Walkway Association?' Celia

\section{Flaxmere}

Interestingly, knowledge of the $i$ Way programme in Flaxmere seemed to be different than that in Hastings or Havelock North: the majority of participants in Flaxmere had noticed the recent implementation of new and refurbished cycle lanes. Nevertheless, they seemed to know little about the background of the programme, or why there had been a sudden increase in infrastructural developments. It is to be noted that Flaxmere was the first location to be targeted for infrastructural change in the first financial year of the $i$ Way programme's implementation. Therefore, the fact that participants had clearly noticed features such as new bright green paint on the existing cycle lanes, the widening of some of the existing cycle lanes and the creation of new cycle paths is a positive sign that they are aware that something is happening (box 19).

All except one participant in Flaxmere showed no particular evidence of knowing about the gist of $i$ Way, even though some participants had read about it in the local free paper and even after being prompted by the researcher about what $i$ Way was about. This led participants to complain about the fact that information seemed to rarely 'travel' to Flaxmere. Respondents felt that the Hastings District Council should make a better effort at reaching out to the Flaxmere community and promoting this type of 
intervention which could be beneficial to all. Ideas were suggested on how the council could potentially achieve this (box 19). These included advertising, circulating explanatory leaflets in mailboxes or organising seminars and workshops on Marae to reach out to the Maori community.

\section{Box 19: $i$ Way in Flaxmere}

'It's the cycle lanes that have just appeared everywhere.' Phillip

'They've sort of got a bit wider and that yeah! And the green paint that's new. Well it was green but they've gone over and repainted it. Cause they did the Ave, on the Ave there's a new seal and they painted it over too. They've widened it a little bit yeah.' Makareta

'No, I mean Flaxmere is usually pretty much last to hear about anything that is happening in Hastings. Like it all happens there first and then comes to us.' Beverly

'Well there was a letter in our mail box, it just told us to clear the road, do not park on the road because there's some road works (to improve a cycle lane)... That was their chance to tell us why they were going to do it, why we had to keep the road cleared... They didn't explain to us, they just said there's road works. But my thoughts were when the message came out in our letter box that they were going to just clean the road again. But they didn't tell us they were going to work on the $i$ Way lanes or whatever.' Pania

\section{Summary}

This chapter suggests that Hastings people generally have positive attitudes and opinions about walking and cycling, and shows that participants understand the benefits associated with active travel. These positive attitudes are however not necessarily translated into high levels of active transport, or high intentions to walk and cycle more often in the near future. This is mainly due to other determining factors perceived as barriers to walking and particularly to cycling. Important arguments arising from the focus groups and interviews on the themes of convenience and practicality, the environment, and behaviour and awareness often relate to the theme of safety. Thus, the dominant feeling is that cycling is generally not perceived as a safe activity, and that the perceptions of risk and safety are a hindrance 
to both walking and cycling levels and uptake among the community. New and improved off-road infrastructure, separated from motor vehicle traffic, combined with more education for all road users at all ages and all levels were agreed by all to be necessary to improve perceptions of active transport and of safety in the Hastings District.

This chapter also shows that levels of awareness of the $i$ Way programme one year after it was launched were fairly low. The ACTIVE questionnaire thus reported $32 \%$ awareness. A number of people had certainly heard about various events associated with $i W a y$, but discussions in the focus groups and interviews confirmed that participants did not know much about the programme, even though some differences in awareness did exist depending on the location. 


\section{Discussion \& Conclusion}

This research sought to examine the perceptions and awareness levels of Hastings people in relation to walking and cycling at an early stage of a local authority programme to promote active travel. This chapter is a critical discussion of the research results and findings, and offers the researcher's views on the research process.

\section{Critical reflection on the research results and findings}

Three objectives work together to fulfil the aim of this study. Each of these objectives is discussed in the following sections, drawing references from the various results found in this study.

Objective one: Explore the effect of psychological and environmental factors on travel behaviour, intentions and mode choice.

The first objective of this study was directly addressed in chapters 6 and 7, chapter 6 providing literature and theory-based evidence while chapter 7 presented the results from both the qualitative and quantitative components of this study. A discussion based on these results is necessary to draw findings and conclusions to the first objective.

\section{Psychological factors}

A review of the psychological literature was used to examine psychological constructs and theoretical frameworks associated with the psychological factors influencing travel behaviour, intentions, and mode choice. Ajzen's (1991) theory of planned behaviour (TPB) was chosen as a starting point for the first objective. The TPB for walking and cycling was thus examined in the context of the ACTIVE questionnaire, with questions put to participants to examine their attitudes, norms and perceived behavioural control with regard to walking and cycling as a mode of transport, and to determine respondents' intentions to walk and cycle more in the near future. Analysis of the resulting data shows that a majority of the sampled population had a 
positive attitude or opinion about active transport, with slightly more positive opinions about walking than cycling. The following composite variables capturing ability and confidence to respectively walk and cycle, designed to examine participant perceived behavioural control, followed a similar type of pattern, albeit that perceived behavioural control was significantly higher for walking than for cycling. More than $20 \%$ of the sample also felt completely unable to cycle as a means of transport. In addition, walking and cycling were also examined as subjective norms. These composite variables show that walking and especially cycling as a mode of transport are not considered a norm in Hastings.

An important question asked of respondents related to their intentions to walk and cycle more in the near future. The results show that a majority of participants intend to walk somewhat more in the near future, while a large majority of participants have little or no intentions to cycle more as a mode of transport in the near future.

\section{Bivariate analyses}

\section{a. Intentions and psychological factors}

Simple bivariate linear regressions were undertaken to determine whether potential relationships exist in the ACTIVE questionnaire sample between declared intentions to walk and cycle more often in the near future, and attitudes, social norms, perceived behavioural control and habits. The results show that each of these four factors is a statistically significant explanatory variable in influencing intentions to walk and cycle more often in the near future when other variables are not accounted for. These results thus support the theory of planned behaviour, and also confirm that habits must also be taken into account.

Two multivariate linear regressions were also undertaken to try to determine the relative strength of these variables. The regression examining the influence of these different factors on walking intentions shows that walking 
being considered a social norm is the only statistically significant explanatory variable in influencing intentions to walk more often in the near future.

The regression examining the influence of the different psychological factors on cycling intentions shows that cycling being considered a social norm and a habit are statistically significant, but that the perceived behavioural control to cycle is the strongest explanatory variable in influencing intentions to cycle more often in the near future.

The multivariate regression suggests there is multicollinearity among the explanatory variables, and the bivariate linear regressions results need to be interpreted in this light. The greater importance of perceived behavioural control in the case of cycling signifies that perceived ability and confidence to cycle is more important for that mode than for walking. It is also important to note that habits are a statistically significant explanatory variable for cycling intentions, but they are not for walking.

\section{b. Intentions, cycling levels and demographics}

Chi-square tests were also undertaken to examine a range of hypotheses between cycling levels and intentions to walk and cycle more in the near future, and demographic characteristics of the sample, namely income, age, ethnicity and gender.

Six relationships were established:

1. Older participants are less likely to cycle more in the near future than younger participants. Participants aged between 31 and 60 are also more likely to cycle more in the near future than all other participants

2. Participants under the age of 66 are more likely to have cycled at least once in the last year than older participants. 
3. Europeans have "polarised" intentions to cycle more in the near future: some are more likely to have high intentions to cycle more in the near future, while some have firm intentions not to cycle more. Maori and other ethnicities are more likely to be neutral on their intentions.

4. Maori are more likely to have cycled at least once in the last year than Europeans and other ethnicities.

5. Men are more likely to have cycled at least once in the last year than women.

6. Men are also more likely to have stronger intentions to cycle more in the near future than women.

In 2007/2008, Sport and Recreation New Zealand (SPARC) implemented the Active NZ Survey to monitor physical activity among New Zealand adults (16 years and over). The aim of that survey was to measure New Zealand participation levels in various sport, recreation and physical activities. Walking and cycling were studied as part of this survey, and SPARC published the findings about cycling in 2009 (Sport and Recreation New Zealand, 2009). Respondents to the SPARC survey were asked to report whether they had participated in cycling at least once in the last twelve months, which allows for comparisons to be made with the data from the ACTIVE questionnaire. The aforementioned findings of the chi-square tests between cycling levels in the last twelve months and demographic characteristics can therefore also be compared to the SPARC Survey.

The cycling data from the SPARC survey show that men (compared with women), adults aged 16 to 49 years (compared with adults over 50) and adults who self-identified as New Zealand European (compared with all other New Zealand adults) were significantly more likely to have participated in cycling in the last twelve months (Sport and Recreation New Zealand, 2009). 


\section{a. Age and gender}

The findings on age and gender patterns from the SPARC survey are thus in agreement with the findings of this study (findings 2 and 6 above), as both studies show that younger people (compared to older people) and men (compared with women) are more likely to have cycled at least once in the last twelve months. These findings are also in agreement with the majority of the empirical literature, which underlines the fact that cycling levels decline with age (Dill \& Voros, 2007; Heinen, et al., 2010; Moudon, et al., 2005; Pucher, Komanoff, \& Schimek, 1999; Zacharias, 2005), and that men tend to cycle more than women, especially in countries with low bicycle transport mode share (Banister \& Gallant, 1999; Dill \& Voros, 2007; Garrard, Rose, \& Lo, 2008; Heinen, et al., 2010; Krizek, Johnson, \& Tilahun, 2004; Moudon, et al., 2005; Pucher, et al., 1999; Rietveld \& Daniel, 2004).

It is also interesting to note that the above patterns are reflected in this study in terms of intentions to cycle more in the near future. The SPARC survey does not touch on intentions to cycle more, and to the best of the researcher's knowledge, no other New Zealand study has yet examined relationships between intentions to cycle more and demographic characteristics. This study therefore provides an insight into these relationships, and is a good starting point to bridge a significant gap in the literature. Should these relationships be confirmed at different scales and at other locations in New Zealand, this research can provide grounds for local authorities and policy makers to undertake more targeted interventions to encourage walking and cycling in New Zealand communities.

\section{b. Ethnicity}

A comparison of the results from the SPARC survey and from this study on ethnicity in relation to likelihood to have cycled at least once in the last twelve months shows a discrepancy. The SPARC findings show that New Zealand Europeans are more likely to have cycled at least once in the last 
twelve months, while this study has found that Maori are more likely to have cycled at least once in the last twelve months than Europeans. This suggests that, even though Europeans are more likely to have cycled at least once in the last twelve months at a national scale, there may be differences among districts and communities in New Zealand, Hastings being a prime example. Whether there are factors encouraging cycling in Hastings that particularly appeal to Maori may warrant further research.

The relationship between intentions to cycle more in the near future and ethnicity from this study is somewhat complicated to interpret, with Europeans seemingly having more polarised intentions to cycle than Maori and other ethnicities, who appear to be more neutral about their intentions. More detailed research to explore the influence of ethnicity on cycling levels, frequency, and intentions in New Zealand may therefore be required.

\section{Environmental factors}

Results in this study suggest that factors from both the built and natural environment play an important part in people's choice to walk or cycle, whether for recreation and sport purposes, or as a mode of transport.

Appropriate infrastructure such as cycling lanes, high quality footpaths and high levels of street connectivity has been identified in the literature as being necessary to lead to more active travel, particularly cycling (Pucher, et al., 2010). However, evidence showing that altering infrastructure and other aspects of the built environment has led to increases in walking and cycling levels or a modal shift from car use is limited (Ogilvie, et al., 2011). In the present study, the focus group participants from all three communities in Hastings argued that more appropriate infrastructure was needed in Hastings to encourage them to cycle more. This was particularly true in relation to perceptions of safety, as most of the participants did not cycle because they were concerned about cycling in traffic, and argued that cycle ways separated from the traffic would definitely make them feel safer and thus 
encourage them to cycle more or more often. It was also argued that more infrastructure to facilitate cycling, for example more bicycle parking spaces and more bike racks, would be beneficial for commuting. The researcher thus believes that characteristics of the built environment are particularly important for cycling for utilitarian trips, and are a definite determinant of people's choice to use active transport.

Factors from the natural environment seemingly have a strong influence on active travel for commuting as well as for recreation purposes. Evidence from the literature suggests that in some cases factors from the natural environment, for example topography, darkness and rainfall have a stronger influence on people's choice to walk or cycle than factors from the built environment (Cervero \& Duncan, 2003; Heinen, et al., 2010). In the present study, the general consensus from participants in the focus groups was that topography and weather were generally favourable in the Hastings district, making walking and cycling in this area quite enjoyable. Seasonality, with the reduction of daylight hours in the winter months, and darkness were identified as the two main negatively influencing factors from the natural environment for walking and cycling for most focus group participants.

While an intervention such as the Model Communities Programme can for obvious reasons not have an influence on exogenous factors from the natural environment such as weather-related events or topography, there does however seem to be an opportunity to develop the built environment in conjunction with the natural environment. Much praise was given in all three focus groups to the Rotary Pathway built on the foreshore from Clifton (approximately 25 kilometres to the South of Napier) to Bay View (approximately 10 kilometres to the North of Napier). Interview participants in Flaxmere suggested that building this type of infrastructure in Flaxmere, to promote the natural assets of the location such as parks and gardens, would encourage more people to walk and cycle, and provide a low cost, 
safe and enjoyable facility for the Flaxmere community. This type of offroad facility may also have beneficial effects on walking and cycling commuting levels. It will, for example, be of considerable interest to measure the change in cycling levels and modal shift between Hastings and Havelock North once a proposed off-road path (part of the $i$ Way project) is completed, as this route is identified as one of the busiest commuting routes in Hawke's Bay. Should this new off-road cycle path be effective in increasing the number of cyclists between Hastings and Havelock North and creating a mode shift, it will provide a strong argument in favour of investment in off-road facilities, and may be applicable to other locations in the Hastings district and in New Zealand.

Objective two: Examine how citizens from different neighbourhoods in Hastings perceive walking and cycling in their community.

\section{Positive perspectives}

This objective was explored in chapter 7 , drawing on results from both the focus groups and the ACTIVE questionnaire. While exploring the cobenefits of walking and cycling was not a primary aim or objective of this study, it is important to note that the environmental, economic and health benefits highlighted in the empirical literature were either directly or implicitly touched upon in the focus groups and interviews.

It would however not be fair to say that the environmental benefits of walking and cycling (in terms of climate change, carbon emissions and air pollution mitigation) were widely raised. On a few occasions and without being prompted, some participants explained that being environmentally considerate was a factor that would encourage them to use active transport rather than use their car. In most cases however, participants would only consider environmental factors when prompted, and phenomena such as climate change and carbon emissions were often reframed as local air 
pollution issues. This suggests a certain lack of knowledge and understanding of these phenomena from the participants, or may simply signify that climate change is not a factor considered as relevant by participants. The lack of importance placed on the environmental perspective was also evident in the questionnaire responses. The environment factor (i.e. taking into account carbon emissions etc...) received the lowest rating out of eight factors, for a question that asked seventy-five people who work or study to rate various factors that may influence their choice of mode (figure 7.6). These results taken together suggest that, while the positive effects of walking and cycling on the environment and the negative effects of driving a car on local air pollution seemed to be understood, these effects were not a substantial determining factor for participants to use active transport. Instead, environmental benefits and reductions in local air pollution were mainly considered as a 'happy' side effect of walking and cycling.

When asked about factors that encourage people to walk or cycle in Hastings, participants in all three communities were however quick to draw on the positive aspects active travel can have for one's life, particularly benefits for personal health and well-being, and on financial savings. The majority of focus group participants thus identified that walking and cycling were simple and enjoyable ways to exercise and keep fit. Important emphasis was placed on the fact that walking and cycling are not only good for physical health, but also for mental and spiritual well-being. Consequently, many of the anecdotes and stories from the focus groups and interviews related to the benefits participants perceive as arising from going for a walk or cycle, either for recreation or for transport. While the acknowledgement of active travel as a source of physical, mental and spiritual well-being was in accordance with the empirical literature, another aspect evident in the present study and less often highlighted in the wider literature was the social benefits and wellness that arise from undertaking 
active transport, particularly walking. Participants in the focus groups were eager to highlight that walking around the streets of Hastings, Havelock North and Flaxmere presented opportunities to meet people and socialise. Certain participants particularly enjoyed taking part in walking groups for company and social interaction, and the general consensus was that promoting more cycling and walking therefore has the potential to increase social well-being, leading individuals and therefore communities as a whole to be happier.

The positive views expressed by focus group participants were confirmed by the results of the ACTIVE questionnaire, as they also show that Hastings respondents have, to a large majority, positive attitudes, views and opinions about walking and cycling. The composite variables opinions of walking and cycling as 'desirable' show that $73 \%$ of the sampled population believes walking to be desirable, and $67 \%$ has positive opinions about cycling (figures 7.7 and 7.8). While these results are not necessarily reflected in intentions to walk and cycle more in the near future, or in actual levels of cycling over the past twelve months, the results nonetheless illustrate that walking and cycling are both perceived as positive among the community.

Many of the focus group and interview participants also acknowledged the economic benefits associated with active transport, whether in terms of strict financial savings from not using a car, or in terms of time savings, as many argued that walking or cycling for most short urban trips is often quicker than dealing with the bother associated with driving a car in town, namely traffic and parking issues. Convenience and cost also received respective average ratings of 3.7 and 3.2 (on a scale from $1=$ not at all important, to $5=$ very important) from the sample of 75 workers and students who were asked to rate various factors influencing their choice of mode (figure 7.6). While these ratings do not specifically refer to active 
transport, they nevertheless confirm that economic factors are wellconsidered in people's choice of mode of transport.

\section{Negative perspectives}

The three most important factors influencing people's choice of route in the questionnaire were getting to the destination quickly, personal safety, and convenience (figure 7.4). These three factors all rated over 3.5 on a scale from 1 to 5, and were reflected to a certain extent in the focus groups. While, quickness and convenience were discussed to a certain extent in the focus groups, the main talking points of all focus groups and all interviews consistently related back to safety. The researcher identified safety as a theme on its own in the focus group analysis, but it is fair to say that the points made when discussing the themes of the environment and behaviour and awareness never deviated far from the theme of safety.

Safety thus related to factors from both the built and natural environment. The discussion surrounding the encouraging factors in the built environment revolved mainly around the attractive nature of dedicated and modeseparated infrastructure for walkers and cyclists. However, just as having access to appropriate infrastructure, such as the off-road path on Crosses Road or the Rotary Pathways, was considered by participants to be an encouraging factor to walk and cycle, the absence of infrastructure or the presence of inappropriate infrastructure was deemed dangerous and therefore unsafe. The other main concern related to both the built environment and safety is the presence of numerous traffic roundabouts in the Hastings district, which were considered to be dangerous for both cyclists and pedestrians. A few "near miss" anecdotes illustrated the fact that roundabouts were clearly not considered to be favourable for cycling, and evidence was given that the presence of roundabouts on a cyclist's most direct route could force a route change to avoid them. The main concern for pedestrians in respect of roundabouts was their ability to cross the road safely, as typically no pedestrian crossings are present at roundabouts in 
Hastings. It became evident that features of the built environment were constantly judged by participants in terms of perceived safety. This has implications for the Hastings District Council team in charge of iWay and for other local authorities in New Zealand who try to promote cycling. Not only do local authorities have a clear role to improve and build new infrastructure, there is also a strong case for them to lead information campaigns and events to change perceptions of safety.

The single most discussed issue in relation to the natural environment and safety was darkness, mainly associated with seasonality. The general consensus was that participants would usually not walk or cycle at night for safety reasons linked both to the fear of not being seen properly and therefore of being hit by a car, and to the fear of being harassed, mugged or assaulted. The issue of darkness can also be associated with the built environment, as many participants agreed that better lighting would make them perceive walking in the dark as safer. The issue of darkness was particularly important in Hastings and Flaxmere, but to a lesser extent in Havelock North. Havelock North was thus perceived as safer than the other two neighbourhoods, with people saying they would not mind walking alone at night there, but would not do it in Hastings or Flaxmere. Havelock North is a higher socio-demographic area, but more research may be required to determine why Havelock North is perceived as being safer than Hastings and Flaxmere, particularly at night time.

For the purposes of the analysis, the theme of safety was broken down into three sub-themes: traffic safety, neighbourhood safety and child safety. The issue of traffic safety was discussed particularly for cycling, as cyclists interact with motor vehicle traffic to a greater extent than pedestrians. While issues such as the ability to be seen properly and obstacles from the built environment were discussed, the biggest issue in relation to traffic safety was associated with the confidence of cyclists (and non-cyclists) to be on 
the road amid the traffic. This can be directly linked to the final theme analysed from the focus groups, behaviour and awareness. Many participants argued that they were too afraid to cycle as they did not feel confident about the attitudes and behaviours of drivers on the road. The traffic safety issue was thus often linked to either driver behaviour and awareness of cyclists on the road, or cyclist behaviour and awareness with regard to drivers. This highlighted what seemed to be a cohabitation problem on the road. It was further emphasised by many comments relating to child safety on the road, as most parents and grandparents participating in the focus groups expressed concerns about letting their children cycle on the road on their own. This was in general due to their lack of skills and experience on the road, but also because parents did not trust other road users who were often perceived as representing a major safety hazard for their children. The common conclusion of these debates however was that the issue of cohabitation on the road was central, and the best way to reduce risks and increase safety for all road users would be to enforce road rules more, and to offer more education for all, at all ages and all levels of confidence. Participants were quick to praise education programmes in schools, and also suggested that more attention should be given to educating drivers about the rights of cyclists. Additionally, the Hastings District Council launched in 2011 a Share the Road campaign as part of iWay, targeted at drivers and cyclists to 'look after each other' while on the road. Future monitoring and evaluation may show whether this type of campaign is effective in improving cohabitation.

The focus group discussions on the general theme of safety also implicitly raised a point which has been prominent in research in recent years: the difference between perceived safety and actual safety. The perception of safety in relation to cycling is often considered of greater importance than the actual safety of cycling, as the risk perceived is likely to be a more 
important determinant of cycling than the actual risks associated with cycling (New Zealand Transport Agency, 2011a; Parkin, 2007).

Studies have shown that the risks of walking and cycling accidents decrease with an increase in walking and cycling levels, the 'safety in numbers' effect (Jacobsen, 2003; Robinson, 2005). There is strong evidence from these studies which suggests that policies which increase the numbers of people walking and cycling are an effective way of improving the safety of people walking and cycling, as accident rates decrease as the number of walkers and cyclists increases (Jacobsen, 2003). If monitoring and evaluation of the $i$ Way programme shows longitudinal increase in walking and cycling levels, more research could be undertaken to examine whether crash rates for walking and cycling decrease in Hastings, potentially confirming the 'safety in numbers' effect, but also potentially showing that a local authority programme can be effective in improving the safety of walkers and cyclists.

Additionally, two interesting points were made in the interviews in Flaxmere. A number of participants argued that more education through policing was necessary in their neighbourhood, particularly in terms of traffic speed and with respect to the helmet laws. It was argued that more enforcement of this law could potentially lead more children to wear their helmets. Participants in Flaxmere also strongly argued in favour of education programmes especially designed for Maori communities to be conducted on marae. Participants believed that Maori, especially through their kaumatua, could potentially reach Maori more effectively on issues surrounding education, driver behaviour and child safety. Participants also agreed that a programme such as $i$ Way has the potential to increase education levels, but that appropriate education methods need to be applied and that education will not necessarily be achieved solely through new infrastructure and marketing. More research may therefore be required on 
the best ways to effectively educate drivers, pedestrians, cyclists and communities in general with regard to issues surrounding active transport.

Objective three: Examine the community's awareness of the iWay programme one year after it was launched.

It is important to remember that Hastings was awarded the title of Model Community and duly received funding from the New Zealand Transport Agency in June 2010. The first two focus groups in Havelock North and Hastings and the first interview in Flaxmere were conducted in the first week of June 2011, exactly one year after Hastings was announced as a Model Community. The ACTIVE questionnaire was conducted between June and September 2011, and the final interviews in Flaxmere were organised in December 2011. Because the timeframe of the iWay programme (June 2010 - July 2012) ${ }^{6}$ is longer than the short timeframe for this study (one year), a longitudinal study of awareness of the iWay programme was not possible. Moreover, the infrastructure investment programme of $i W a y$ has inevitably taken some months to get underway, with most infrastructure scheduled to be put in place over 2011/2012. This study therefore only provides a snapshot of the community's awareness barely a year into the programme, and establishes a baseline for future research. This objective was thus investigated through both the ACTIVE questionnaire and the focus groups. Five questions were asked about $i$ Way awareness in the questionnaire, and the final part of each focus group and interview was also dedicated to participant awareness of the programme.

The goal listed by the Hastings District Council as a key project indicator in relation to awareness of the programme is that iWay exceeds $50 \%$ of "marketing awareness" in the community by the end of the monitoring

\footnotetext{
${ }^{6}$ Funding may in fact be extended.
} 
period in 2013 (Hastings District Council, 2011b). The results of the ACTIVE survey show that approximately one third (32\%) of the 121 respondents had heard about the project, which is an encouraging figure, but still a long way from the awareness target of $50 \%$. Of the thirty-eight respondents who had heard about $i W a y, 13 \%$ indicated they knew nothing about it and a further $30 \%$ claimed to know only a little about the programme. This shows that the Hastings district council and their partners still have a great deal of advertising, promoting and marketing work ahead of them to reach their awareness targets. Interestingly though, the majority of participants had heard of $i$ Way through the local newspapers, and to some extent through social media and outside advertising. These results show that these three methods of communication are currently the most effective for spreading information about $i W a y$. It is also possible that once awareness levels reach a certain point among the community, word of mouth will also become increasingly effective.

The focus group and interview results triangulated the ACTIVE questionnaire results and confirmed the vast majority of the participants in all three locations did not know much (if anything) about the iWay programme. Interestingly though, responses from people who knew about $i$ Way varied depending on their location. Participants thus seemed to know more about the programme basics (background information, promotional events etc.) than about actual changes in Havelock North and Hastings, while participants in Flaxmere seemed to have noticed actual iWay infrastructural changes and improvements without knowing that these changes were part of a programme. It is important to link these findings back to the actual implementation of $i$ Way. While marketing and promotion have been unfolding across the entire district since the beginning of the programme, by way of advertising and promotional events, the timeframe for actual infrastructural changes has varied depending on the location. Changes in Flaxmere and Hastings were planned to take place in the first 
financial year of the programme (before the focus groups were conducted), while changes in Havelock North were scheduled to take place in the second financial year (after the focus groups were conducted). This may explain why participants in Flaxmere had clearly noticed more changes in their community than Havelock North residents had.

Participants in all three communities seem to have heard about various events happening around the district, such as Big Bike Fix-Ups, Bike to Breakfast, Heels on Wheels etc, but did not necessarily link them to $i$ Way. This shows that people do notice when events are taking place, but more marketing work around the $i$ Way brand and the gist of the programme may be required for $i W a y$ to be embedded in the Hastings culture. Additionally, among the twenty-one focus group and interview participants, none had actually participated in any of the organised events or activities, even though some had heard about them. While this does not necessarily suggest apathy from the community, the council may have to rethink their strategy or further incentivise participation in these events to attract more people.

It is difficult to evaluate the effectiveness of a local government active transport programme in influencing community perceptions and awareness of walking and cycling when the timeframe for the study does not allow for a systematic longitudinal analysis. Results from the ACTIVE questionnaire and the focus groups have however shown that, in general, the majority of the population has positive attitudes and opinions towards walking and cycling, but that other factors, particularly surrounding safety perceptions, can strongly constrain active transport activity levels or any further uptake. In the words of the Hastings community, where a local authority programme such as iWay can really help is in building appropriate infrastructure, increasing education levels, and in contributing towards rendering active transport (particularly cycling) a safe, cheap and fun activity. In turn, this could help raise walking and cycling to the status of mainstream activities. 
These findings are in accordance with those of the NZTA (2011a), who found that the solutions most likely to effect significant change in numbers of people cycling as a mode of transport relate to the nature and consistency of appropriate infrastructure, and to education for motor-vehicle drivers and cyclists on how to best and most safely use it.

\section{Critical reflection on the research process}

The research methodology applied for this research was selected to best pursue the aims and objectives of the study, given the nature of these objectives and the allocated timeframe. This methodology enabled a comprehensive and contextualised analysis and discussion of the research aims and objectives, as the qualitative and quantitative components of the study allowed the researcher to approach the aim from different perspectives. Additionally, components of both the qualitative and quantitative methods were complementary in many ways: information from the focus groups and interviews has in many cases been used to illustrate trends found in the ACTIVE questionnaire, while some of the quantitative data from the questionnaire confirms perspectives and opinions provided by focus group and interview participants. However, while the methodology has generally been successful in achieving results, a critical reflection on this methodology seems appropriate and necessary, and is provided in the following paragraphs.

\section{Literature reviews}

The literature review in chapter 3 provided a background and contextual picture of the co-benefits of walking and cycling, as well as an insight into the efficacy and implementation of interventions to promote and encourage more active transport. It also allowed the researcher to determine a range of research gaps needing to be filled. The main issue encountered for this part of the study was that the objectives of this particular research study, compounded with a short timeframe, did not allow for a full, comprehensive and systematic literature review of all the empirical literature surrounding 
walking and cycling. The main aims of this literature review however were to broadly introduce the reader to the topic, to provide contextual information and highlight some of the research gaps. The short literature review in chapter 3 fulfils these three aims.

A literature review was also undertaken to examine the first objective of this study, exploring the effect of psychological and environmental factors on travel behaviour, intentions, and mode choice. Much of the literature surrounding the influence of environmental factors (both built and natural) on active transport is relatively well-known, but the theoretical psychological literature is more specialised and requires a greater level of specialist knowledge. The researcher however believes that analysing the theoretical concepts in relation to the psychological factors influencing travel behaviour has added valuable background information to this study. The theory also allows a richer interpretation of the ACTIVE questionnaire.

\section{Focus groups and interviews}

The focus groups and interviews were thoroughly enjoyed by the researcher, who found it valuable to be among the community and to listen to participants share their stories. Two main issues were however of note. The first was the recruitment process, particularly for the focus group in Flaxmere. The researcher found it difficult to recruit people in this community, even with the aid of a financial incentive. Two focus groups were organised in Flaxmere, and only one of the confirmed participants was present. This posed a challenge, but this challenge was overcome by changing both the recruitment strategy and limiting participation in the discussions to three interviewees at a time. This change of strategy was effective, with a total of six participants ultimately being interviewed in Flaxmere. However, the process was more time-intensive for the researcher.

The second issue encountered by the researcher surrounded biases and population representation. Many of the participants already had favourable 
views about active transport as the advertisements used in the recruitment process did mention that the topic of the research was around walking and cycling. There may therefore have been a lack of representation of people having negative views about active transport. It would perhaps have been valuable to witness and analyse a conversation between participants with favourable and unfavourable opinions about walking and cycling. Regarding population representation, fifteen females and six males participated. One may think that a more gender balanced sample would have been more appropriate. However, the relative lack of interest from people in participating in these communities did not offer the researcher the opportunity to balance participation evenly between females and males. Interestingly however, the sample for the household questionnaire also presents the same challenge, with eighty-three females responding to the questionnaire compared to only forty-six males. The focus groups and interviews were very informative nonetheless.

\section{ACTIVE questionnaire}

The researcher was extremely privileged to have been able to participate in the ACTIVE study, and to have been able to participate in collecting data in Hastings, and use it for the purposes of this thesis. The fact that the ACTIVE questionnaire was a comprehensive questionnaire asking respondents about various aspects and variables relating to walking and cycling habits and perceptions allowed the researcher to select invaluable data to complement the examples and stories shared by focus group and interview participants. Even though a slightly larger sample size and possibly a better gender balance would perhaps have been beneficial in the ACTIVE study, the available data nevertheless allowed the researcher to test a number of statistical hypotheses based on demographic characteristics of the sample. These resulted in certain statistical relationships being established, an outcome which was rewarding for the researcher. These 
relationships may also provide grounds for future research on the links between socio-demographic characteristics and active transport.

\section{Further research}

Further research around the topics of community perceptions of walking and cycling in New Zealand, and walking and cycling in Hastings, would usefully augment the findings of this study. In particular, research to:

- Examine whether the links found in this study between sociodemographic characteristics (particularly ethnicity) and active transport frequency and intentions apply in other cities and towns in New Zealand;

- Determine the strength of psychological explanatory variables in influencing travel mode choices and intentions in New Zealand;

- Determine the effects of off-road walking and cycling facilities on active transport levels and modal shift;

- Determine whether off-road facilities are the most cost-effective investment to increase walking and cycling levels;

- Examine why some areas of the Hastings district are perceived as safer than others;

- Longitudinally examine the effects of $i$ Way on active transport levels and crash rates involving pedestrians and cyclists, to evaluate the 'safety in numbers' effect.

- Determine the basis for a best practice guide to effectively educate drivers, cyclists and communities in general with regard to active transport safety. 


\section{Conclusion}

This study aimed to address one core research question:

What are the perceptions and awareness levels of Hastings people in relation to walking and cycling at an early stage of a local authority programme to encourage active travel?

To address this question, three separate research objectives were determined:

- Explore the effect of psychological and environmental factors on travel behaviour, intentions, and mode choice

- Examine how citizens from different neighbourhoods in Hastings perceive walking and cycling in their community.

- Examine the community's awareness of the iWay programme one year after it was launched.

It was found that both psychological and environmental factors play an important part in people's behaviour with regard to transport and mode choice. The theory of planned behaviour was broadly confirmed, as attitudes, norms and perceived behavioural control were each found to have an influence on people's intentions to walk and cycle more often in the near future. Additionally, habits were also found to being significant in influencing intentions, confirming the view that habits must be included when examining transport behavioural intentions, to augment the theory of planned behaviour.

This study also draws relationships between socio-demographic characteristics and cycling levels and intentions to cycle more. The relationships between age, gender and cycling activity were comparable to the findings of the SPARC (2009) survey, in that men (compared with women) and younger people (compared with older people) are more likely to have cycled at least once in the last twelve months. There was however a 
difference with regard to ethnicity, as the SPARC survey found that Europeans are more likely than other ethnicities to have cycled at least once in the last twelve months, whereas this study has found that Maori are more likely to have done so than other ethnicities. This suggests that such behavioural differences depend on the area or community under consideration.

Results from the focus groups and interviews and from the ACTIVE questionnaire showed that the people of Hastings have generally positive attitudes and opinions with regard to walking and cycling. These positive attitudes are however not necessarily translated into high levels of active transport, or high intentions to walk and cycle more in the near future. This is mainly due to other determining factors perceived by the Hastings community as barriers to walking and particularly to cycling. These factors related to four main themes, convenience and practicality, the environment, safety, and behaviour and awareness. It became evident that the dominant feeling for the community is that cycling is generally not perceived as a safe activity, and that the perceptions of risk and safety are a hindrance to both walking and cycling levels and uptake among the community. The improvement of current infrastructure, the creation of new, dedicated, offroad facilities for cycling, and more education on driver and cyclist behaviour and cohabitation on the road appear to be some of the key factors to work on to further improve perceptions of active transport in Hastings, and potentially lead to an increase in the uptake of active transport and to a modal shift.

This creates many opportunities for the $i$ Way programme to fulfil its role in encouraging more people to walk and cycle in Hastings, and 'make walking and cycling irresistible'. Community awareness of $i$ Way was at a relatively low level a year into the programme, implying considerable potential for the Hastings District Council to increase awareness levels over the second year 
of the programme. While the timeframe for this study has not allowed the researcher to draw clear conclusions on the effectiveness of the programme, follow-up research would be of significant value in determining whether this local authority programme is effective in making Hastings truly become a model community. 


\section{References:}

Aarts, H., Verplanken, B., \& van Knippenberg, A. (1998). Predicting Behavior From Actions in the Past: Repeated Decision Making or a Matter of Habit? Journal of Applied Social Psychology, 28(15), 1355-1374.

Ajzen, J. (1991). The theory of planned behaviour. Organisational Behaviour and Human Decision Processes, 50, 179-211.

Ajzen, J., \& Fishbein, M. (1980). Understanding Attitudes and Predicting Social Behaviour. Englewood Cliffs: Prentice-Hall.

Banister, D., \& Gallant, N. (1999). Sustainable commuting: a contradiction in terms? Regional Studies: Journal of the Regional Studies Association, 33(3), 274-280.

Braun, V., \& Clarke, V. (2006). Using thematic analysis in psychology. Qualitative Research in Psychology, 3, 77-101.

Cervero, R., \& Duncan, M. (2003). Walking, bicycling, and urban landscapes: Evidence from the San Francisco Bay Area. American journal of Public Health, 93(9), 1478-1483.

Chapman, R., Howden-Chapman, P., Keall, M., Witten, K., Abrahamse, W., Muggeridge, D., et al. (2012). Evaluating the Model Communities Programme - literature, methodology and some preliminary results. Paper presented at the 2 Walk and Cycle Conference, Hastings, February 2012.

Creswell, J. (2007). Qualitative Inquiry \& Research Design: Choosing Among Five Approaches. Thousand Oaks, California: Sage Publications.

Creswell, J. (2009). Research Design: Qualitative, Quantitative, and Mixed Methods Approaches. Thousand Oaks, California: SAGE Publications. 
Cycling England (2009). Cycling Demonstration Towns: Monitoring Project Report 2006 to 2009. United Kingdom.

de Bruijn, G.-J., Kremers, S. P. J., Schaalma, H., van Mechelen, W., \& Brug, J. (2005). Determinants of adolescent bicycle use for transportation and snacking behavior. Preventive Medicine, 40(6), 658-667.

de Bruijn, G.-J., Kremers, S. P. J., Singh, A., van den Putte, B., \& van Mechelen, W. (2009). Adult active transportation: Adding habit strength to the theory of planned behavior. American Journal of Preventive Medicine, 36(3), 189-194.

Dill, J., \& Voros, K. (2007). Factors affecting bicycling demand: initial survey findings from the Portland, Oregon Region. Transportation Research Record: Journal of the Transportation Research Board, 2031, 9-17.

Fishbein, M., \& Ajzen, J. (1975). Belief, Attitude, Intention and Behaviour. Reading, MA: Addison-Wesley.

Forsyth, A., \& Krizek, K. J. (2010). Promoting walking and bicycling: Assessing the evidence to assist planners. Built Environment, 36(4), 429-446.

Garrard, J., Rose, G., \& Lo, S. (2008). Promoting transportation cycling for women: the role of bicycle infrastructure. Preventive Medicine, 46, $55-59$.

Genter, J., Donovan, S., Petrenas, D., \& Badland, H. (2008). Valuing the health benefits of active transport modes. Wellington: NZTA.

Giles-Corti, B., Broomhall, M., Knuiman, M., Collins, C., Douglas, K., Ng, K., et al. (2005). Increasing walking: How important is distance to, attractiveness, and size of public open space? American Journal of Preventive Medicine, 28(2, Supplement 2), 169-176. 
Giles-Corti, B., \& Donovan, R. (2002). The relatve influence of individual, social and physical environment determinants of physical activity. Social Science \& Medicine, 54, 1793-1812.

Giles-Corti, B., Foster, S., Shilton, T., \& Falconer, R. (2010). The cobenefits for health of investing in active transportation. New South Wales Public Health Bulletin, 21(5-6), 122-127.

Harland, P., Staats, H., \& Wilke, H. A. M. (1999). Explaining proenvironmental intention and behavior by personal norms and the theory of planned behavior. Journal of Applied Social Psychology, 29(12), 2505-2528.

Hastings District Council (2010a). Our Vision: Making Walking and Cycling Irresistible. Hastings.

Hastings District Council (2010b). Overview of Hastings' Model Communities Programme Proposal. Hastings.

Hastings District Council (2011a). About iWay Retrieved 22 March, 2012 http://www.iway.org.nz/about-iway

Hastings District Council (2011b). The iWay Monitoring Strategy. Hastings.

Heinen, E., Maat, K., \& van Wee, B. (2011). The role of attitudes toward characteristics of bicycle commuting on the choice to cycle to work over various distances. Transportation Research Part D, 16, 102109.

Heinen, E., Van Wee, B., \& Maat, K. (2010). Commuting by bicycle: an overview of the literature. Transport Reviews, 30(1), 59-96.

Hillman, M. (1997). Public policy on the green modes. In RS Tolley (Ed.), The greening of urban transport: planning for walking and cycling in western cities. Chichester, NY: John Wiley \& Sons Ltd.

Jacobsen, P. (2003). Safety in numbers: more walkers and bicyclists, safer walking and bicycling. Injury Prevention, 9(3), 205-209.

Khan, M., \& Manderson, L. (1992). Focus groups in tropical diseases research. Health Policy \& Planning, 7(1), 56-66. 
Kingham, S., Longley, I., Salmond, J., Pattinson, W., Shrestha, K., \& Liu, H. (2011). Determinants of personal exposure to traffic pollution while travelling by different modes. Wellington: NZTA.

Kitamura, R., Mokhtarian, P., \& Laidet, L. (1997). A micro-analysis of land use and travel in five neighborhoods in the San Francisco Bay Area. Transportation, 24, 125-158.

Krizek, K., Barnes, G., Wilson, R., Johns, R., \& McGinnis, L. (2007). Nonmotorized Transportation Pilot Program Evaluation Study. Minnesota: Minnesota Department of Transportation.

Krizek, K., Johnson, P., \& Tilahun, N. (2004). Gender differences in bicycling behaviour and facility preferences. Paper presented at the Conference on Research on Women's Issues in Transportation, Chicago, IL, 18-20 November 2004.

Liamputtong, P., \& Ezzy, D. (1999). Qualitative Research Methods. South Melbourne, Victoria: Oxford University Press.

Ministry of Transport (2005). Getting there-on foot, by cycle: A strategy to advance walking and cycling in New Zealand transport. Wellington. Ministry of Transport (2008). New Zealand Transport Strategy 2008. Wellington.

Ministry of Transport (2009a). Government Policy Statement on Land Transport Funding 2009/10-2018/19. Wellington.

Ministry of Transport (2009b). How New Zealanders Travel: Trends in New Zealand household travel 1989-2008. Wellington.

Montano, D., \& Kasprzyk, D. (2008). Theory of Reasoned Action, Theory of Planned Behaviour, and the Integrated Behavioural Model. In K. Glanz, B. Rimer \& K. Viswanath (Eds.), Health Behaviour and Health Education: Theory, Research, and Practice (4th ed., pp. 590). San Francisco: Jossey-Bass.

Morais, R. (2010). Refocusing Focus Groups: A Practical Guide. Ithaca, NY: Paramount Market Publishing. 
Morgan, D. (1988). Focus Groups as Qualitative Research (Vol. 16). Newbury Park, California: SAGE Publications.

Morse, J. (2003). Principles of Mixed Methods and Multimethod Research Design. In A. Tashakkori \& C. Teddle (Eds.), Handbook of Mixed Methods in Social and Behavioural Research (pp. 768). Thousand Oaks, California: SAGE Publications.

Moudon, A., Lee, C., Cheadle, A., Collier, C., Johnson, D., Schmid, T., et al. (2005). Cycling and the built environment, a US perspective. Transportation Research Part D, 10, 245-261.

Nankervis, M. (1999). The effect of weather and climate on bicycle commuting. Transportation Research Part A, 33, 417-431.

New Plymouth District Council (2010). NPDC Model Walking and Cycling Strategic Vision. New Plymouth.

New Zealand Transport Agency (2008). Walking and Cycling Strategy Stocktake. New Zealand.

New Zealand Transport Agency (2010). Model Communities Q\&A Retrieved 22nd March, 2012 http://www.nzta.govt.nz/planning/process/model-communitiesfaq.html

New Zealand Transport Agency (2011a). Assessment of the type of cycling infrastructure required to attract new cyclists. NZ Transport Agency research report 449, 152pp.

New Zealand Transport Agency (2011b). Model Communities: information Sheet. Wellington.

Ogilvie, D., Bull, F., Powell, J., Cooper, A., Brand, C., Mutrie, N., et al. (2011). An applied ecological framework for evaluating infrastructure to promote walking and cycling: The iConnect study. American Journal of Public Health, 101(3), 473. 
Ogilvie, D., Egan, M., Hamilton, V., \& Petticrew, M. (2004). Promoting walking and cycling as an alternative to using cars: systematic review. BMJ, 329(7469), 763-766.

Parkin, J. (2007). Models of perceived cycling risk and route accessibility. Accident Analysis and Prevention, 39, 364-371.

Parkin, J., Wardman, M., \& Page, M. (2008). Estimation of the determinants of bicycle mode share for the journey to work using census data. Transportation, 35, 93-109.

Pucher, J. (2001). Cycling safety on bikeways vs. roads. Transportation Quarterly, 55(4), 9-11.

Pucher, J., \& Buehler, R. (2008). Making cycling irresistible: Lessons from the Netherlands, Denmark and Germany. Transport Reviews, 28(4), 495-528.

Pucher, J., \& Dijkstra, L. (2003). Promoting safe walking and cycling to improve public health: lessons from the Netherlands and Germany. American Journal of Public Health, 93(9), 1509-1517.

Pucher, J., Dill, J., \& Handy, S. (2010). Infrastructure, programs, and policies to increase bicycling: an international review. Preventive Medicine, 50, 106-125.

Pucher, J., Komanoff, C., \& Schimek, P. (1999). Bicycling renaissance in North America? Recent trends and alternative policies to promote bicycling. Transportation Research Part A, 33(7/8), 625-654.

Randall, T., \& Baetz, B. (2001). Evaluating pedestrian connectivity for suburban sustainability. Journal of Urban Planning and Development, 127, 1-15.

Rietveld, P. (2000). Non-motorised modes in transport systems: a multimodal chain perspective for The Netherlands. Transportation Research Part D, 5, 31-36. 
Rietveld, P., \& Daniel, V. (2004). Determinants of bicycle use: do municipal policies matter? Transportation Research Part A, 531550.

Robinson, D. (2005). Safety in numbers in Australia: more walkers and bicyclists, safer walking and bicycling. Health Promotion Journal of Australia, 16, 47-61.

Saelens, B., Sallis, J., \& Lawrence, F. (2003). Environmental correlates of walking and cycling: Findings from the transportation, urban design, and planning literatures. Annals of Behavioral Medicine, 25, 80-91.

Sallis, F., \& Owen, N. (1999). Physical Activity and Behavioural Medicine. Thousand Oaks, CA: Sage Publications.

Sloman, L., Cavill, N., Cope, A., Muller, L., \& Kennedy, A. (2009).

Analysis and synthesis of evidence on the effects of investment in six Cycling Demonstration Towns.

Sport and Recreation New Zealand (2009). Sport and Recreation Profile:

Cycling - Findings from the 2007/08 Active NZ Survey. Wellington: SPARC.

Statistics New Zealand (2006). QuickStats About Hastings District Retrieved 22nd March, 2012 http://www.stats.govt.nz/Census/2006CensusHomePage/QuickStats/ AboutAPlace/SnapShot.aspx $?$ type $=$ ta\&ParentID $=1000006 \&$ tab $=$ Inc ome\&id=2000030

Stewart, D., \& Shamdasani, P. (1990). Focus Groups: Theory and Practice (Vol. 20). Newbury Park, California: SAGE Publications.

Sullivan, C., \& O'Fallon, C. (2011). Walking and cycling: improving combined use of physical activity/health and transport data. Wellington: NZTA.

Verplanken, B., Aarts, H., \& Van Knippenberg, A. (1997). Habit, information acquisition, and the process of making travel mode choices. European Journal of Social Psychology, 27, 539-560. 
WHO (2000). Transport, Environment and Health. Copenhagen: WHO.

Woodcock, J., Banister, D., Edwards, P., Prentice, A., \& Roberts, I. (2007).

Energy and health 3: energy and transport. Lancet, 370, 1078-1088.

Woodcock, J., Edwards, P., Tonne, C., Armstrong, B., Ashiru, O., Banister, D., et al. (2009). Public health benefits of strategies to reduce greenhouse-gas emissions: urban land transport. Lancet, 374, 19301943.

Woodward, A., \& Lindsay, G. (2010). Changing modes of travel in New Zealand cities. In P. Howden-Chapman, K. Stuart \& R. Chapman (Eds.), Sizing up the City: Urban form and transport in New Zealand. Wellington: Steele Roberts Publishers.

Zacharias, J. (2005). Non-motorized transportation in four Shanghai Districts. International Planning Studies, 10(3-4), 323-340. 


\section{Appendix One: Extracts from the ACTIVE Questionnaire (Transport and Lifestyle Survey)}

\section{FACTORS INFLUENCING CHOICE OF ROUTE}

Ask the following question if the respondent has walked or cycled to work or school in the last 7 days (i.e. take into account the responses to Qs 6 and 9). If not a walker or cyclist, skip to Q.H1

I would now like to ask you about your route to your workplace or place of education.

I will list a few factors that may influence your choice of route. Could you please rate these factors according to their importance to you? (Showcard C)

10.

Being the quickest or most direct route

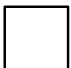

Personal safety (for example well-lit, fewer intersections, slower road and traffic...)

11.

12.

Convenience (for example goes past shops...)

Enjoyment (for example goes through pleasant green space, good views, past interesting

13. places, quiet...)

The quality of the surface for cycling or walking (for example smooth surface for cycling, 14. not muddy, few steps etc...)

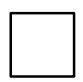

Another factor? Please specify and rate

15. 
Ask the following question of all respondents who work or attend education.

If neither student nor worker, skip to Q.16

H1 I would now like to focus on safety in getting to your workplace or school.

I will list a few safety factors: could you please rate each of them according to how

important they are to your choice of route. (Showcard C)

a Speed of traffic on the road

b Traffic volume on the road

c Driver behaviour on the road (for example, some drivers being impatient or unobservant...)

d Street lighting on the way

$\mathrm{e}$

Reassuring presence of people on the footpath

f Number of intersections / road crossings on the route

g Parking provision (for your mode of transport)

h Presence of a route separated from motor traffic

i Another factor? (please list and rate) 


\section{FACTORS INFLUENCING CHOICE OF MODE}

H2 I would now like to ask you about reasons why you choose to walk, or drive a car, etc. to your workplace or school.

I will list a few factors that may or may not influence your choice of mode.

Could you please rate these factors according to their importance to you? (Showcard C)

a

Getting there as quickly as possible

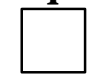

b

Personal safety (for example, if I were to walk home in the evening...)

c Risk of injury (for example, if I were to cycle....)

d

Convenience (for example, I may decide to stop on way)

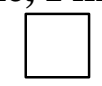

e

Enjoyment (for example, enjoying exercise, or enjoying driving...)

$\mathrm{f}$

Health (for example, keeping healthy by walking...)

\begin{tabular}{|c|c|}
\hline g Environment (for example, taking into account emissions...) \\
\hline $\mathrm{h}$ \\
\hline $\mathrm{i} \quad$ Another factor (please specify and rate) \\
\hline
\end{tabular}


25. Do you have access to a functioning bike?

Yes

No $\square 2$

26. Do you have access to a car?

Yes

No

$\square 2$

27. Do you have a physical condition that has prevented you from walking or cycling at all in the last 7 days?

Yes ................. $\square 1 \quad$ No
(If yes, skip to $Q .36)$ $\square 2$

\section{HABITS AND PERCEPTIONS}

I will now mention some transport situations. Please indicate, as quickly as possible for each of these situations, which transport mode springs to mind that you would choose. There are no right or wrong answers, but it is important that you answer as quickly as you can, and state the transport mode that first comes to mind. (Showcard D)

36. Which mode of transport would you choose if you are:

Going shopping in town?

Going to work?

Going to school or educational facilities?

Going to sports or other recreational activities?

Going to the nearest park or green space for a walk?

Going to the nearest supermarket?

Visiting someone who lives elsewhere in town?

Going to the beach?

Going to the local dairy? 
Now, I would like to ask you a few questions about your opinion about walking and cycling as a means of transport, that is, for getting from place to place Please indicate by circling a number on the scales on this page, and the next, how much you agree or disagree with the following statements about walking: (Place page in front of respondent).

\begin{tabular}{|c|c|c|c|c|c|c|c|c|c|c|}
\hline $37 \mathrm{a}$. & \multicolumn{10}{|c|}{ Walking as a means of transport belongs to my daily or weekly routine } \\
\hline \multirow{3}{*}{ b. } & Agree & & 1 & 2 & 3 & 4 & 5 & ( & 7 & Disagree \\
\hline & \multicolumn{10}{|c|}{ It would make me feel strange if I did not walk as a means of transport } \\
\hline & Agree & & 1 & 2 & 3 & 4 & 5 & ( & 7 & Disagree \\
\hline c. & \multicolumn{10}{|c|}{ Walking as a means of transport is something that I have done for a long time } \\
\hline & Agree & & 1 & 2 & 3 & 4 & 5 & ( & 7 & Disagree \\
\hline d. & \multicolumn{10}{|c|}{ I never walk as a means of transport } \\
\hline & Agree & & 1 & 2 & 3 & 4 & 5 & ( & 7 & Disagree \\
\hline e. & \multicolumn{10}{|c|}{ Walking as a means of transport is something that is typically me } \\
\hline & Agree & & 1 & 2 & 3 & 4 & 5 & & 7 & Disagree \\
\hline f. & & & 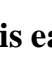 & nd $n$ & al f & to & as & ans & ins & \\
\hline & Agree & & 1 & 2 & 3 & 4 & 5 & & 7 & Disagree \\
\hline \multirow[t]{2}{*}{ g. } & \multicolumn{10}{|c|}{ I automatically walk as a means of transport } \\
\hline & Agree & & 1 & 2 & 3 & 4 & 5 & & 7 & Disagree \\
\hline \multirow{2}{*}{38.} & \multicolumn{10}{|c|}{ In your opinion, walking as a means of transport is: } \\
\hline & & $\mathrm{Bad}$ & 1 & 2 & 3 & 4 & 5 & 6 & 7 & Good \\
\hline a. & & Pleasan & & 2 & 3 & 4 & 5 & 6 & 7 & Unpleasant \\
\hline b. & & Sensible & & 2 & 3 & 4 & 5 & 6 & 7 & Not sensible \\
\hline c. & & Realisti & & 2 & 3 & 4 & 5 & 6 & 7 & Unrealistic \\
\hline d. & & Foolish & 1 & 2 & 3 & 4 & 5 & 6 & 7 & Wise \\
\hline f. & & Safe & 1 & 2 & 3 & 4 & 5 & 6 & 7 & Unsafe \\
\hline
\end{tabular}


Please circle a number on the scales on this page also.

\begin{tabular}{|c|c|c|c|c|c|c|c|c|c|}
\hline 39a. & \multicolumn{9}{|c|}{ Most of my friends would approve of me walking as a means of transport } \\
\hline \multirow{3}{*}{ b. } & Agree & 1 & 2 & 3 & 4 & 5 & 6 & 7 & Disagree \\
\hline & \multicolumn{9}{|c|}{ Most people who are important to me approve of my walking as a means of transport } \\
\hline & Agree & 1 & 2 & 3 & 4 & 5 & 6 & 7 & Disagree \\
\hline c. & Mos & le v & are & & to & & $\mathbf{a}_{\mathbf{r}}$ & S O & Insport \\
\hline \multirow{3}{*}{ d. } & Agree & 1 & 2 & 3 & 4 & 5 & 6 & 7 & Disagree \\
\hline & \multicolumn{9}{|c|}{ Most people like me walk as a means of transport } \\
\hline & Agree & 1 & 2 & 3 & 4 & 5 & 6 & 7 & Disagree \\
\hline 40a. & \multicolumn{9}{|c|}{ I feel capable of walking as a means of transport } \\
\hline & Agree & 1 & 2 & 3 & 4 & 5 & 6 & 7 & Disagree \\
\hline b. & \multicolumn{9}{|c|}{ It is not possible for me to walk as a means of transport } \\
\hline & Agree & 1 & 2 & 3 & 4 & 5 & 6 & 7 & Disagree \\
\hline c. & \multicolumn{9}{|c|}{ I am confident that I can walk as a means of transport } \\
\hline \multirow{3}{*}{ d. } & Agree & 1 & 2 & 3 & 4 & 5 & 6 & 7 & Disagree \\
\hline & \multicolumn{9}{|c|}{ I intend to walk more often as a means of transport in the near future } \\
\hline & Agree & 1 & 2 & 3 & 4 & 5 & 6 & 7 & Disagree \\
\hline
\end{tabular}


OPINION ABOUT CYCLING

Please indicate by circling a number on the scales on this page and the next, how much you agree or disagree with the following statements about cycling.

\begin{tabular}{|c|c|c|c|c|c|c|c|c|c|}
\hline $41 \mathrm{a}$ & \multicolumn{9}{|c|}{ I often cycle as a means of transport } \\
\hline & Agree & 1 & 2 & 3 & 4 & 5 & 6 & 7 & Disagree \\
\hline b. & \multicolumn{9}{|c|}{ It would make me feel strange if I did not cycle as a means of transport } \\
\hline & Agree & 1 & 2 & 3 & 4 & 5 & 6 & 7 & Disagree \\
\hline c. & \multicolumn{9}{|c|}{ Cycling as a means of transport belongs to my daily or weekly routine } \\
\hline & Agree & 1 & 2 & 3 & 4 & 5 & 6 & 7 & Disagree \\
\hline d. & \multicolumn{9}{|c|}{ It is not easy and natural for me to cycle as a means of transport } \\
\hline & Agree & 1 & 2 & 3 & 4 & 5 & 6 & 7 & Disagree \\
\hline e. & \multicolumn{9}{|c|}{ Cycling as a means of transport is something that is typically me } \\
\hline & Agree & 1 & 2 & 3 & 4 & 5 & 6 & 7 & Disagree \\
\hline f. & \multicolumn{9}{|c|}{ I have not cycled as a means of transport for a long time } \\
\hline & Agree & 1 & 2 & 3 & 4 & 5 & 6 & 7 & Disagree \\
\hline 42. & \multicolumn{9}{|c|}{ In your opinion, cycling as a means of transport is: } \\
\hline a. & $\mathrm{Bad}$ & 1 & 2 & 3 & 4 & 5 & 6 & 7 & Good \\
\hline b. & Pleasant & 1 & 2 & 3 & 4 & 5 & 6 & 7 & Unpleasant \\
\hline c. & Sensible & 1 & 2 & 3 & 4 & 5 & 6 & 7 & Not sensible \\
\hline $\mathrm{d}$. & Realistic & 1 & 2 & 3 & 4 & 5 & 6 & 7 & Unrealistic \\
\hline e. & Foolish & 1 & 2 & 3 & 4 & 5 & 6 & 7 & Wise \\
\hline f. & Safe & 1 & 2 & 3 & 4 & 5 & 6 & 7 & Unsafe \\
\hline
\end{tabular}


Please circle a number on the scales on this page also.

\begin{tabular}{|c|c|c|c|c|c|c|c|c|c|}
\hline \multirow{3}{*}{$\begin{array}{r}\text { 43a. } \\
\\
\text { b. }\end{array}$} & \multicolumn{9}{|c|}{ Most people like me cycle as a means of transport } \\
\hline & Agree & 1 & 2 & 3 & 4 & 5 & 6 & 7 & Disagree \\
\hline & \multicolumn{9}{|c|}{ Most people who are important to me cycle as a means of transport } \\
\hline \multirow{5}{*}{ d. } & Agree & 1 & 2 & 3 & 4 & 5 & 6 & 7 & Disagree \\
\hline & \multicolumn{9}{|c|}{ Most of my friends would approve of me cycling as a means of transport } \\
\hline & Agree & 1 & 2 & 3 & 4 & 5 & 6 & 7 & Disagree \\
\hline & \multicolumn{9}{|c|}{ Most people who are important to me would approve of my cycling as a means of transport } \\
\hline & Agree & 1 & 2 & 3 & 4 & 5 & 6 & 7 & Disagree \\
\hline 44a. & \multicolumn{9}{|c|}{ It is not possible for me to cycle as a means of transport } \\
\hline \multirow{3}{*}{ b. } & Agree & 1 & 2 & 3 & 4 & 5 & 6 & 7 & Disagree \\
\hline & \multicolumn{9}{|c|}{ I am confident that I can cycle as a means of transport } \\
\hline & Agree & 1 & 2 & 3 & 4 & 5 & 6 & 7 & Disagree \\
\hline c. & & not & l ca & & clir & a & IS C & ans & \\
\hline \multirow{3}{*}{ d. } & Agree & 1 & 2 & 3 & 4 & 5 & 6 & 7 & Disagree \\
\hline & \multicolumn{9}{|c|}{ I intend to cycle more often as a means of transport in the near future } \\
\hline & Agree & 1 & 2 & 3 & 4 & 5 & 6 & 7 & Disagree \\
\hline
\end{tabular}




\section{AWARENESS}

Now a few more general questions.

45a. Have you heard of the iWay programme?

Yes

No (Skip to Q.48)

No (Skip to Q. 48)

45b. How did you hear about it?

$\begin{array}{ccr}\text { Social media } & \text { Newspaper } & \text { Radio } \\ \square_{\text {A }} & \square_{\text {B }} & \square \text { с }\end{array}$

Outside advertising Word of mouth

Other

$\square$ D

$\square$ E

46. On a scale from 1 to 7 ( 1 meaning 'nothing', 7 meaning 'a lot'), $\begin{array}{lllllllll}\text { Nothing } & 1 & 2 & 3 & 4 & 5 & 6 & 7 & \text { A lot }\end{array}$ how much do you know about it?

47. Have you taken part in any of the organised iWay activities? 
53. And now, three final questions.

When were you born (month and year)?

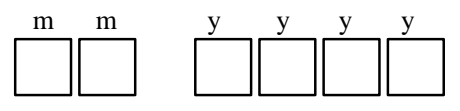

54. (All ages) Looking at card $\mathbf{H}$, which of these ethnic groups do you belong to? (Showcard H)
Code:

Don't know

Object to stating

Code:

Don't know

Object to stating

55. (If 16 years or older) And from card I, which of these categories best represents your personal income before deductions like tax or superannuation? (Showcard I) 
Appendix Two: Habitual modes of transport for different destinations (ACTIVE questionnaire question 36)

$$
\mathrm{N}=129
$$
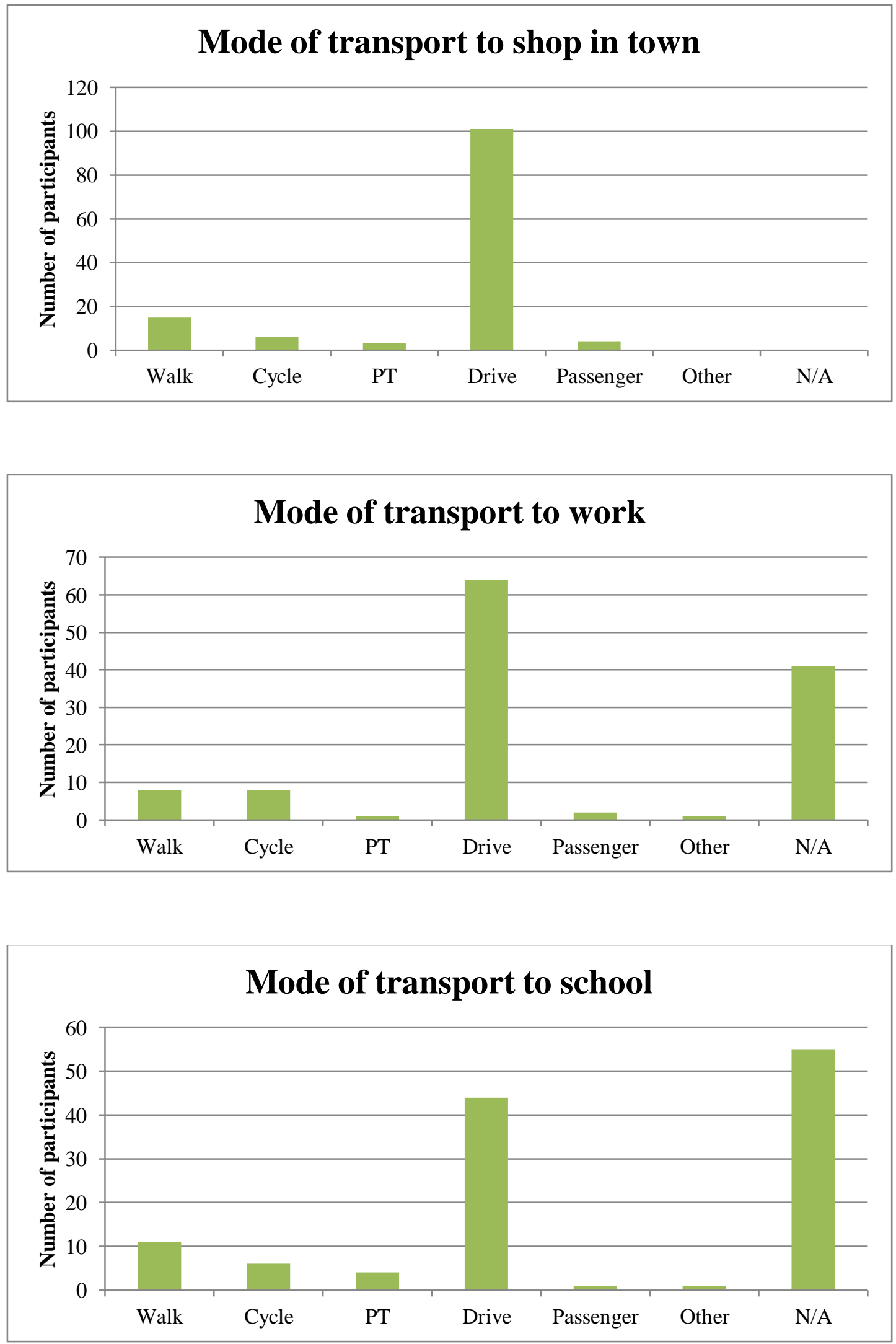

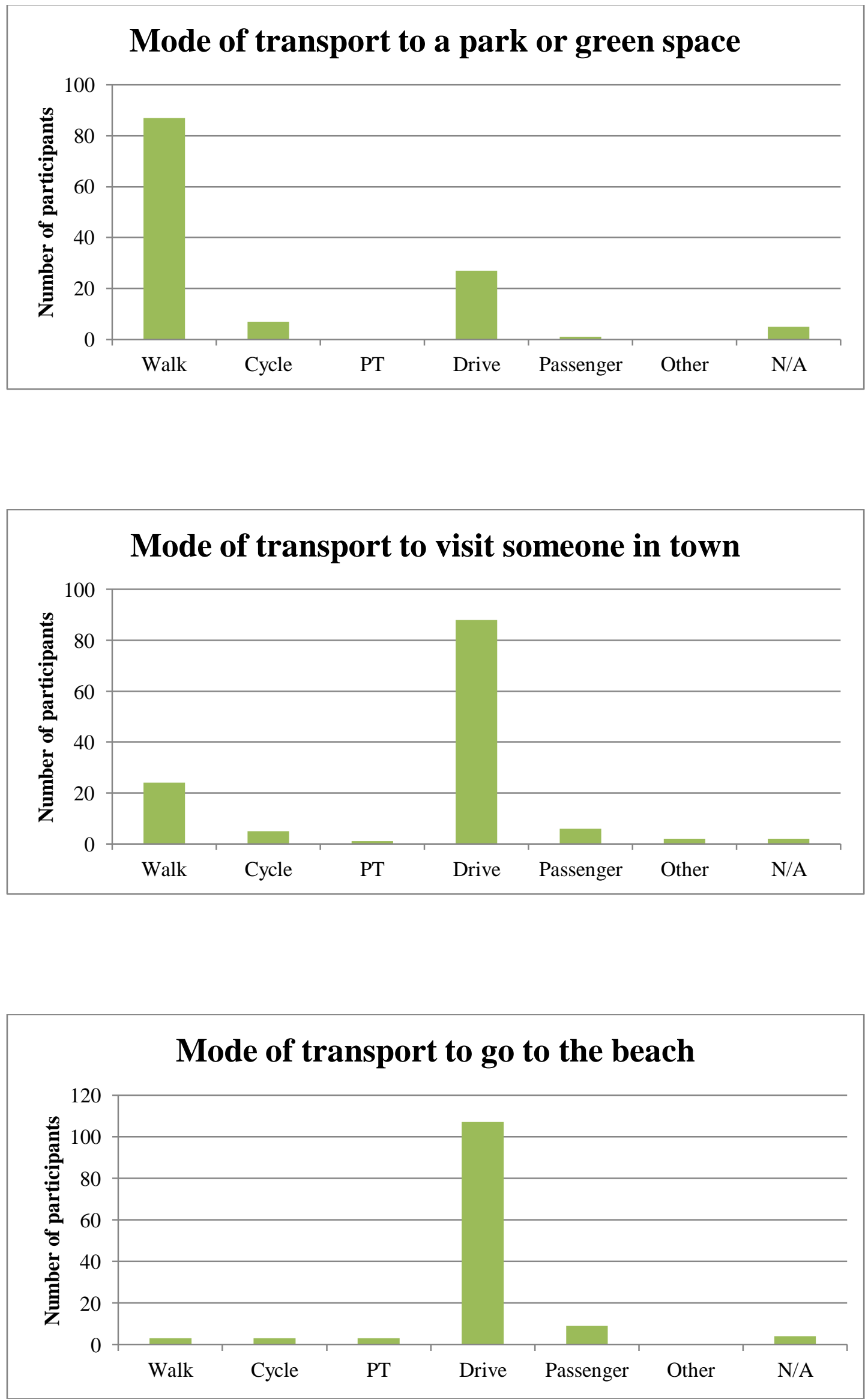


\section{Appendix Three: Focus groups and interviews human ethics approval}

TE WHARE WĀNANGA O TE ŪPOKO O TE IKA A MĀUI

MEMORANDUM

Phone $\quad 0-4-4635676$

Fax $\quad 0-4-4635209$

\begin{tabular}{l|l}
\hline TO & Dylan Muggeridge \\
\hline COPY TO & Ralph Chapman \\
\hline FROM & Dr Allison Kirkman, Convener, Human Ethics Committee \\
\hline DATE & 13 April 2011 \\
\hline PAGES & 1 \\
\hline & $\begin{array}{l}\text { Ethics Approval: 18377 Community awareness and } \\
\text { perceptions of walking and cycling in Hastings, New } \\
\text { Zealand }\end{array}$ \\
\hline
\end{tabular}

Thank you for your application for ethical approval, which has now been considered by the Standing Committee of the Human Ethics Committee.

Your application has been approved from the above date and this approval continues until 27 February 2012. If your data collection is not completed by this date you should apply to the Human Ethics Committee for an extension to this approval.

Best wishes with the research.

Allison Kirkman

Human Ethics Committee 


\title{
Appendix Four: Focus groups and interviews Information sheet
}

\author{
Master's Thesis Research Project: \\ "Community awareness and perceptions of walking and cycling in Hastings, New Zealand"
}

\begin{tabular}{|lc|l|}
\hline $\begin{array}{l}\text { Researcher: Dylan Muggeridge, Masters in } \\
\text { Environmental Studies student } \\
\text { Telephone: } \quad \text { (04) } 9345594\end{array}$ & $\begin{array}{l}\text { School of Geography, Environment } \\
\text { and Earth Sciences (SGEES) } \\
\text { Victoria University of Wellington } \\
\text { Mobile: } 0272206494\end{array}$ \\
$\begin{array}{ll}\text { Email: } & \text { Dylan.muggeridge @ goX } 600 \\
\text { Supervisor: } & \text { Associate Professor Ralph Chapman }\end{array}$ & Wellington 6140 \\
& (04) 4636153 & (04) $463-5337$ \\
\end{tabular}

Dear Participant,

You are being asked to take part in a focus group for a research project contributing to my master's thesis at Victoria University of Wellington. The project will investigate the level and nature of community perceptions and awareness of walking and cycling in Hastings. This research project has received ethics approval by the Victoria University of Wellington Human Ethics Committee.

\section{Purpose of the Study}

The study will explore the nature of varying community perceptions and awareness about walking and cycling among three socio-economic groups throughout the Hastings District Council.

This focus group research is one part of the research project.

The themes of interest during the focus group sessions include

- Factors encouraging and discouraging walking and cycling in Hastings, including safety

- Awareness of the Iway programme

\section{Use of results from the focus group}

The results collected will be reported in my thesis, and will be potentially presented in academic journals and conferences. The thesis will be submitted for marking to the School of Geography, Environment and Earth Sciences, Victoria University of Wellington. 


\section{Right of Withdrawal}

During the course of the focus group, you will have the right to withdraw from the focus group or refuse to answer any question(s) at any time.

\section{Provision of Feedback}

You have the right to check the focus group transcript, and will be able to provide any corrections at any time, prior to final analysis of data.

\section{Storage and Disposal of Data}

Access to the written and electronic material will be restricted to my supervisor and I. All written material will be kept in a locked file, and all electronic material will be password protected. After two years following the conclusion of the research, any focus group material, or similar will be destroyed and the audio recordings of the interviews will be electronically wiped.

\section{Access to Research Results}

In order to ensure that the results of this research project are accessible to the participants, a summary of the completed research output will be available. You may request it by circling 'Yes' in the 'Informed Consent Form' (attached), or by later request (email). Furthermore, copies of the completed research output will be available from the School of Geography, Environment and Earth Sciences Library, and in the Victoria University of Wellington electronic database of theses.

If you have any other questions about this project, please feel free to ask me now, or contact me or my supervisor, Associate Professor Ralph Chapman, later. Our contact details are provided on the first page of this sheet.

Thank you for participating!

Sincerely,

\section{Dylan Muggeridge}




\section{Appendix Five: Focus groups and interviews participant statement of informed consent}

1. I agree to participate in this focus group which is being audio-recorded

2. I understand that my opinions will remain confidential, and that my views in the subsequent transcription and future publication of the results will only be described in terms of my sex, age group and occupation.

3. I agree to keep the information and opinions of others expressed at the focus group confidential to the group.

4. I understand that the data I provide will not be used for any other purpose than described in the 'Information Sheet' or released to others without written consent.

5. I have read the "Information Sheet for Focus Group Participants" and have received details about the objectives of the research project, and any questions that I wanted to ask have been answered to my satisfaction.

6. I understand that I have the right to withdraw from the focus group, or refuse to answer any question(s) at any time.

7. I would like to receive a summary of the results of this research when it is completed.

If yes, My address is:

My email is:

\section{Participant:}

Name:

Date:

Signature: 
